Development of Range Design Elements and Quality Control/Quality Assurance Guidance to Reduce Maintenance Requirements on Training Ranges

J. Hernandez, R. Smith, V. Petty, and J. Lock 


\title{
DEVELOPMENT OF RANGE DESIGN ELEMENTS \\ AND \\ QUALITY CONTROL/QUALITY ASSURANCE GUIDANCE TO REDUCE MAINTENANCE REQUIREMENTS ON TRAINING RANGES
}

\author{
Prepared for: \\ Construction Engineering Research Laboratory (CERL) \\ and \\ U.S. Army Engineering and Support Center \\ Huntsville, Alabama
}

January 2006

Prepared by:

HSW Engineering, Inc.

3820 Northdale Blvd., Suite 210 B

Tampa, Florida 33624

The Mason \& Hanger Group, Inc.

300 W. Vine Street, Suite 1300

Lexington, KY 40507
R. Ward \& Associates, Inc. 1812 N. $22^{\text {nd }}$ Street

Ozark, MO 65721 


\section{Table of Contents}

Executive Summary ........................................................................................ iii

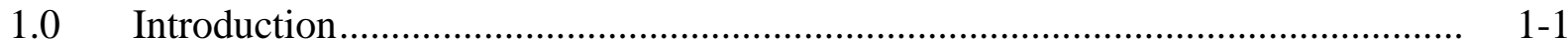

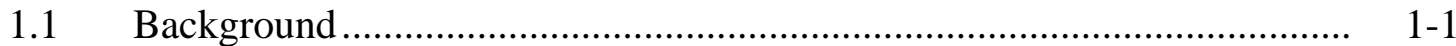

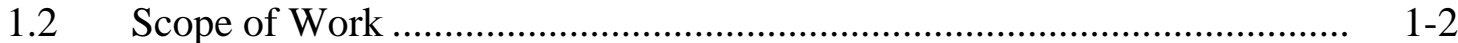

1.2.1 Meetings........................................................................... 1-2

1.2.2 Development of Innovative Range Design Elements ................ 1-3

1.2.3 Quality Control/Quality Assurance Guidelines ......................... 1-3

1.2.4 Final Report ....................................................................... 1-4

$2.0 \quad$ Pre-Design Elements.............................................................................. $2-1$

$2.1 \quad$ Programmatic Concerns ....................................................................... 2 2-1

$2.2 \quad$ Siting of Ranges ........................................................................... 2-2

2.3 Conceptual Range Planning and Layout.............................................. 2-8

3.0 Range Design Elements .........................................................................

3.1 Current Range Designs .................................................................. $3-1$

3.2 Stationary and Moving Armor Target Berms ..................................... 3-3

3.2.1 Current Design Principals ............................................................ 3-3

3.2.2 Design Alternatives for Berms.................................................. 3-7

3.2.2.1 Siting of Heavy Use Target Locations........................ 3-8

3.2.2.2 Combination Berm Design ..................................... 3-8

3.2.2.3 Berm Slopes and Erosion Controls ............................... 3-9

3.2.2.4 Soil Amendments........................................................ 3-9

3.2.3 Recommendations............................................................. 3-11

3.3 Tank Trails and Range Roads .......................................................... 3-12

3.3.1 Current Design Principals ............................................................ 3-12

3.3.2 Design Alternatives for Tank Trails .......................................... 3-14

3.3.2.1 Tank Trail Usage Impacts.......................................... 3-14

3.3.2.2 Soil Amendments for Dust Control and Improved Life-Cycle Cost....................................................... 3-19

3.3.2.3 Other Products ...................................................... 3-22

3.3.3 Recommendations.............................................................. 3-22

S.4 Low Water Crossings................................................................. 3-24

3.4.1 Current Design Principals ......................................................... 3-24

3.4.2 Design Alternatives for Low Water Crossings ........................... 3-25

3.4.3 Recommendations................................................................. 3-30

3.5 Battle Positions …........................................................................ 3-31

3.5.1 Current Design Principals ......................................................... 3-31

3.5.2 Design Alternatives................................................................ 3-34

3.5.2.1 Concrete Turning Pads............................................. 3-34

3.5.2.2 Battle Position Front Wall and Berm.......................... 3-36

3.5.3 Recommendations.................................................................. 3-38 


\section{Table of Contents (Continued)}

4.0 Quality Control/Quality Assurance Guidance during Design and Construction .... 4-1

$4.1 \quad 15 \%$ Design/3086 .......................................................................... 4 4

4.2 Final Design ....................................................................................... 4-3

4.3 Communications between Agencies on Meeting Action Items ................... 4-5

4.4 Environmental Considerations during Range Design................................... 4. 4-6

$4.5 \quad$ Pre-Construction Meeting Attendance.......................................................... 4. 4

4.6 Typical Construction Packages.................................................................. 4-8

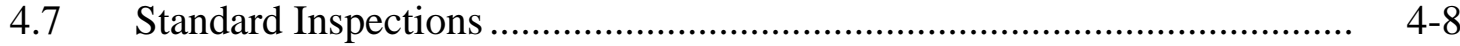

$4.8 \quad$ Construction Oversight ....................................................................... 4 4

4.9 Improve Environmental Sustainability ................................................

4.10 Recommendations for Improving QA and Adherence to Specifications

In Construction...................................................................................... 4-11

4.11 Post-Construction of Ranges ..................................................................... 4-17

$\underline{\text { Appendices }}$

A. $\quad$ Kick Off and Quarterly Meeting Notes ……….................................................... A-1

B. Application Rates and Cost of Soil Amendments................................................... B-1 


\section{EXECUTIVE SUMMARY}

\section{Project Overview}

HSW Engineering, Inc. (HSW) and its sub-consultants, The Mason \& Hanger Group (MHG) and R. Ward \& Associates (RWA), were contracted by the U.S. Army Corps of Engineers, Huntsville Engineering and Support Center (USACE-HNC) and Corps of Engineers Research Laboratory (CERL), to evaluate and develop innovative range designs and Quality Assurance and Quality Control (QA/QC) guidelines for Army training ranges.

This project represented the initial efforts to review the current status of specific range design elements and construction QA/QC issues related to selected civil engineering range elements. The scope of work evolved as it was performed based on the findings from specific efforts, project discussions, and during meetings that took place on a quarterly basis.

\section{Scope of Work}

The HSW Team was provided ten current range designs, including drawings, specifications, and design analyses, by the USACE-HNC. The HSW Team reviewed the specific engineering elements of each design, including stationary and mover berms, roads and trails, low-water crossings, and battle positions (defilades, firing points, and other offensive and defensive positions). Based on the review of current range designs, input from range managers, and on-going discussions with the team, the goal was to develop new designs which focus on environmental compliance and reduced maintenance cost attributes. As stated in the scope of work, this effort did not include any electrical, mechanical, targetry, or other component not directly related to environmental compliance.

The HSW Team reviewed current practices and policies for quality control and quality assurance for Army range construction projects to identify potential weak spots, develop best practices, and prepare guidelines to maintain appropriate levels of quality for future range activities from range design through construction completion. Guidelines should be developed for range planning, siting, design, and construction for existing and future ranges. 


\section{Pre-Design Elements}

The nature of the scope of work for this project provided the project team members a broad range of issues to discuss and consider as it relates to the design and construction of our training range facilities. Important discussions and ideas evolved during the course of this project which the team wanted to convey and which may be important to consider in a more detailed effort in the future. These issues included:

- Programmatic concerns that focused on continuity of communication and knowledge during the entire process that can stretch over several years.

- $\quad$ Range siting issues regarding surface danger zones, environmental assessments, unexploded ordnance, utilities, noise, and dust control.

- $\quad$ Conceptual range planning and layout performed with limited site data and in an era of quickly changing strategic training needs.

\section{Range Design Elements}

The overall project objective was to review current designs and standards for specific civil engineering range elements, develop innovative new designs that reduce environmental constraints and maintenance costs and increase the life expectancy of the elements, and examine construction policies and practices that will improve the range elements long-term. In general, the designs reviewed followed very closely, with little or no variation, the U.S. Army Huntsville Range Design Manual (CEHNC 1110-1-23) and other range design guidance documents provided to the design engineer. Recent revisions to the standard design guides have been generated as the range design program continues to evolve. The most recent design standards have recently been published and are available at the following internet web site:

http://www.hnd.usace.army.mil/rdg/InterTemplate.aspx.

\section{$\underline{\text { Recommendations for Berm Designs }}$}

The targetry berm review included a variety of possible changes to the existing berm designs in order to expand the maintenance cycle of the berm as well as provide added protection 
to the local environment by reducing erosion and runoff into water bodies.

Recommendations for further evaluation and field studies are as follows:

- $\quad$ Conduct field studies of the impact of varying berm slopes and compaction on soil erosion and maintenance cycles. A cost analysis should be included.

- $\quad$ Conduct field studies for soil amendments mixed into berm materials to determine the positive impacts on soil erosion and maintenance cycles. Include in this study as a minimum “Soil Sement,” manufactured by Midwest Industrial Supply, Inc., and Envirotac II, manufactured by Environmental Products and Applications, Inc. A cost analysis should be included as part of the study.

- Emphasize in the updated USACE-HNC design guidance documents the importance of heavy-use targetry siting in areas that are not environmentally sensitive or near streams and other water bodies.

- $\quad$ Emphasize the preference is to design in-ground targetry so the berms are minimized.

\section{$\underline{\text { Recommendations for Design of Tank Trails }}$}

Recommendations for Design of Tank Trails and, to a lesser degree service roads, must take into account the local site soil characteristics and geotechnical testing in order to develop a stable road base. Additionally, soil amendments during construction and as part of ongoing maintenance appear to have strong potential to reduce environmental impacts from dust and erosion, as well as extend the maintenance cycle of the range trails.

Recommendations for design consideration, further evaluation and field studies are as follows:

- $\quad$ Concrete turn pads should be placed in every location tracked vehicles turn off or on to the course road.

- $\quad$ Obtaining early in the design process geotechnical data on the soils where course roads are proposed, including determination of CBR values, can have a significantly positive impact on the trail design.

- $\quad$ Consideration should be given during design to apply amendments to poor 
subgrade materials through soil stabilization measures, which may drastically reduce the required aggregate surface thicknesses.

- New soil amendment products, including Soil Sement and Envirotac II, should be field tested at several armor ranges, with various climate and soil conditions. The product evaluation should be focused on the reduction of environmental impacts including dust reduction during use, extension of maintenance cycles, and associated life-cycle costs.

\section{Recommendations for Low Water Crossings}

Standard designs for LWCs may be impractical as each LWC is unique to its specific site location and the stream characteristics. There are, however, categories of LWCs that can be described (i.e. stream bed submerged crossing, base flow control with culverts with high flow submerged crossing, total flow control with culverts, bridges) and presenting a typical pictorial of each type along with some guidance on costs of LWCs may be sufficient. This guidance would illustrate to the designer that the objective can be met with a variety of designs that are dependent on such issues as local and State environmental requirements, site hydrology, stream bed and flow characteristics, and available funds. A checklist of issues that should be addressed by the designer and planning team early in the range design process were developed.

- Installations should conduct an assessment of the LWCs based on environmental issues, including aquatic life impacts, sedimentation, long-term erosion of embankments, water quality impacts, as well as other local issues that may arise.

- Identify areas where the construction of LWCs minimizes environmental impact without degrading current training capabilities and adjust the range layout to best fit these crossing areas.

- $\quad$ Obtain consensus of the type of crossing preferred by key personnel. Incorporate into the final decision the environmental impacts, the preferred crossing type, and the associated costs.

- $\quad$ The LWC design should include an analysis of vehicle type, level of activity, potential for drop-off from edge of crossing, and other user oriented data to determine the thickness of crossing materials and width of the crossing. 
Accessibility for long-term maintenance of the crossing as well as the upstream and downstream impacted areas should also be incorporated into the design.

- Develop a central LWC database that is accessible to all installation ITAM offices. The database will maintain all the information that pertains to each LWC.

- In the event of an existing LWC failure, minimize the repair to the LWC to what is absolutely necessary. Use this opportunity to construct a modern LWC that supports all considerations.

- $\quad$ For LWCs that are periodically dry beds or are constructed when flow is diverted, and for stream banks that are subject to scouring during heavy rains, consider the possibility of applying soil amendments that improve water resistance and erosion control and decrease maintenance costs and down time for repair.

- $\quad$ Ensure Best Management Practices are used in the design and construction of LWCs. State level Department of Transportation criteria, local forestry services, and other government organizations can provide excellent local guidance to the designer.

\section{$\underline{\text { Recommendations for Battle Positions }}$}

The battle position and defilades design has evolved over the past few years, with dramatic improvements already being applied during new range construction. The following summary recommends the most appropriate design criteria.

- $\quad$ The preferred design includes a concrete turning pad for entry/ exit. While this has higher capital costs, it will have a much longer life-expectancy, is more protective of environmental issues (i.e. erosion and dust control), and has much smaller maintenance costs. The packed dirt access trails are the least desirable due to erosion and dust control.

- $\quad$ The front wall of the battle position must be able to absorb the impact of current training ammunitions and made of an easily repairable/replaceable material. The current design which eliminates the front wall and uses the blast mats as a protective barrier appears to be the concrete walls which are not easily repairable.

- $\quad$ Berms around the sides of the battle positions should be an installation requested 
addition rather than part of the standard design. The savings in time and money over the number of battle positions on a range may be significant.

- $\quad$ Berm stability may be enhanced by applying soil amendments as discussed in previous sections for tank trails and targetry berms. The application during design should be further considered.

\section{Quality Control/Quality Assurance Guidance During Design and Construction}

This report addresses Quality Assurance/Quality Control guidance beginning with the 15\% design phase and going through construction with recommendations of how to improve the process and improve environmental sustainability as it applies to Range design in general and roads, berms, defilades, and low-water crossings in particular.

The findings are generally classified into two areas: communication, continuity, and knowledge; and implementing/enforcing standard construction QA procedures in the field. Communication and continuity of the range design team, including the end-user range manager responsible for training, SRP support agencies, environmental and facility personnel, and design specialists is the single theme that evolved throughout the specific design elements discussed. This need for good communication and continuity of personnel through the pre-construction meetings and construction activities can be the most important element to assure the range facility that is built is consistent with and meets the primary training objectives while maximizing environmental protection and minimizing costs. 


\subsection{INTRODUCTION}

HSW Engineering, Inc. (HSW) and its sub-consultants, The Mason \& Hanger Group (MHG) and R. Ward \& Associates (RWA), were contracted by the U.S. Army Corps of Engineers, Huntsville Engineering and Support Center (USACE-HNC) and Corps of Engineers Research Laboratory (CERL), to evaluate and develop innovative range designs and Quality Assurance and Quality Control (QA/QC) guidelines for Army training ranges. In general, the scope of work guidelines were aimed to reduce deviation from predetermined design attributes, thereby reducing potential maintenance requirements. As part of this effort, the HSW Team examined existing range design elements and construction policies and practices for specific civil engineering design elements. This report describes the tasks completed and project findings and conclusions.

\subsection{Background}

Range operation and maintenance requirements constrain the amount of time that ranges can be used for training purposes. These requirements can be exacerbated by design elements that result in environmental compliance problems such as soil erosion, water quality degradation, poor air quality, heavy metals accumulation, and habitat destruction. Standard range designs often do not prevent environmental degradation due to repeated, long-term use experienced by most training ranges. Consequently, there was identified a need to review current range design elements as they relate to environmental compliance risks in order to modify existing range design elements to reduce future operation and maintenance requirements while maintaining training realism and improving environmental compliance. Furthermore, design elements must be periodically reviewed and appropriately modified to account for new weapons and vehicles associated with the objective force. 
Inadequate adherence to design criteria often results in substandard construction, which increases maintenance costs and lowers life expectancy of ranges. In addition, a need exists to modify current range construction practices and policies to ensure appropriate levels of QA/QC are maintained. This need may be met through the development of quality control guidelines for range-specific construction.

\subsection{Scope of Work}

This project represented the initial efforts to review the current status of specific range design elements and construction QA/QC issues related to selected civil engineering range elements. The scope of work evolved as it was performed based on the findings from specific efforts, project discussions, and during meetings that took place on a quarterly basis. The following summarizes the scope of work.

\subsubsection{Meetings}

A kick off meeting with USACE-HNC, CERL, and the HSW Team, was conducted to formulate the project objectives and work to be accomplished under this task order. The kick off meeting was held in Champaign, Illinois at the CERL facility. During the meeting, the process, decision makers, objectives and deliverables, and contents of the approach were discussed. The purpose of the meeting was for the contractor to become familiar with expectations and to begin preliminary data gathering.

Quarterly meetings with USACE-HNC, CERL, and the HSW Team were also conducted. The quarterly meetings were used to provide a status of the project findings and discuss and redirect the efforts, as appropriate, based on the findings to date. The third meeting also included a presentation by Mr. Andy Andrews, the Fort Knox Range Manager, and a site visit of several ranges at Fort Knox, Kentucky. The site visit allowed the team to view first-hand the specific range elements constructed and to obtain valuable information on the operation and maintenance efforts required to keep the ranges active.

The meeting notes and presentation materials for the kick off meeting and quarterly meetings are included as Appendix A. 


\subsubsection{Development of Innovative Range Design Elements}

The HSW Team was provided ten current range designs, including drawings, specifications, and design analyses, by the USACE-HNC during the kick off meeting in December 2004. The HSW Team reviewed the specific engineering elements of each design, including stationary and mover berms, roads and trails, low-water crossings, and battle positions (defilades, firing points, and other offensive and defensive positions). The reviews focused only on environmental compliance and maintenance issues related to the civil engineering aspects of each element.

Based on the review of current range designs, input from range managers, and on-going discussions with the team, the goal was to develop new designs which focus on environmental compliance and reduced maintenance cost attributes. As stated in the scope of work, this effort did not include any electrical, mechanical, targetry, or other component not directly related to environmental compliance.

\subsubsection{Quality Control/Quality Assurance Guidelines}

The HSW Team reviewed current practices and policies for quality control and quality assurance for Army range construction projects to identify potential weak spots, develop best practices, and prepare guidelines to maintain appropriate levels of quality for future range activities from range design through construction completion. Guidelines should be developed for range planning, siting, design, and construction for existing and future ranges. This effort included:

- Identification of current policies and practices for maintaining QA/QC on range projects. This review should demonstrate how current policies and practices fail to ensure that appropriate levels of QA/QC are being maintained. Areas with high potential for failure should be highlighted.

- Development of QA/QC Guidelines. Guidelines should provide appropriate levels of detail regarding what steps need to be taken to ensure range construction contracts are being adhered to and how to maintain an appropriate level of oversight of range construction contracts for previously outlined range elements. Guidelines should eliminate problems arising from vague statements of work, 
inadequate oversight, failure to adhere to contract specifics, and any other pitfalls that were identified previously.

\subsubsection{Final Report}

The final report should describe the shortfalls of current design guidance and provide architectural drawings, descriptions, and justifications for modifications to existing designs. The Report shall have an executive summary, along with narrative and summary discussions, calculations, engineering evaluations, and schematics for proposed design changes. 


\subsection{PRE-DESIGN ELEMENTS}

The nature of the scope of work for this project provided the project team members a broad range of issues to discuss and consider as it relates to the design and construction of our training range facilities. Important discussions and ideas evolved during the course of this project which the team wanted to convey and which may be important to consider in a more detailed effort in the future. This section highlights the initiation of the design process which influences the entire range design and construction program.

\subsection{Programmatic Concerns}

Early discussions by the project team identified some specific programmatic issues which appear relevant to many range designs the team has participated in over several years. They are not issues that can be resolved within the context of this report, but are issues the team felt merited mentioning, and may be appropriate for future evaluation. In summary, the areas for further consideration at the programmatic level are:

- $\quad$ Lack of individuals with complete knowledge of the Sustainable Range Program (SRP) process - There are many components to the range program and the process from beginning to end is stretched over several years. There appears to be, many times, a lack of continuity throughout this lengthy process which creates many inefficiencies in the program. Additionally, there is no clear system or process in place to retain people with range development knowledge which would, in time, provide the program continuity needed.

- $\quad$ Agencies act independently - no maximizing of joint resources.

- No clear agency with central enforcement authority; few standard processes that are documented/enforced. Dissemination of best standard practice instruction and education about most effective product use is neither widely effected nor centrally controlled.

- $\quad$ Programmatic/Project schedules are assumed to be monitored by involved agencies.... No system to ensure execution. QA/QC procedures are required to 
ensure an effective monitoring process is followed and measures for corrective action are in place to handle discrepancies and variances from schedules.

- No database available to all agencies of historical/operational information. For example, various dust control products have been tested at a number of military installations; but there is no central clearing entity to dispense the data obtained nor make recommendations or set standards. Lessons learned from these tests, such as the fact that rainfall on certain new polymer products can actually enhance the water resistance and load-bearing capacity of the roadway, have not been made known to a wide audience.

\subsection{Siting of Ranges}

Range location and layout is a critical first step in minimizing changes throughout the design and construction phases. To develop a more accurate DD 1391 cost estimate that is reflective of the final range design, the involvement of the trainer and end-user, the Corps design center experts, and the design engineer is critical. In cases where these entities have been involved in the planning stage of the project the result has been reduction of delays due to unforeseen problems during the design phase and also reduced cost by finding better solutions for the range designs.

Specific areas that are critical to the overall range design process and to assuring the final range design meets the important training objectives were characterized as follows.

\section{- Surface Danger Zone (SDZ)}

\section{Area of Concern:}

SDZ represents the impact area of all rounds downrange, including ricochet. SDZs may not leave an installation's boundary or overlap any occupied area of the facility. There are operational methods \& land impacts which may waiver an SDZ.

\section{Potential Resolution:}

1. SDZs must be addressed early in the Siting Process to ensure that no safety issues are overlooked which might slow or stop a project in later stages of development. 
2. SDZs, while traditionally drawn by hand can now be automated using GIS technology. This technology adds a uniformity and interaction with topographic data which was not available to the Installation previously. The GIS SDZ process does not reduce or negate the requirement for trained safety personnel to be involved in the application of SDZs, but does make the development of SDZs more efficient and consistent.

\section{- Environmental}

\section{Area of Concern:}

Environmental concerns encompass endangered species, historical, archeological, and NEPA areas of concern. Due to the large acreage of training ranges and their remoteness, environmental concerns are often unknown or the data available is of varying quality. Environmental documentation is supposed to be utilized in the site selection process to determine the best site for each project. This documentation is, in a perfect design scenario, to be complete prior to the submittal of the 1391 documentation, and no construction is to begin until the documentation is complete. Installations often assume that since a site has supported training for years that the environmental significance of a site will be "No Impact". This assumption may no longer be true due to changing environmental laws. Environmental Impact Statements (EIS) and Environmental Assessments (EA) can require months to years to complete depending on the complexity of environmental factors involved on any range site.

\section{Potential Resolution:}

1. The Sustainable Range Program (SRP) has made great strides partnering with the Army Environmental Center (AEC) for proactively pursuing environmental approval of sites early in the range selection process. This available resource needs to be advertised to the Installation community so that they know a resource exists which will help them field ranges. 
2. SRP has also established processes to ensure that funding is available to execute EA \& EIS early in the siting process. Again this resource needs to be advertised to the Installations to ensure that they realize the process exists and is available to aid them.

\section{- Unexploded Ordnance (UXO)}

\section{Area of Concern:}

UXO due to current live fire training activities or, more likely, past live fire training activities is a major safety and cost factor in range modernization. Many Installations had very intense training regimes during this Nation's prior conflicts; in the past, concern over UXO was superseded by involvement in war and the belief that land was affordable and readily available. Since many Installations created UXO due to firing which happened 20-50 years ago, personal knowledge of where certain types of ammunition were fired is non-existent. To complicate this issue, UXO is not a surface-only problem; ordnance penetrates the surface and may be as deep as six feet. This creates a detection problem and removal challenge.

\section{Potential Resolution:}

1. Several federal agencies are currently researching detection and removal processes for UXO. SRP needs to partner with these agencies, in support and resources, to advance detection and removal processes. SRP also needs to stress their particular removal issues. Many agencies are concerned only with complete UXO removal for land returned to the public, whereas SRP in most instances are concerned about a safe construction/operation environment but fully intend to continue live fire operations on the range.

2. SRP has established processes for the funding of UXO clean-up prior to construction. An advertising method to educate the Installation on these processes needs to be implemented to ensure full community participation. 


\section{- Utilities}

\section{Area of Concern:}

Utilities present several range siting issues: availability, capacity, and ownership. Utilities are the responsibility of the Installation's Department of Public Works (DPW) and, as such, are normally funded and built through the DPW funding chain. Range projects tie into these systems. The conflicts arise concerning how far away a utility can be for a range to pay to tie into it $(1,000 \mathrm{ft}$ or $10,000 \mathrm{ft}$ or 1 mile, etc.). In addition, if a range project requires 3-phase power, but only single-phase power is available, who funds the upgrade? In recent years, the privatization of Installation utility systems has further complicated these issues. Private utility provider's contracts must be considered. The Range Officer must also ensure that he is not inadvertently drawn into funding an Installation utility upgrade or be pressured to provide utility systems not required by training.

\section{Potential Resolution:}

1. SRP guidance on who funds what and for what distance exists within the program; this information needs to be advertised to the Installations for their use.

2. Private utility providers and their DPW representatives must be included in the siting process. By contract, they may have to either install or approve of all utilities features in a range design \& construction. Metering \& payment of utilities may also impact the future operation of a range.

\section{- Pre-existing range or virgin ground}

\section{Area of Concern:}

Pre-existing ranges have the possibility of UXO from prior training and the demolition requirements to remove the features from the existing range which are no longer needed in the new range. Virgin ground has the same possibility of UXO and a higher possibility of SDZ issues, environmental, and public conflicts. Also, inaccurate historical record keeping may state that a site is UXO free when, in fact, it may be UXO contaminated from prior war-time training. 


\section{Potential Resolution:}

1. UXO issues that may exist must be considered. Even though the virgin ground has not had construction on it previously, this does not negate the possibility that ammunition impacted it due to overshots or human error.

2. Virgin ground most likely has not previously undergone the investigative process of environmental and public impacts studies; this makes the site a candidate for findings.

\section{- Noise/Dust}

\section{Area of Concern:}

Due to the encroachment of the civilian population on what were once remote range complexes, noise is now a major concern on range siting. Dust created by training operations can create public perceived impacts which can seriously restrict or halt training exercises.

\section{Potential Resolution:}

1. Installations must ensure that they understand the composition of civilian populations outside of their boundaries and the amount of noise and or dust to be generated by a range complex.

2. Installations anticipate the impact that noise restrictions will have on a proposed range (times of allowable firing, maximum allowable noise contour allowed, etc.).

\section{- SRP Support Agencies}

\section{Area of Concern:}

SRP support agencies provide a wide variety of programmatic support which is commonly centrally funded by the Department of Army (DA). Many times the Installation's awareness of this resource is limited or unknown. 


\section{Potential Resolution:}

1. SRP Support Agencies available services (both funded by DA and by the customer) need to be advertised to the Installations to ensure their inclusion of these valuable resources in their range development initiatives.

\section{- “Lessons Learned” Documentation \& Usage}

\section{Area of Concern:}

Part of the reason that the Range Modernization program was "stood-up" in 1984 was to reduce duplication or loss of effort expected by multiple agencies executing the upcoming range buildup. As the planning/design/construction and instrumentation processes proceed, various parts of the process will have both positive and unique innovations as well as systematic problems which need to be documented, distributed, resolved, and integrated into all agencies' activities involved in the range modernization process.

\section{Potential Resolution:}

1. A database to capture lessons learned at each phase of a range's development process needs to be centrally available with procedures in place on mandatory entry for each Support Agency within SRP. The database must be able to segregate the lessons learned by category and section to facilitate callback of the information. If the database is not interactive it will quickly become too cumbersome to use.

2. Lessons Learned database output needs to be formally added to the range design process to ensure the usage of the data. One way that this could be implemented would be to require the planner/designer to include applicable Lessons Learned Sections from the database as part of their product submittal.

3. The Lessons Learned database would need to be reviewed and old comments archived on a regular basis. Maintain probably no more than $\sim 50$ comments in 
each design phase or the material would become overwhelming and too cumbersome for use.

\subsection{Conceptual Range Planning and Layout}

The initial stages of range planning have a tremendous impact on the long-term funding and design process that follows. Unfortunately, and typically, very little site information is available at this initial stage. Additionally, the current era of quickly changing strategic training needs required to match the services' transformations create a situation where the range envisioned may not be the same range to be constructed 3 to 5 years later. While these issues are well beyond the scope of this report, the discussions that took place did identify some areas of consideration as the program develops further.

\section{- Pre-approved Site prior to DD 1391 Team Visit}

\section{Area of Concern:}

Installations submit a DD 1391 for a range project, due to pressure for enhanced training or in anticipation of new training objectives, without having a single site selected or alternatively having several possible sites identified for the range. There are numerous reasons for this to occur, but the impact is that the uncertainty of the range location will stop the planning process. The SRP process calls for a Team to visit each Installation and finalize their DD1391 documentation; lack of site selection can potentially delay a project indefinitely.

\section{Potential Resolution:}

The installation should include an initial site plan (map with layout) with its DD1391 documentation and its planning process should include Master Plan approval. If during the DD1391 Team visit a site is undefined or if it is determined that the proposed site will not support the range, then it will be the DD1391 Team and the installation planners' responsibility to determine a new site for the range. A definite time limit should be provided to the Installation for site approval; if a site cannot be approved the project should be delayed. 


\section{- Preliminary Range Site Layout}

\section{Area of Concern:}

Many times due to funding and time restraints standard layouts are used in the early planning stages of range projects. While these standards layouts are correct for most qualification range sites, they are seldom realistic for large range complexes. This leads to unforeseen complications during design, normally associated with funding overruns due to unexpected terrain features.

\section{Potential Resolution:}

1. Installations to the maximum extent possible should utilize accurate survey data. Design will normally be based on 1-foot contour intervals. This level of information is typically not available at the planning stages of range development. Therefore, the Installation should use the best available information, which is for most installations ITAM data at 2-3 meter resolution. The use of 1:25,000 or 1:50,000 military installation maps should not be used except for orientation \& surface danger zone analysis.

2. Installation trainers, SRP Support Agency trainers or contract training specialists should layout each range based on the composition defined in the standard designs but the range layout should also be laid-out on the topography of the proposed range site (again ITAM data if it is the best available). Including a range design specialist during this process will further assist in identified engineering issues that may impact the proposed range. Range siting must consider the topography as well as the potential of UXO simultaneously; a perfect valley contaminated with UXO is an unacceptable range site.

\section{- EA/EIS Completion}

\section{Area of Concern:}

Once the installation determines a need for a new range, the planners should select the most appropriate site or sites for the range and initiate an EA/EIS for each site location. Based on the outcome of the EA/EIS or defined interim decision points, the 
best site should be selected that meets the requirements for the new range. Once the EA/EIS is completed, the DD 1391 is submitted for MACOM approval. Many times in the rush to get a new range submitted and the DD 1391 approved, the EA/EIS has not been initiated or has not been completed. Environmental documentation is mandatory for military construction.

\section{Potential Resolution:}

Enforce the priorities of the SRP. If an Installation follows the procedures of SRP with its support agencies involved since range siting, then all parties will be familiar with any EIS/EA issue and reasonable decisions can be made concerning the value of continuing range development. If an Installation does not avail itself of the SRP Support Agencies assistance and does not have a plan for the prompt execution of an EIS/EA at this stage of development, the range project should be moved to an out year - to facilitate the corporate goals of the Army.

\section{- Installation specific requirements/Deviations from Standard} Area of Concern:

Many Installations have mission critical changes \& requirements to be incorporated into their range projects. These changes can come from units, Commanders, agencies on post, etc. Deviations from range standard designs normally affect costs which then affects funding programmatically.

\section{Potential Resolution:}

Changes to standard process should be approved or disapproved by a SRP Support Agency team. This team should have a pre-defined time limit to respond to submittals with a pre-defined team member composition so that changes could be reviewed consistently. Only mission-critical changes and deviations should be considered. Infrastructure changes/deviations should be deleted from range DD1391 documentation and funded by the appropriate Installation proponent. 


\section{- Identify Nonstandard Construction}

\section{Area of Concern:}

During the design development of a range, the installation may want to change the design of a support building, consolidate buildings, and/or modify the downrange area of the range. These changes may better support the installations' mission or the installation believes their design is better for their specific installation. However, the installations have been told they cannot deviate from the Standard Design.

\section{Potential Resolution:}

Once the installation planners understand that the Standard Design can be modified, they have 2 methods to pursue the modification:

1. The modification(s) and the installation's justification for deviating from the Standard Design are documented in the DD 1391.

2. After the DD 1391 is approved and placed in the AMRP, the installation planners can submit a memorandum to the Support Agencies requesting "Deviation to the Standard Design.” If the Support Agencies approve the request, usually it must meet construction and cost guidelines, then the modification will be built. 


\subsection{RANGE DESIGN ELEMENTS}

The range design team is typically selected and provided the DD 1391 and a preliminary design layout of the range. While each range is unique because of the range location and topography, there are many standard design elements common to most ranges. This section focuses on specific range elements that meet these criteria, including stationary and moving target berms, roads and trails, low-water crossings, and battle positions (defilades, firing points, and other offensive and defensive positions). The reviews focused only on environmental compliance and maintenance issues related to the civil engineering aspects of each element.

\subsection{Current Range Designs}

The overall project objective was to review current designs and standards for specific civil engineering range elements, develop innovative new designs that reduce environmental constraints and maintenance costs and increase the life expectancy of the elements, and examine construction policies and practices that will improve the range elements long-term.

At the Project Kick Off Meeting in November 2004, ten range designs were selected as examples of existing range design practices. The design team reviewed specific elements for each of these ranges: soil classification, target berms, tank trails and service roads, defilades and firing positions, fighting trenches, and low-water crossings. The objective was to identify: design and operational issues that should be further studied; unique design features that may be valuable as standard practice design; and what specific action items should be taken to continue research efforts.

The 10 range designs reviewed included:

\begin{tabular}{|l|l|}
\hline Camp Atterbury, Indiana & Multipurpose Training Range \\
\hline Ft Knox, Kentucky & MPDTR, Wilcox Tank Range \\
\hline Fort Stewart, Georgia & Red Cloud Alpha Range - Multi-purpose \\
\hline Camp Shelby, Mississippi & Multipurpose Range Complex - Heavy \\
\hline Fort Hood, Texas & Digital Multipurpose Range Complex \\
\hline
\end{tabular}




\begin{tabular}{|l|l|}
\hline Fort Wainwright, Alaska & IPBC / DMPTR at Yukon Training Area \\
\hline Fort Polk, Louisiana & Digital Multipurpose Battle Area Complex \\
\hline Fort Pickett, Virginia & Multipurpose Range Complex - Heavy \\
\hline Fort Benning, Georgia & Digital Multipurpose Range Complex \\
\hline Fort Shafter, Hawaii & Combined Arms Training Facility at KTA \\
\hline
\end{tabular}

These ranges were selected for review to allow for comparison of designs conducted by several engineering design firms at installations from various regions of the country. The elements were inventoried for specific design characteristics (i.e. berm thickness, slopes, soil type, compaction requirements, variation for geographic areas, etc.), as well as reviewed for positive and negative (or non-stated) design components. Not all ranges reviewed had each element being considered as illustrated in the following table.

\begin{tabular}{|c|c|c|c|c|c|c|c|c|c|}
\hline Location & $\begin{array}{c}\text { Tank } \\
\text { Roads }\end{array}$ & $\begin{array}{l}\text { Service } \\
\text { Roads }\end{array}$ & Defilade & $\begin{array}{l}\text { Low Water } \\
\text { Crossings }\end{array}$ & $\begin{array}{l}\text { Fighting } \\
\text { Trenches }\end{array}$ & $\begin{array}{c}\text { Stationary } \\
\text { Armor Targets }\end{array}$ & $\begin{array}{l}\text { Stationary } \\
\text { Infantry } \\
\text { Targets }\end{array}$ & $\begin{array}{l}\text { Moving } \\
\text { Infantry } \\
\text { Targets }\end{array}$ & $\begin{array}{c}\text { Moving } \\
\text { Armor } \\
\text { Targets }\end{array}$ \\
\hline Camp Atterbury, Indiana & YES & YES & YES & NO & YES & YES & YES & NO & NO \\
\hline Ft Knox, Kentucky & YES & YES & 6 & YES & NO & 57 & 135 & 7 & 6 \\
\hline Fort Stewart, Georgia & YES & YES & YES & NO & NO & YES & YES & NO & YES \\
\hline Camp Shelby, Mississippi & YES & YES & 30 & $\mathrm{NO}$ & NO & 20 & 55 & 15 & YES \\
\hline Fort Hood, Texas & YES & YES & YES & YES & YES & YES & YES & $\mathrm{NO}$ & YES \\
\hline Fort Wainwright, Alaska & YES & YES & NO & YES & YES & YES & YES & YES & YES \\
\hline Fort Polk, Louisiana & YES & YES & NO & YES & NO & 50 & 215 & 10 & 8 \\
\hline Fort Pickett, Virginia & NO & No & YES & No & No & YES & YES & YES & YES \\
\hline Fort Benning, Georgia & YES & YES & YES & YES & YES & 55 & 245 & NO & 11 \\
\hline Fort Shafter, Hawaii & NO & NO & NO & NO & NO & NO & NO & NO & NO \\
\hline
\end{tabular}

In general, the designs reviewed followed very closely, with little or no variation, the U.S. Army Huntsville Range Design Manual (CEHNC 1110-1-23) and other range design guidance documents provided to the design engineer. Recent revisions to the standard design guides have been generated as the range design program continues to evolve. The most recent 
design standards have recently been published and are available at the following internet web site http://www.hnd.usace.army.mil/rdg/InterTemplate.aspx.

\subsection{Stationary and Moving Armor Target Berms}

\subsubsection{Current Design Principals}

Berm designs that were reviewed followed closely the Huntsville Range Design Manual (CEHNC 1110-1-23), Chapter 6. This design addresses force/dissipation of impacts by projectiles but does little to address surface impacts and soil erosion. The USACE-HNC participants stated that the design figures in Chapter 6 for determining berm crest width have a factor of safety embedded into the compaction curves. A typical crest width curve based on geotechnical parameters is as follows:

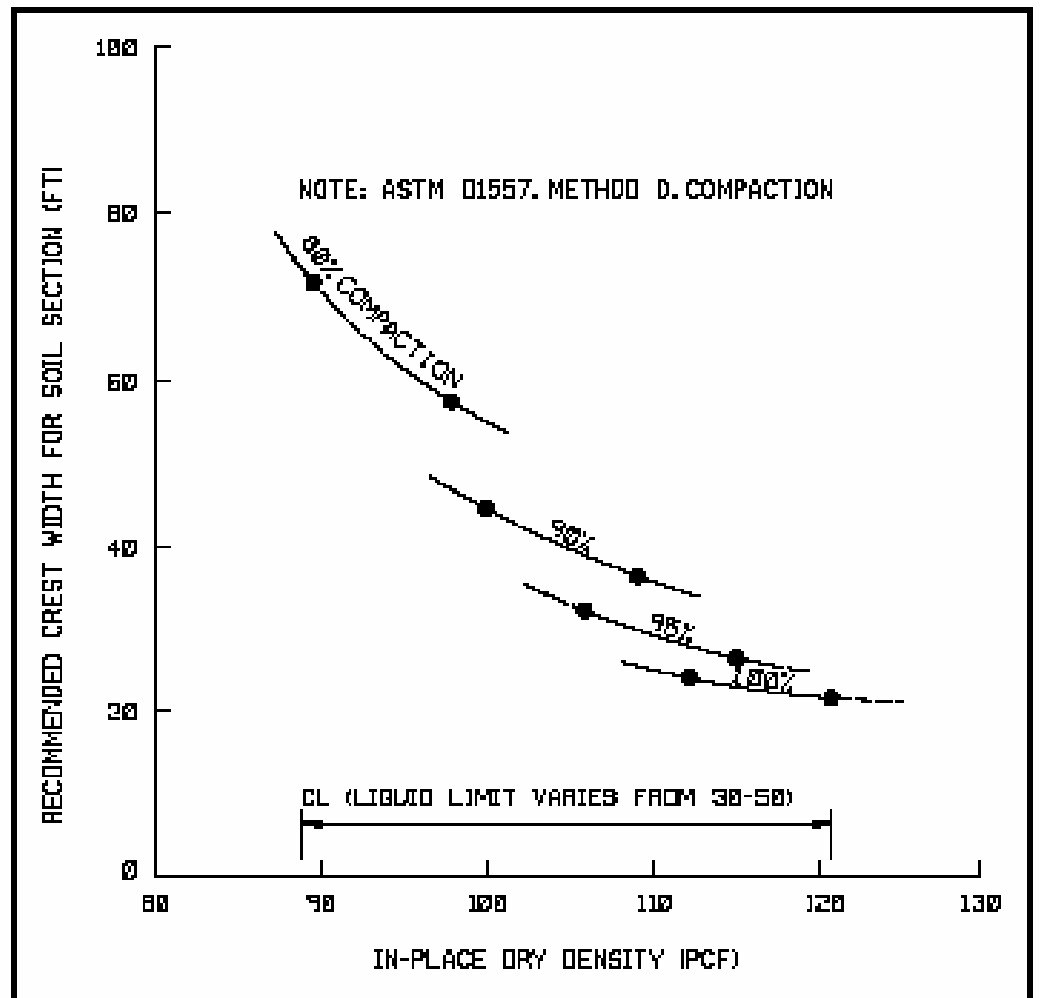

Figure 6-13. Required thickness of soll section versus dry density for CL solls (25-wn, 105-9nn, and I20-mw projectiles)

However, designers are generally adding additional berm width either as a safety factor or to aid in the berm maintenance based upon the local range manager's experience. Consequently, some over design appears to be common practice in berm design and 
construction. Additionally, once the range is placed in service, the berms can be significantly impacted within only a three month time frame but the repairs that occur are not typically placed to the same compaction standards as the original construction. The following table summarizes the berm widths identified for specific munitions.

\begin{tabular}{|c|c|c|c|c|c|c|}
\hline \multirow[b]{3}{*}{ Location } & \multicolumn{3}{|c|}{ Smaller Munitions } & \multicolumn{3}{|c|}{ 25-mm, 105-mm, 120-mm } \\
\hline & & Berm & pes & & Berr & lopes \\
\hline & Width & Front & Back & Crest Width & Front & Back \\
\hline $\begin{array}{l}\text { Camp Atterbury, } \\
\text { Indiana }\end{array}$ & $5 \mathrm{ft}$ & $4: 1$ & 4:1 & $28 \mathrm{ft}$ & $3: 1$ & 3:1 \\
\hline Ft Knox, Kentucky & $20 \mathrm{ft}$ & $3: 1$ & $3: 1$ & $50 \mathrm{ft}$ & $3: 1$ & $3: 1$ \\
\hline Fort Stewart, Georgia & & & & $10 \mathrm{~m}$ & $3: 1$ & $3: 1$ \\
\hline $\begin{array}{l}\text { Camp Shelby, } \\
\text { Mississippi }\end{array}$ & $20 \mathrm{ft}$ & $3: 1$ & 3:1 & $50 \mathrm{ft}$ & $3: 1$ & $3: 1$ \\
\hline Fort Hood, Texas & & & & $6.1-12.2 m$ & $3.5: 1$ & $3: 1$ \\
\hline $\begin{array}{l}\text { Fort Wainwright, } \\
\text { Alaska }\end{array}$ & $2 m$ & $3: 1$ & $3: 1$ & $8 m$ & $3: 1$ & $3: 1$ \\
\hline Fort Pickett, Virginia & & & & $60 \mathrm{ft}$ & $3: 1$ & $3: 1$ \\
\hline Fort Benning, Georgia & & & & $40 \mathrm{ft}$ & $3: 1$ & $3: 1$ \\
\hline
\end{tabular}

In general, geotechnical investigations and soil classification are being utilized during the design process. However, it appears this data is more focused on structural integrity for building foundations and not necessarily performed for berm design consideration. The discussions brought out the need to emphasize that geotechnical work is needed to classify borrow soil that will be used in either first-time berm construction or berm repair.

Finally, it was agreed targetry protection is best accomplished by placing below-grade emplacements and eliminating the berm. Although this option can create some emplacement drainage issues and is subject to collection of silt and debris, it is still preferred if the range layout and target locations can accommodate this design. The photos below provide a couple examples of an in-ground installation. 


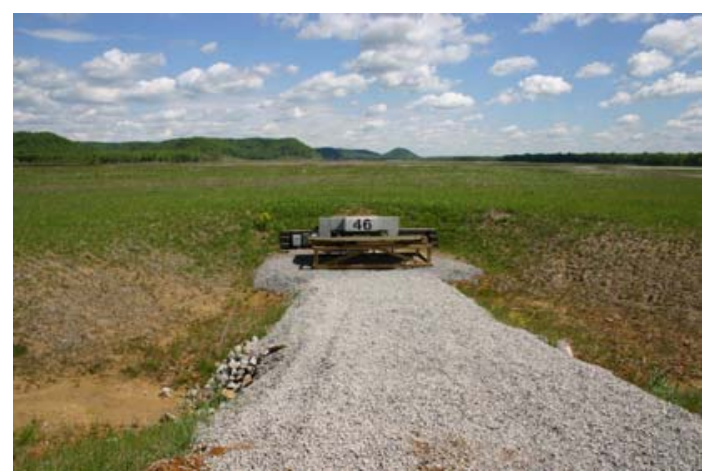

Ft Knox Wilcox D-MPTR In Ground SAT

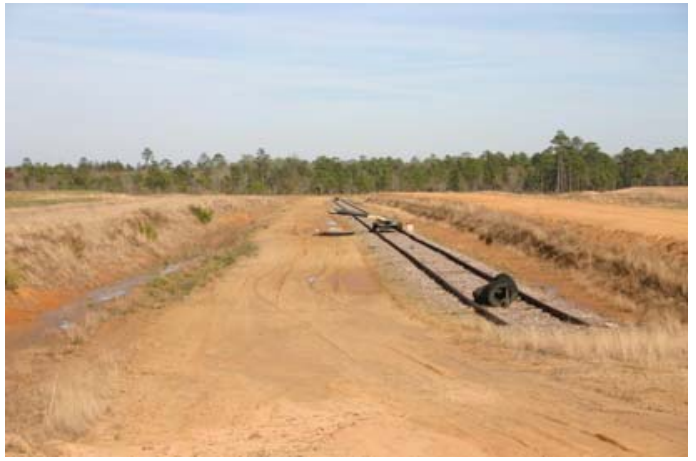

Ft Stewart Redcloud MPRC In Ground

Remote Controlled MAT

However, in practice, the designs reviewed had very few below-grade emplacements due to topography and assumed line-of-sight concerns.

Standard drawings for a stationary armor target (SAT) and a moving armor target (MAT) copied from the USACE-HNC web site are illustrated below. As shown, the berm designs are the same for both the SAT and MAT.

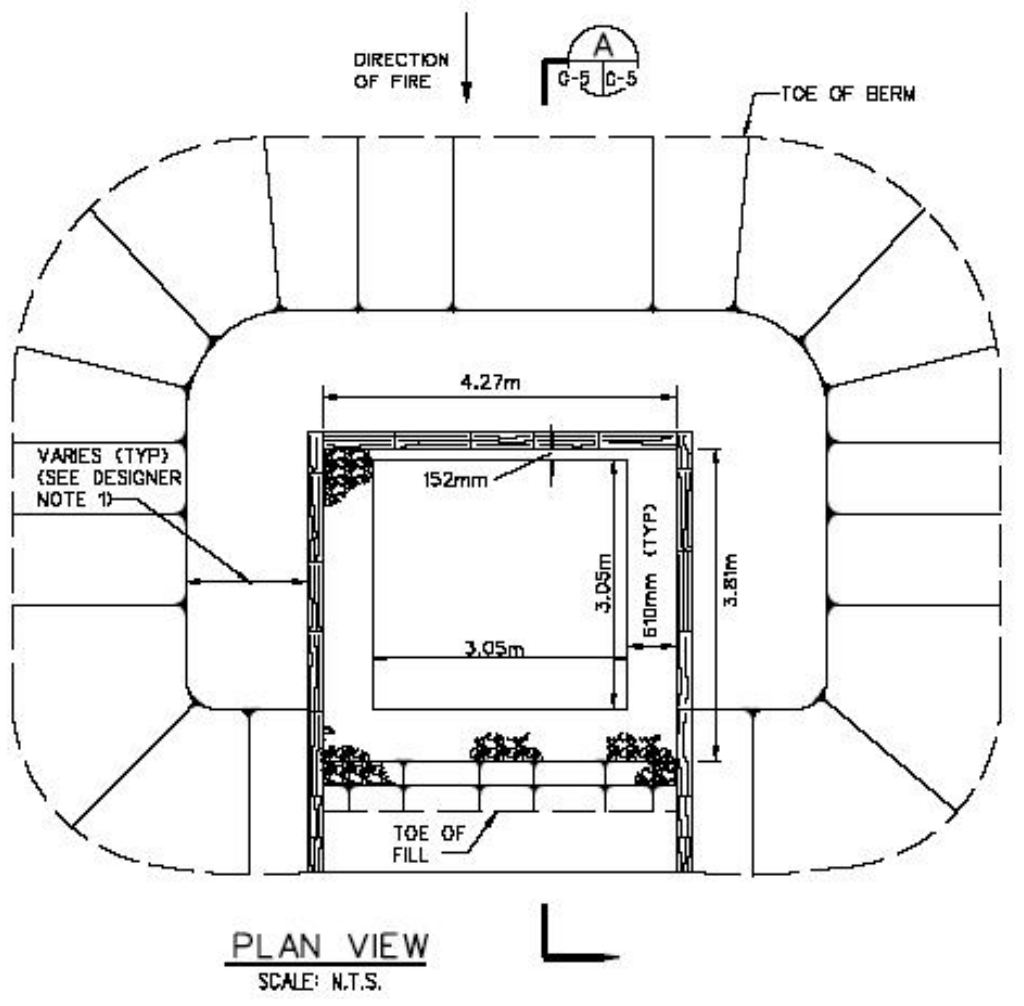

Standard Design SAT Position from Above 


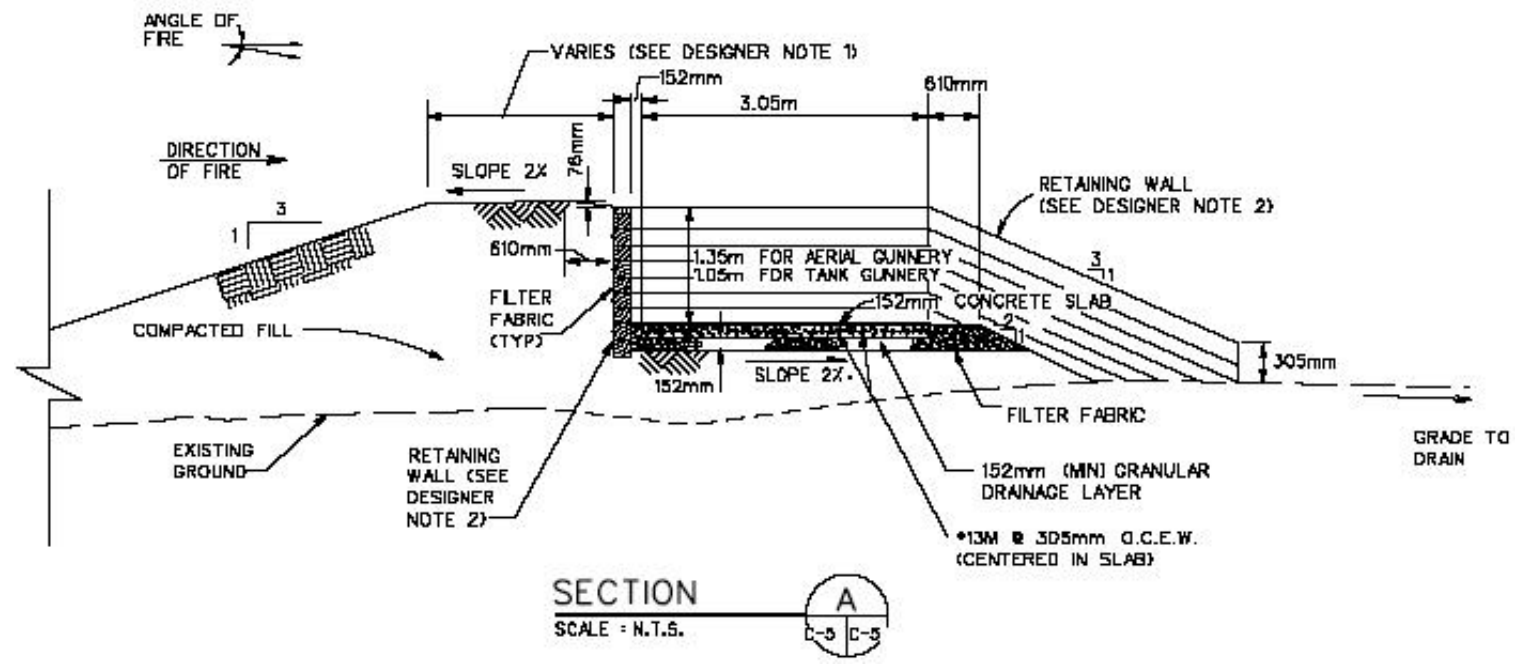

Standard Design SAT Position Cross-Section
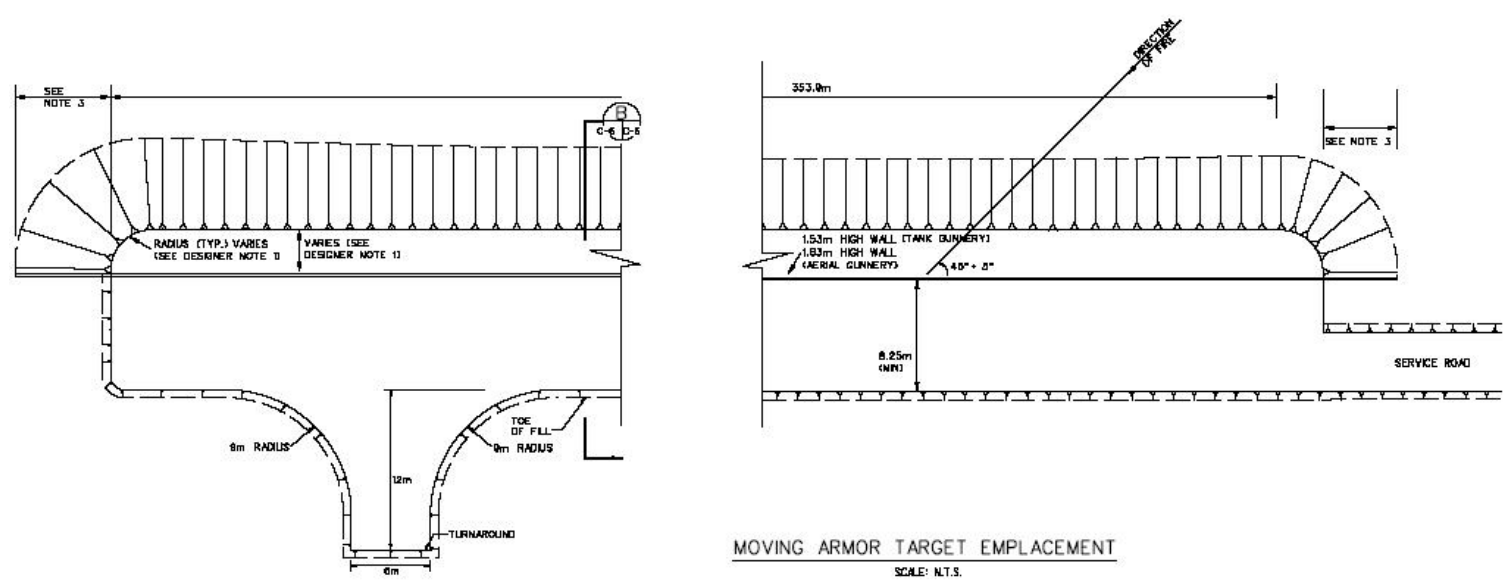

Standard Design MAT Position from Above

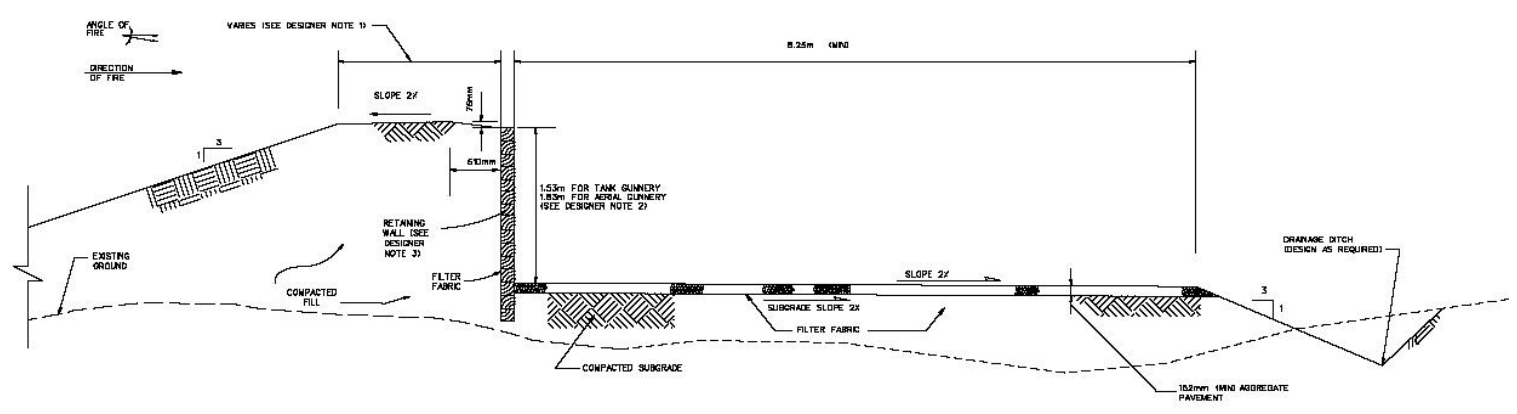

Standard Design MAT Position from Side 


\subsubsection{Design Alternatives for Berms}

The rate of berm erosion and significant adverse impacts due to range usage is the primary focus of this section. The current berm design appears to be successful in protecting the targetry during range operations. Consequently, the design as it relates to force/dissipation of impacts was not an area of focus.

The utilization of the range and the use of specific targets on a range for qualifications for example, create a variable with respect to berm erosion and significant impacts. The initial berm design assumes all targets are equally used. However, when in operation, target utilization can be characterized as high, medium, or low usage. The usage rate of the target impacts the berm deterioration rate of the individual target as well as the berms of targets that may be behind the primary target, but still in the line of fire.

As described by the range manager at Ft. Knox, one armor round hitting a berm can penetrate 2 to 4 feet into the berm; and skips can create literally a trench in the top of the berm. High use berms/targets can lose 10-15 feet of berm per month which requires major maintenance every three months. He further stated that in practice, repairs are always made by bringing in new dirt from borrow areas to fill holes; scooping dirt in front of berms to fill holes creates mud pools which are bigger problems over the life of the range. Vegetation is used initially to help stabilize the berms, but is difficult to maintain through the changing seasons and constant impacts from training activities.

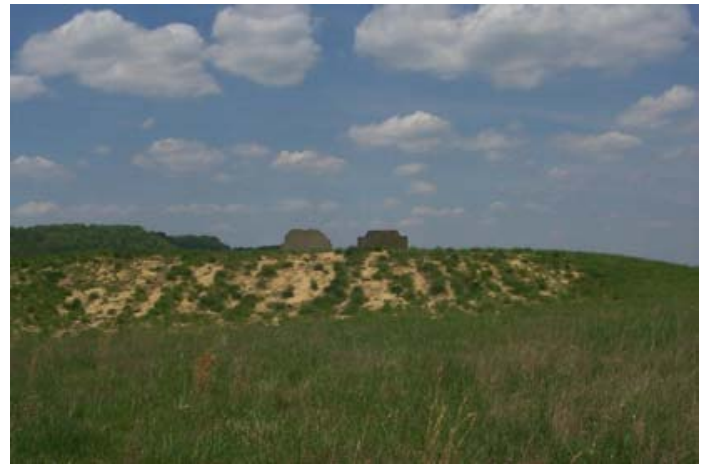

Ft Knox Yano MPRC Dual SAT Berm

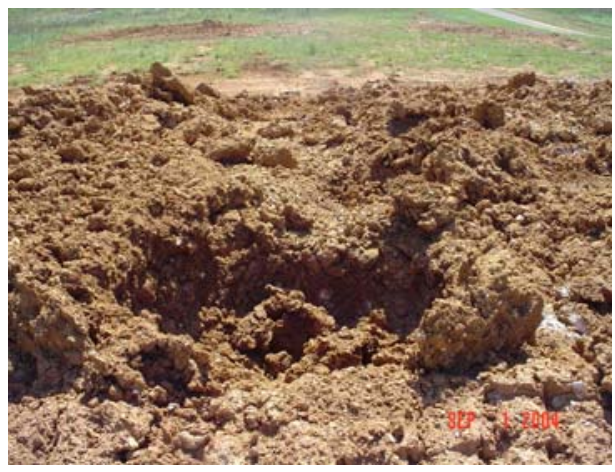

Ft Knox St Vith MPTR Projectile Impact Damage on SAT Berm 
Design alternatives to provide added environmental protection and longer life expectancy before significant berm maintenance is required as described above were identified as follows:

- $\quad$ Strategic siting of heavy use target locations

- $\quad$ Combination berms to minimize soil requirements

- $\quad$ Soil Amendments to slow the erosion process

\subsubsection{Siting of Heavy Use Target Locations}

Although the ultimate range usage is highly variable and ever-changing based on the training missions, the design team should attempt to identify the probable heavy use firing lanes and targets. These targets should be located as far as possible from sensitive environmental areas and drainage paths so that the soil that is eroded will not migrate to areas where adverse impacts may occur. Control swales and low-profile berms may also be considered for retaining the soils at sensitive locations, caution being taken to not obstruct line of sight to targets.

\subsubsection{Combination Berm Design}

Huntsville Range Design Manual (CEHNC 1110-1-23) includes a section on combination berm design with the objective of reducing the amount of soil required to protect the targetry. A combination berm design incorporates a sacrificial wall (concrete, gravel, or other material) designed and built within the berm, to resist the penetration force of the impact. Since these alternate materials have more resistive strength than compacted soil, the width of the berm can be substantially reduced. This design is not often used because it is typically less expensive to use available soils. Additionally, there is still and always a concern regarding ricochet of projectiles, should the soil cover erode and the projectiles impact the imbedded materials.

While this approach in itself does not address the surface erosion issue, it does result in less soil initially required and, consequently, less potential for environmental impacts during construction. As described during this study, typically when berm widths are reduced to about 20 feet, the target is taken out of service until the berm can be re-built. By using a combined berm design, the width before the target is not usable may be reduced to about 10 feet, which may result in a higher up time for the target.

Softer materials and recycled products (wood, plastics, and tires) were also considered for 
use within the berm to reduce the ricochet potential. Additionally, different configurations of these materials within the berm were considered to effectively capture the soils so they do not erode as quickly. While these may be items for future review, the use of plastics, recycled plastics, wood timber, and re-cycled wood products in a combination berm design did not evolve into a realistic design alternative.

\subsubsection{Berm Slopes and Erosion Controls}

The typical berm designs for the ranges reviewed followed the USACE-HNC design guide and included a 3 horizontal to 1 vertical slope (3:1 slope) from the berm crest to the existing grade. While this slope is adequate for standard berm designs, and in many cases is necessary due to site limitations, there may be some advantage to decreasing the berm to $4: 1$ slopes to reduce erosion potential. The concept being that the flatter the slope, the greater the tendency will be for disturbed "spray" soils to fall back onto the surface slope rather than being eroded down the slope, providing added environmental protection and longer maintenance cycles.

Erosion control using a variety of erosion mats, vegetative covers, and geotextile fabrics is common in the construction industry to stabilize slopes and embankments. These various product types were reviewed for application at range facilities. The review team's conclusion is that these products would certainly help stabilize the berm during the initial construction activities, but the belief is the penetration of projectiles would quickly destroy the stabilizing effects of these products. Furthermore, products that may better withstand the impacts (i.e. imbedded wood timbers, rubber tires, other recyclable materials) may create ricochet issues that would need to be addressed. They would also add cost during construction and maintenance.

No specific studies were identified to evaluate if the berm slope can extend the maintenance cycle of a target berm.

\subsubsection{Soil Amendments}

There are numerous methods used to control dust and limit soil erosion on military installations, aircraft runways/airstrips/taxiways, haul roads, paths/walkways, and training areas. The more traditional methods include:

- $\quad$ Chloride based products $\left(\mathrm{CaCl}_{2}, \mathrm{MaCl}_{2}\right.$, etc.) 
- $\quad$ Lignin based products (Lignosulfonates)

- $\quad$ PAM (polyacrylamides)

- $\quad$ Petroleum Emulsions

- $\quad$ Resin Emulsions

- $\quad$ Organic Oils

- $\quad$ Enzymes

- Watering

CERL has investigated and tested a variety of these technologies for dust control of tank and service trails. CERL has study results showing significant dust control obtained by addition of amendments during the construction phase, incorporating the additive throughout the top layer of road material. There is a website that has dust control suggestions for gravel roads. The website is located at: http://aec.army.mil/usaec/technology/rangexxi04.html. However, we believe soil amendments for targetry berms may also be applicable to reduce the soil erosion potential and extend the timeframe between maintenance activities.

New non-traditional soil stabilizers are now available to replace these traditional stabilizers. These are more elaborate treatments to make the soil less likely to become airborne or suffer from erosion and can help contain the berm material after a hit and minimize the area affected. A few of these methods are proprietary processes and include:

- $\quad$ Dewatered Residual Wood Fiber

- $\quad$ Soil Sement

- $\quad$ Ubix

- Dustrol

- $\quad$ Baseline

- $\quad$ Asphotac

- $\quad$ Envirotac II ${ }^{\circledR}$

These products are used for

- $\quad$ Unpaved Road Stabilization \& Pothole Elimination

- $\quad$ Dust Abatement, Dust Containment \& Dust Control 
- $\quad$ Dust Remediation Suppressant

- $\quad$ Erosion Control, Sediment Control \& Silt Containment

• $\quad$ Hazardous Site Sealing, Capping \& PPM Elimination

- $\quad$ Soil Stabilization \& Sediment Stabilizer

- $\quad$ Sub-Base Hardening

- $\quad$ Surface Sealing

Two of the listed products have shown promise as particularly effective dust suppression and erosion control agents. One is identified as "Soil Sement," manufactured by Midwest Industrial Supply, Inc., which is portrayed as an environmentally safe polymer emulsion that is designed to affect dust control, erosion control and soil stabilization. The other product is Envirotac II, which its manufacturer, Environmental Products and Applications, Inc. in Palm Desert, California, claims to provide effective bonding, cohesion, versatility, cost-effectiveness, and environmental compliance. A more detailed discussion of these amendment products is included in the following section focused on tank trails and service roads.

As these amendment products relate to berm design, the design concept is to add soil amendments to berm materials to make the berm more cohesive to reduce the "spray" effects of impacts and to slow the overall erosion process, thereby providing added protection to the range environment. This would also extend the period that range targets can be used before being taken off-line for repair.

\subsubsection{Recommendations}

The targetry berm review included a variety of possible changes to the existing berm designs in order to expand the maintenance cycle of the berm as well as provide added protection to the local environment by reducing erosion and runoff into water bodies.

Recommendations for further evaluation and field studies are as follows:

- $\quad$ Conduct field studies of the impact of varying berm slopes and compaction on soil erosion and maintenance cycles. A cost analysis should be included.

- $\quad$ Conduct field studies for soil amendments mixed into berm materials to determine 
the positive impacts on soil erosion and maintenance cycles. Include in this study as a minimum “Soil Sement,” manufactured by Midwest Industrial Supply, Inc., and Envirotac II, manufactured by Environmental Products and Applications, Inc. A cost analysis should be included as part of the study.

- Emphasize in the updated USACE-HNC design guidance documents the importance of heavy-use targetry siting in areas that are not environmentally sensitive or near streams and other water bodies.

- $\quad$ Emphasize the preference is to design in-ground targetry so the berms are minimized.

\subsection{Tank Trails and Range Roads}

\subsubsection{Current Design Principals}

Tank trail designs are typically based on Huntsville Range Design Manual (CEHNC 1110-1-23), Chapter 7. This design guide considers two primary parameters: the required thickness of the trail for normal conditions and the effects of frost conditions on the design. The thickness of the aggregate trail is based on the design index (i.e. number of passes per week) and the California Bearing Ratio (CBR) values. The revised Design Manual recently made available through the internet web site provides the full design details http://www.hnd.usace.army.mil/rdg/InterTemplate.aspx. Where tracked vehicles are required to make turns, the preference was to design thick concrete pavement to prevent aggregate pulverizing and rutting that can occur with the aggregate trails. In cases where concrete turning pads are not used, maintenance of the trails becomes more significant.

The following table provides a summary of the design parameters for tank trails for the ranges reviewed as part of this study. In general, the designs appear to follow the USACE-HNC design manual as well as incorporating references to local Department of Transportation road bed materials. Service road designs followed the same process, with lighter vehicle loads the primary difference. 


\section{Tank Trail Summary}

\begin{tabular}{|c|c|c|c|c|c|c|}
\hline Location & Width & Shoulders & Aggregate & $\begin{array}{l}\text { Filter } \\
\text { Fabric }\end{array}$ & Subbase & Compaction \\
\hline Camp Atterbury, Indiana & $22 \mathrm{ft}$ & $1 \mathrm{ft}$ & $\begin{array}{l}10 " \# 2 \text { course graded } \\
\text { crush stone, 10" \#53 } \\
\text { fine graded crushed } \\
\text { stone }\end{array}$ & YES & proof rolled & $90-95 \%$ \\
\hline Ft Knox, Kentucky & $16 \mathrm{ft}$ & $2 \mathrm{ft}$ & $\begin{array}{l}3 \text { inches kydot \#610, } 18 \\
\text { inch kydot \#357 }\end{array}$ & YES & $\begin{array}{l}\text { compacted } \\
\text { subgrade }\end{array}$ & NS \\
\hline Fort Stewart, Georgia & $6.1 \mathrm{~m}$ & $1 \mathrm{~m}$ & NS & NS & NS & $85-90 \%$ \\
\hline Camp Shelby, Mississippi & $20 \mathrm{ft}$ & $2 \mathrm{ft}$ & $\begin{array}{l}\text { 4" MSDOT No. 57, 8" } \\
\text { MSDOT No. } 3\end{array}$ & NS & $\begin{array}{l}\text { 6" compacted } \\
\text { subgrade/2' } \\
\text { undercut for }(\mathrm{CH}) \\
\end{array}$ & NS \\
\hline Fort Hood, Texas & $6.1 \mathrm{~m}$ & $.61 \mathrm{~m}$ & $\begin{array}{l}100 \mathrm{~mm} \text { type AA } 100 \% \\
350 \mathrm{~mm} \text { Grade } 695 \%\end{array}$ & YES & $\begin{array}{l}300 \mathrm{~mm} \text { subgrade } \\
90 \%\end{array}$ & $90-100 \%$ \\
\hline Fort Wainwright, Alaska & $4.5 \mathrm{~m}$ & NS & $\begin{array}{l}0.1 \mathrm{~m} \text { surfacing material, } \\
0.51 \mathrm{~m} \text { classified base } \\
\text { course material }\end{array}$ & NS & exisiting ground & NS \\
\hline Fort Polk, Louisiana & $\begin{array}{r}\text { Note } \\
\text { design }\end{array}$ & $\begin{array}{r}\text { Fort Polk, Lf } \\
\text { hot provided; } \\
\text { not beer }\end{array}$ & $\begin{array}{l}\text { - Volumes } 2 \text { and } 3 \text { of } \\
\text { therfore detail review has } \\
\text { completed. }\end{array}$ & & & \\
\hline Fort Pickett, Virginia & $20 \mathrm{ft}$ & $1 \mathrm{ft}$ & 16" TY 21A or 21B & YES & 6" \#57 & $90 \%$ \\
\hline Fort Benning, Georgia & $20 \mathrm{ft}$ & $2 \mathrm{ft}$ & $\begin{array}{l}\text { No. } 357 \text { and 6" GA DOT } \\
\text { No. } 4\end{array}$ & YES & $\begin{array}{l}10 " \text { compacted } \\
\text { subgrade }\end{array}$ & $95 \%$ \\
\hline Fort Shafter, Hawaii & \multicolumn{3}{|c|}{$\begin{array}{l}\text { Residential / commercial road design for } \\
\text { Stryker vehicles }\end{array}$} & & & \\
\hline
\end{tabular}

The practical application of the standard design for course road construction is the hard packed rock roadbed. This design provides the best base for vehicles to maneuver while engaging targets. An important part of this road is concrete turn pads for heavy vehicles. These pads allow tracked vehicles to turn off the course road without damaging the road during the turn. An item learned at Fort Knox is that the turn pads need to be swept of rock regularly to prevent damage to the pads when vehicles crush the rock as they roll across the pad.

These course roads require periodic replacement of the surface rock. Experience has shown heavy use of the course roads will crush the surface rock. Once the rock is crushed, the course road will become soup when it rains and dust when it is dry; creating significant environmental and erosion concerns. 


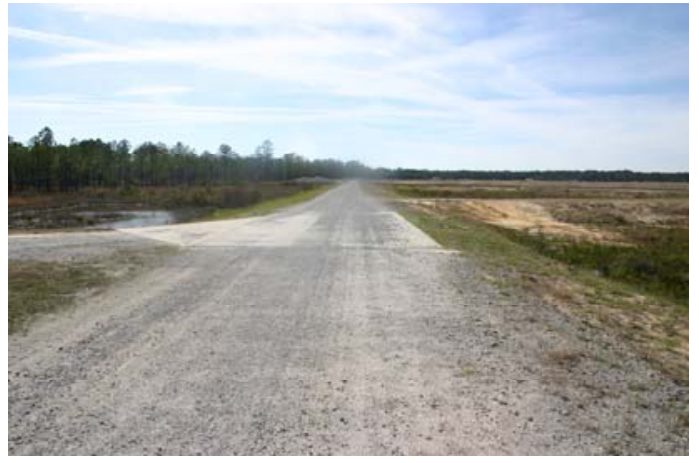

Course Road at Redcloud Alpha

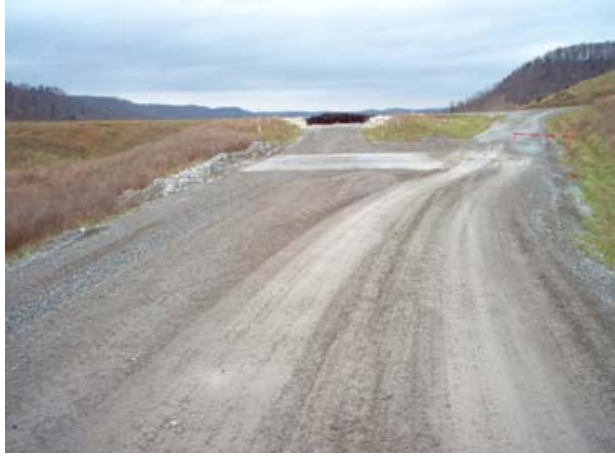

Course Road on Cedar Creek MPTR

Ft. Knox, Kentucky

Only a very brief discussion within the design manual is focused on dust control. Dust and soil erosion caused by tracked vehicles and other training vehicles has a significant environmental impact on the range site and causes training delays during operations. While the designs reviewed did address dust control during construction, the designs did not require soil amendments or other dust suppression options focused on range operational dust control measures.

\subsubsection{Design Alternatives for Tank Trails}

The review of tank trails and service roads resulted in two primary areas of focus for this study: the impact of usage rates on the trail thickness, and measures to control dust and erosion during operation.

\subsubsection{Tank Trail Usage Impacts}

Currently, most range course roads are designed and built to a similar depth (approximately 12") as a standard practice. This is mainly due to the similarity in the types of vehicles that are utilizing the ranges. The current standard tank trail design takes into account usage rate through the design index which is based on the number of vehicle passes per week. However, this index does not look at the variability of usage within a range. For example, on a 4,000 meter armor trail the first 1,500 meters may be used in every training session, but the last 1,000 meters of the trail may only be used every fifth training session. 
The objective of this analysis was to run several sample roadway designs with variations in the volume traffic for the life of the roadway. In order to minimize the number of variables, the designs were based on non-frost areas. The Engineered Management System PCASE program was utilized for the initial roadway design analysis. The roadway designs were based upon the course roads that would need to be designed for the M1-series Abrams tank. The following summarizes the three main trials that were utilized on the PCASE program.

Heavy usage was designated as the standard design criteria, which was assumed to occur along the first section of the range course road. This design uses a total number of passes for the life of the road as 1,000,000, which is equivalent to about 110 passes a day. This is a reasonable amount of traffic for a range that will be used for qualification purposes. The total required depth of aggregate for this section is 11.82 inches. This number fits the typical 12 inches used on various ranges across the country. The PCASE printout below depicts the heavy traffic usage.

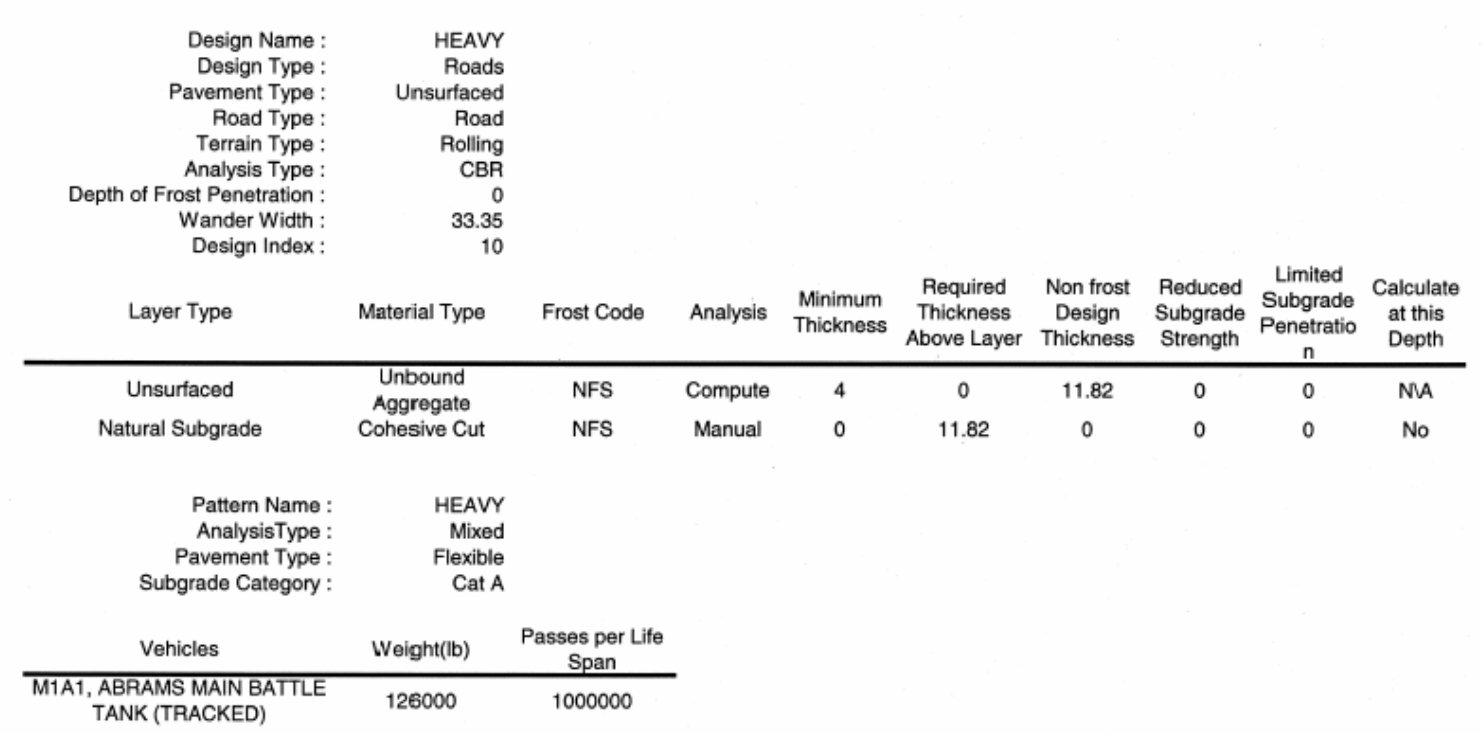

Further downrange it was assumed the course roads would be used less frequently, which was considered medium usage. The total passes for this scenario was reduced to about 80 passes a day which is equivalent to approximately 750,000 passes during the life of the road. This level of usage requires a total aggregate depth of 11.56 inches, only $2.2 \%$ less than the depth for heavy usage. The PCASE printout below depicts the medium traffic usage. 


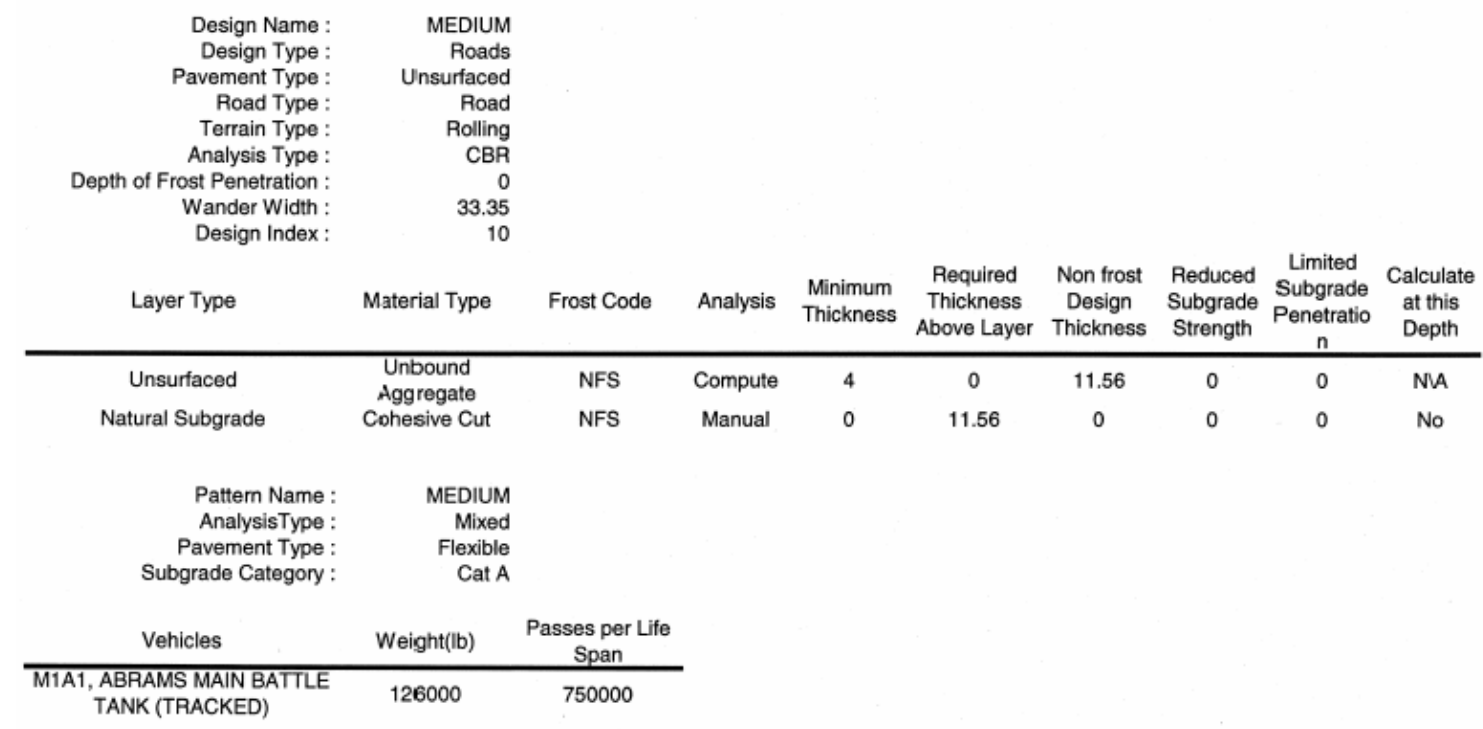

The usage rate at the farthest downrange portion of the range was assumed to be light usage. This usage was characterized to be approximately 25 passes a day or 250,000 passes during the life of the road. This rate resulted in a calculated aggregate for the road to be 10.48 inches, or $11.3 \%$ less than the depth for heavy usage. Even this drastic reduction in the traffic volume for the course road resulted in a savings of only about 1 inch of aggregate to the project. The PCASE printout below depicts the light traffic usage.

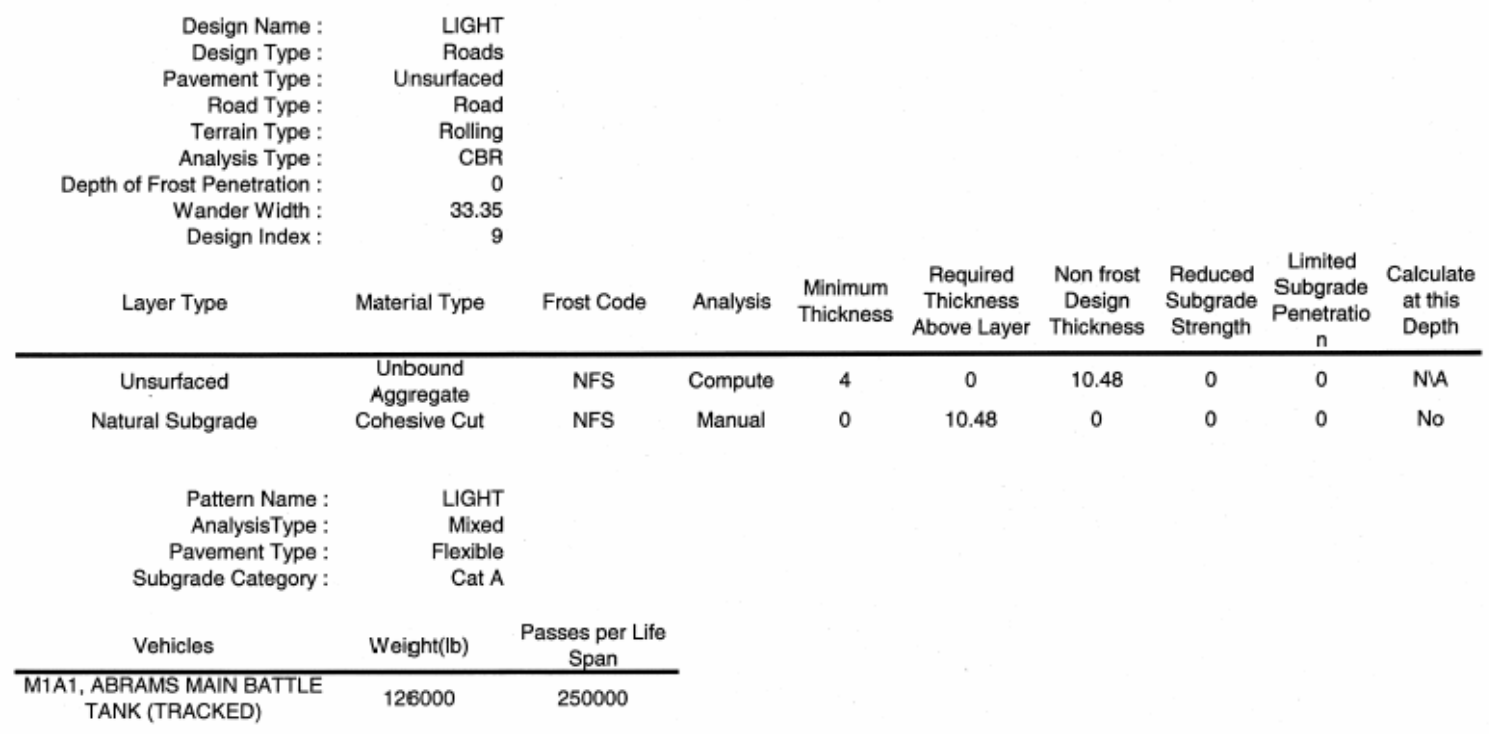


A second factor in the determination of the total required aggregate surface thickness for a trail is the California Bearing Ratio (CBR) of the supporting existing soil. The higher the CBR value, the more subgrade support is provided for the new course road and the less aggregate the roadway will require. The previous design analysis used a CBR value of 10 for the existing soil. The following design analysis show the same three designs with the exception of the CBR value lowering from 10 to 5 .

The Heavy traffic design analysis resulted in the required thickness increasing to 25.96 inches from 11.82 inches by reducing the CBR of the existing soil from 10 to 5 . This represents a $120 \%$ increase. The Medium traffic design increased to 25.4 inches (120\%) and the Light design increased to 23.41 inches (123\%). The PCASE printouts below depict the heavy, medium, and light traffic usage.

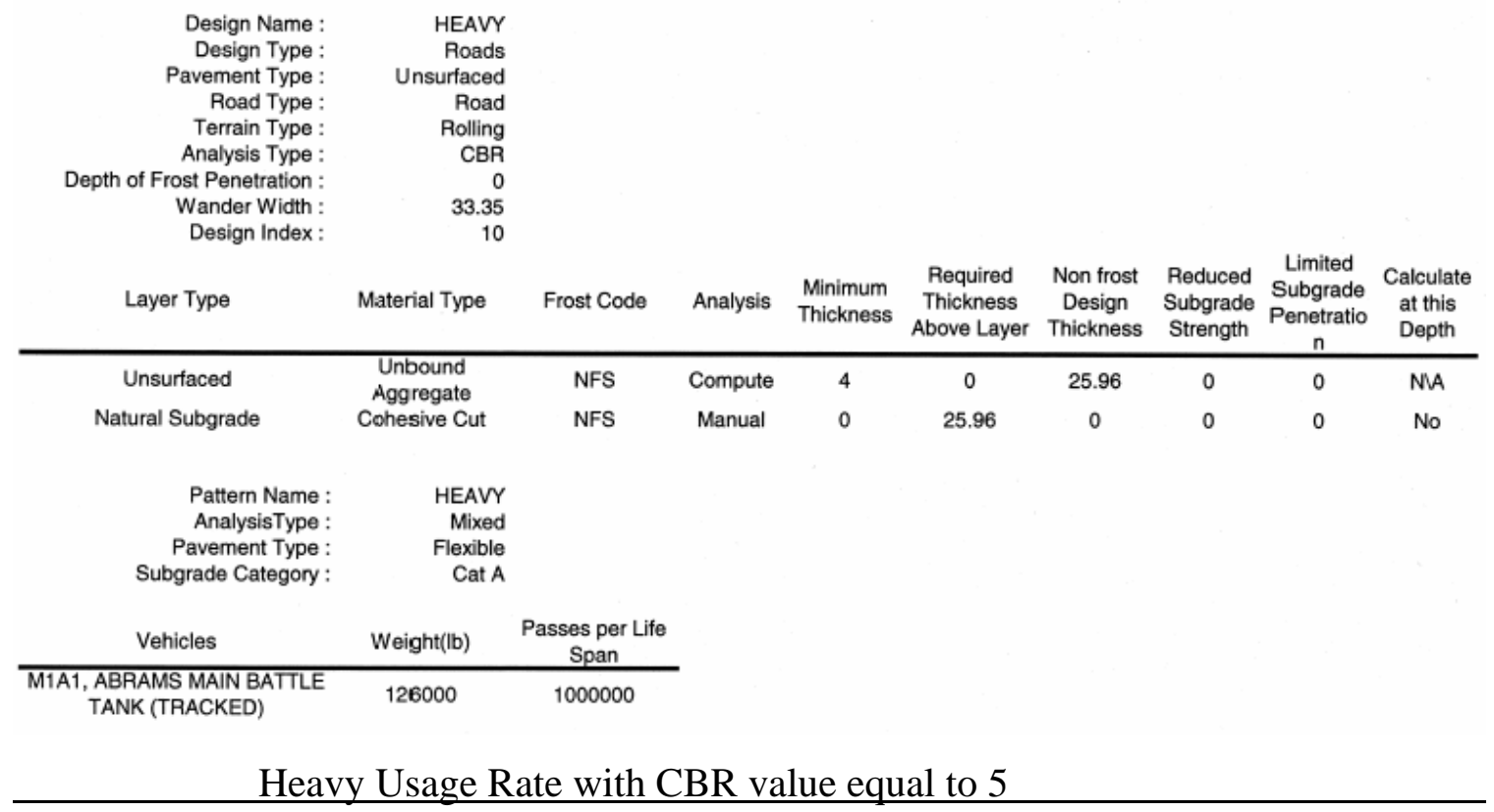




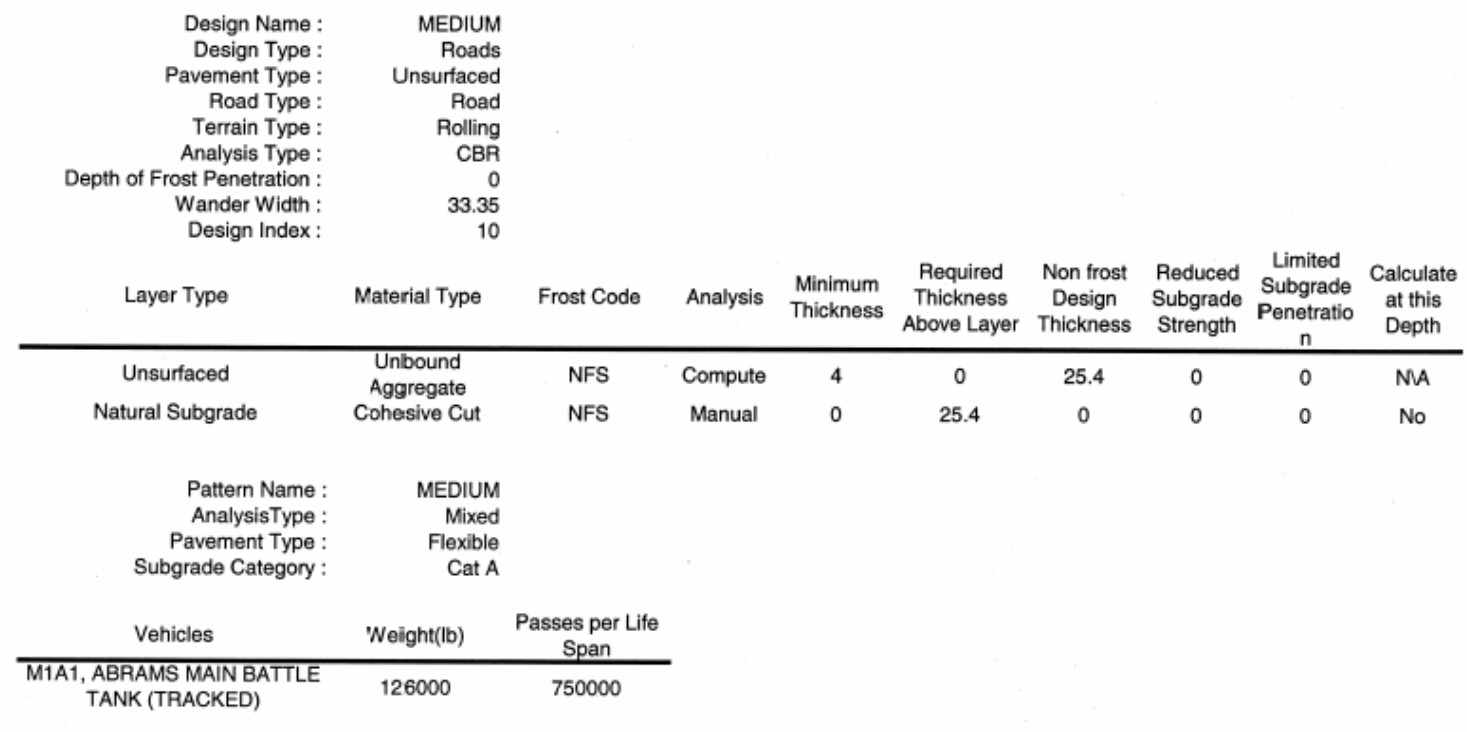

Medium Usage Rate with CBR value equal to 5

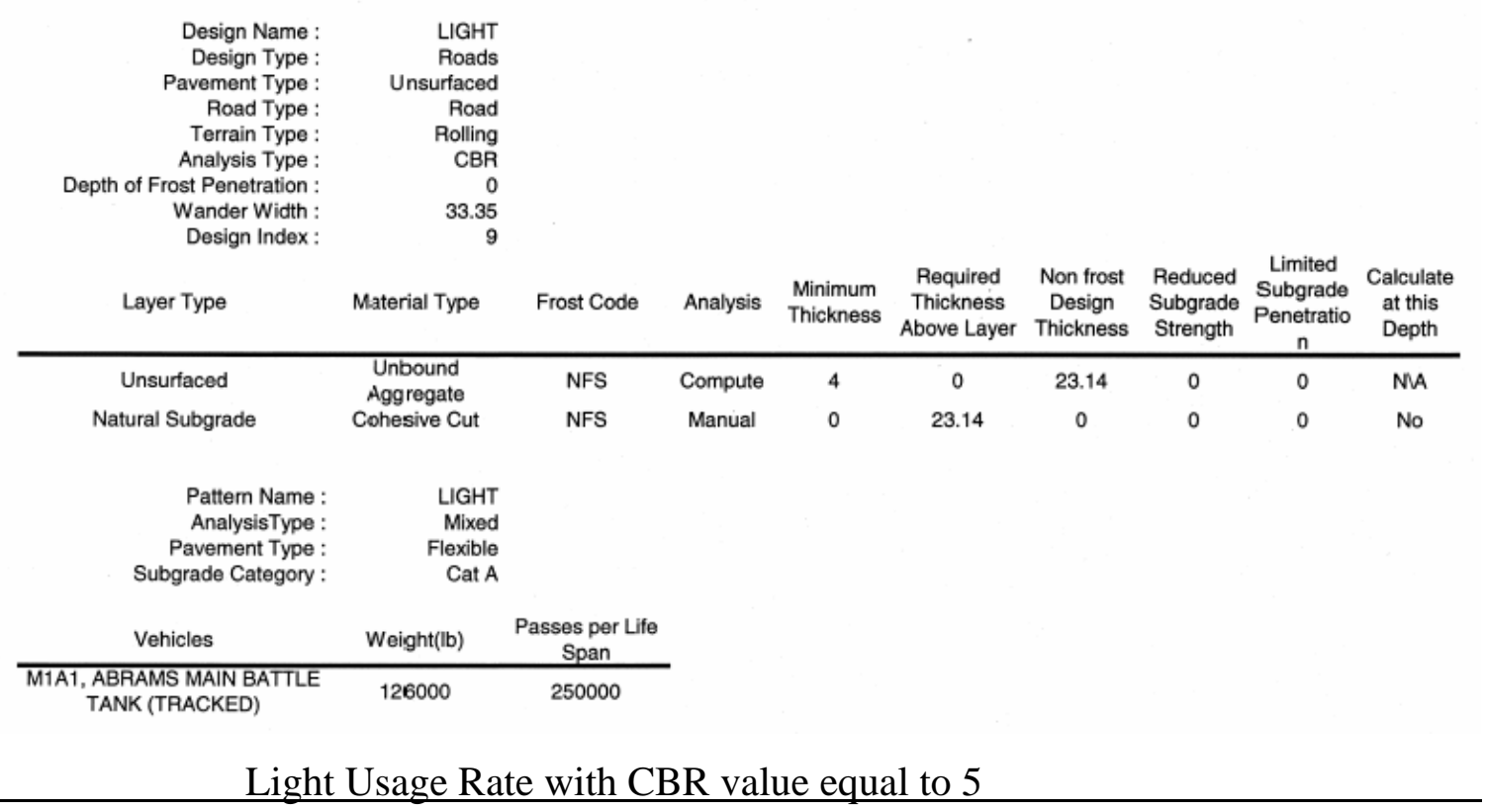

The utilization of the varying degrees of usage along the course roads does not have a significant impact on savings in the construction phase of the range projects. Additionally, the individual facilities indicated the usage rates can vary significantly on a particular range as 
training requirements are modified. Consequently, it is not recommended that design course roads be designed with varying thicknesses based upon projected usage.

The factor that has the largest effect on the required trail design is the CBR value of the soil base. The CBR variation analysis confirmed the variation of soil from location to location is significant and requires that each project have the roadway sections designed to the individual range purpose, soil characteristics and climate.

\subsubsection{Soil Amendments for Dust Control and Improved Life-Cycle Cost}

As mentioned in Section 3.2.2, there are new soil treatments that have shown promise as life extenders for course roads, tank trails, berms, and firing positions. They are environmentally safe polymer emulsions designed to affect dust control, erosion control and soil stabilization. These product materials are advertised as being able to provide effective bonding, cohesion, versatility, cost-effectiveness, and environmental compliance. As dust suppressants these products are designed to eliminate particulate matter (PM10 and PM2.5), and they do not contain any detectable polycyclic organic matter (POM) as defined by the Federal Clean Air Act section 112 (b). This includes polynuclear aromatic hydrocarbons (PAH). They also do not contain detectable levels of fluorinated or brominated compounds that could be expected to contribute to ozone depletion. These products are supposed to be non-toxic, non-corrosive, non-flammable and non-polluting of groundwater.

Of equal importance is the fact that products such as these can actually increase the loadbearing strength of all types of soils and surfaces as well as prevent water from seeping into and destabilizing the surface. These products dry clear and meet air, water, groundwater and stormwater compliance requirements. Many have already been evaluated by environmental certifying agencies, such as California Air Resources Board, and found to be acceptable products.

Some evaluations by military organizations have also been made of these processes. The results of the products tested are shown in the table below and indicate significantly better performance by two of the entries, Soil Sement and Envirotac II. When applied to the surface of any soil, the product penetrates into the soil to create a layer of protection. Upon drying, it binds the soil's particles together forming a clear, plastic, resin bond. Light applications are effective for cementing soil particles together for dust and erosion control, while allowing water and air to still penetrate the surface. Heavier applications build a waterproof layer of protection. This hard 
surface is flexible and can withstand vehicle traffic. It can be mixed or tilled into the soil for more extreme protection.

The following table is taken from a report prepared for the Naval Facilities Engineering Service Center, Port Hueneme, California, in an evaluation of dust suppression products conducted for the Marine Corps Air Ground Combat Center, Twentynine Palms, California. (Site Specific Report SSR-2343-ENV).

Winter Test (28 days after product application)

\begin{tabular}{|l|c|c|}
\hline \multicolumn{1}{|c|}{ Product Name } & $\begin{array}{c}\text { Captured Dust } \\
\text { Particles (mg) }\end{array}$ & $\begin{array}{c}\text { Average Measured Deflection } \\
\text { (cm) }\end{array}$ \\
\hline Envirotac II & $16.3 / 4 \mathrm{hrs}$ (Note1) & 0.04 \\
\hline Soil Sement & $514 / 4 \mathrm{hrs}$ (Note 1) & 0.31 \\
\hline Dewatered Residual Wood & $1770 / 2 \mathrm{hrs}$ (Note 2) & 2.10 \\
\hline Fiber & & 2.14 \\
\hline Usphotac & $3794 / 2 \mathrm{hrs}$ & See note 1 \\
\hline Dustrol & (Note 3) & See note 3 \\
\hline Baseline & (Note 4) & 1.28 \\
\hline
\end{tabular}

Note 1: Since both products had substantially less dust capture than the baseline after a visual inspection of the filter at two hours, their run times were doubled.

Note 2: DWRF was dislodged under normal foot traffic upon setup of the ventilation system. Once dislodged, winds carried the product from its respective test bed.

Note 3: Product was not applied until spring since ambient temperatures were below curing temperature.

Note 4: Product did not cure within 2 weeks after application. Performance testing of this product was aborted.

The lower dust capture of the Envirotac II samples indicates a significant improvement over the other methods in dust suppression. Similarly the compression test data of the six methods show a higher force at failure for Envirotac II samples than the other evaluated processes demonstrating higher load capacity. (See table below). 


\begin{tabular}{|l|c|c|c|}
\hline \multicolumn{1}{|c|}{ Product Name } & Force at Failure (lb) & Force at Failure (lb) & Average \\
\hline Envirotac II & 2246 & 2110 & 2178 \\
\hline Soil Sement & 1610 & 1396 & 1503 \\
\hline Tall Oil & 1060 & 650 & 855 \\
\hline Ubix & 536 & $*$ & 536 \\
\hline Baseline & $*$ & $*$ & $*$ \\
\hline DWRF & $* *$ & $* *$ & $* *$ \\
\hline
\end{tabular}

* Denotes samples that had broken apart during the canister removal.

** Dewatered residual wood fibers were not tested in compression because the application of the product is not designed to change the compressive strength of the soil.

A field demonstration was conducted along an unpaved section of roadway to substantiate the results of the bench testing. The field demonstration consisted of applying Envirotac II and Soil Sement, the products that generated the least amount of dust, to a test section of unpaved roadway on base. The evaluation process was conducted visually by monitoring dust as random vehicles passed through two treated sections. The site selected for field demonstration was an unpaved roadway trafficked primarily by rubber-tired vehicles. As a result of these demonstrations, the products were approved for use on the base and are currently being employed there.

Some of these products also have physical properties that would enhance their environmental acceptability.

- $\quad$ Non-toxic, non-combustible and considered non-hazardous under the OSHA

Hazard Communication Standard (29CFR 1910.1200)

- Water soluble and will not damage any equipment if rinsed after use

- $\quad$ Does not dissipate (wash away) with rain

- $\quad$ PM-10 \& PM-2.5 Compliant

- $\quad$ Resists Breakdown from Water, UV Rays and Alkaline

- $\quad$ Non-Flammable

- $\quad$ Non-Leaching

- $\quad$ Non-Tracking 
- $\quad$ Self Mixes with Water (to apply)

- Dries Odorless

One of these products is currently in use stabilizing the silty sand runways, landing pads, roads and camp facilities for the U.S. Marine, Army, and Navy overseas efforts in Afghanistan, Kuwait, and Uzbekistan. Application rates and cost information are provided in Appendix B.

\subsubsection{Other Products}

One consideration in using acrylic co-polymers is that once they break-down, they cannot re-combine - - they must be replaced. There are other products that are used that are somewhat self-healing with minor repair. These are synthetic fluids that are sprayed on like the copolymers but are easier to apply and are gradable to take on continued traffic. One such new product, currently under evaluation by Midwest Supply, is called EnvroClean which they claim to be cheaper to apply and easier to maintain. More information needs to be obtained about these types of dust suppressants before any usage can be evaluated.

\subsubsection{Recommendations}

Design of tank trails, and to a lesser degree service roads, must take into account the local site soil characteristics and geotechnical testing in order to develop a stable road base. Additionally, soil amendments during construction and as part of ongoing maintenance appear to have strong potential to reduce environmental impacts from dust and erosion, as well as extend the maintenance cycle of the range trails.

Recommendations for design consideration, further evaluation and field studies are as follows:

- $\quad$ Concrete turn pads should be placed in every location tracked vehicles turn off or on to the course road. Based on conversations with range managers, concrete turn pads are critical to reducing trail maintenance, excessive dust, and erosion of trails. Unfortunately, one of the first items that are dropped from a project when budget issues arise is replacing the concrete turn pads with gravel. While the initial construction cost for gravel turns is less, the long term cost of constant 
maintenance is not considered, and may actually exceed the initial cost of a concrete turning pad over the life of the range. The picture below depicts a turn on St. Vith MPTR at Fort Knox that is constantly damaged and constantly being repaired. Efforts to have a turn pad installed have been met with a lack of money to fund the initial construction. This appears to be a common problem within the range community.

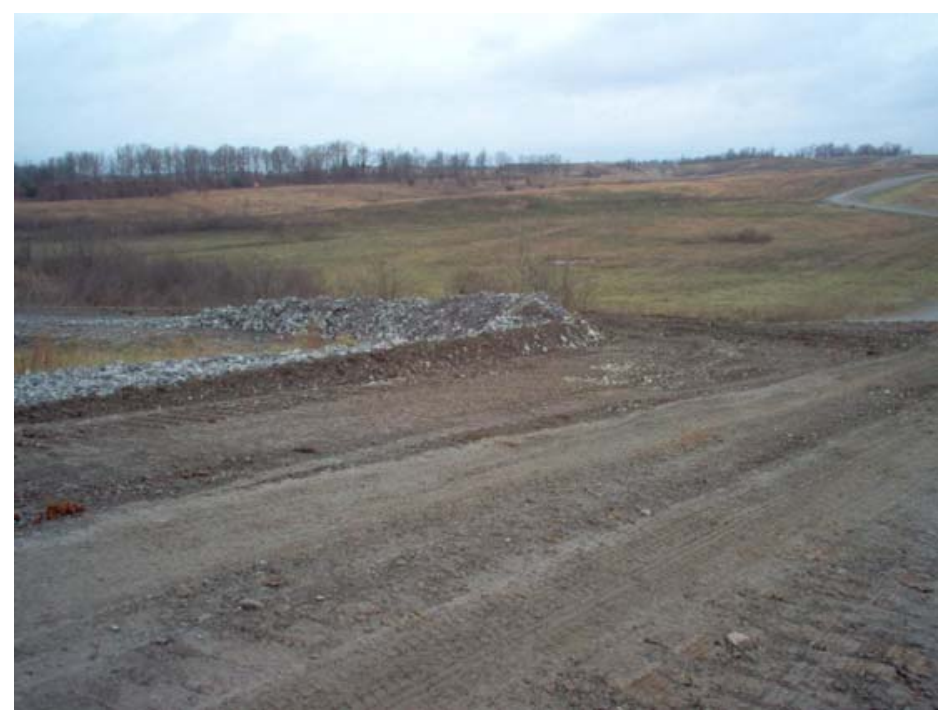

Turn around point on St. Vith MPTR at Fort Knox

- $\quad$ Obtaining early in the design process geotechnical data on the soils where course roads are proposed, including determination of CBR values, can significantly impact the trail design.

- $\quad$ Consideration should be given during design to apply amendments to poor subgrade materials through soil stabilization measures, which may drastically reduce the required aggregate surface thicknesses.

- New soil amendment products, including Soil Sement and Envirotac II, should be field tested at several armor ranges, with various climate and soil conditions. The product evaluation should be focused on the reduction of environmental impacts including dust reduction during use, extension of maintenance cycles, and associated life-cycle costs. 


\subsection{Low Water Crossings}

\subsubsection{Current Design Principals}

Low Water Crossings (LWC) are sites where vehicles must cross flowing water within the range site. The design and construction methods are based on the terrain where the crossing is located, the projected water flow and each Installation's specific requirements. There is no real training objective associated with these crossings, but they do need to be designed to allow the range to be safely used during all types of weather.

A LWC design is typically based on local and State roadway design guidelines which include environmental protection and control of sediment and other issues that may be specific to the location. The designs can include concrete or gravel trails and can be designed to be submerged (stream flows over the road surface), with culverts to manage the total flow, or a combination design where the base flow is managed through culverts, but extreme flows can submerge the structure. Each design is unique to the facility and stream characteristics.

During the design of the LWC, there are some general environmental and hydrologic considerations that need to be considered including:

- Is an Environmental Assessment required?

- How is fish and aquatic animal migration maintained?

- $\quad$ How will sedimentation be controlled during construction and once the range is active?

- What is the amount of water flow and flood levels?

- Will the 100 or 500-year flood event undermine or move the LWC?

- $\quad$ Will the LWC be subject to scouring, and what measures will be taken to minimize this?

Once the decision has been made to design and construct the LWC, the process of keeping the sedimentation to a minimum during construction is introduced. One method is temporarily diverting the stream and then constructing the LWC in the dry stream bed. This will work best where there is sufficient room for the stream diversion and the construction. Another method is dredging out the stream bed while the stream is still flowing through it. Dredging can be completed within environmental limits with proper precautions in place which includes 
reducing sedimentation flowing downstream which can be achieved by placing a rock dam or other temporary control structure in the stream bed across the width of the stream downstream from the construction site. This control structure will slow the water flow and allow silt and sedimentation to drop out of the water column. Care must be taken not to create a dam that will cause the stream to leave its banks. After construction is complete, the control structure can be removed or left in place to provide long-term protection downstream of the LWC.

Maintenance is a key issue with low water crossings. Debris brought downstream may collect and block the flow of water through the crossing. Water can then backup and eventually flow around the crossing causing unwanted scouring and erosion of the side embankments. The Environmental and Range Control offices must jointly ensure that the flow of water is not impeded. This is an item which should be included in their joint inspections of the training area.

\subsubsection{Design Alternatives for Low Water Crossings}

The design of a LWC is as varied as the site conditions for the individual range. The designs are unique to the stream conditions, topography, and environmental constraints that exist. Consequently, there is not one design alternative or standard design that can be applied. The following discussion illustrates the variety of LWCs that have been constructed at ranges throughout the country.

Fort Stewart, GA has slow moving water, with soft streambeds and flat topography (i.e. the width of the water crossing increases dramatically with only a small increase in flow). Their preference is to use a packed rock crossing along the streambed and allow the trail to be submerged.

Fort Stewart has many acres of wetlands and swamps in the training areas. The LWCs are constructed with long, packed rock approach and exit roads. The crossing is below the level of normal water level and it allows water to flow over the top and percolate through. During construction, silt fences are erected to reduce the amount of sediment entering the stream. After construction the fences are maintained by the installation's ITAM/LRAM offices.

Once construction is complete, the ground areas damaged by the construction vehicles will be seeded and natural vegetation will start reclaiming this ground. The new vegetation and the silt fences will reduce the amount of sedimentation entering the waterway. 


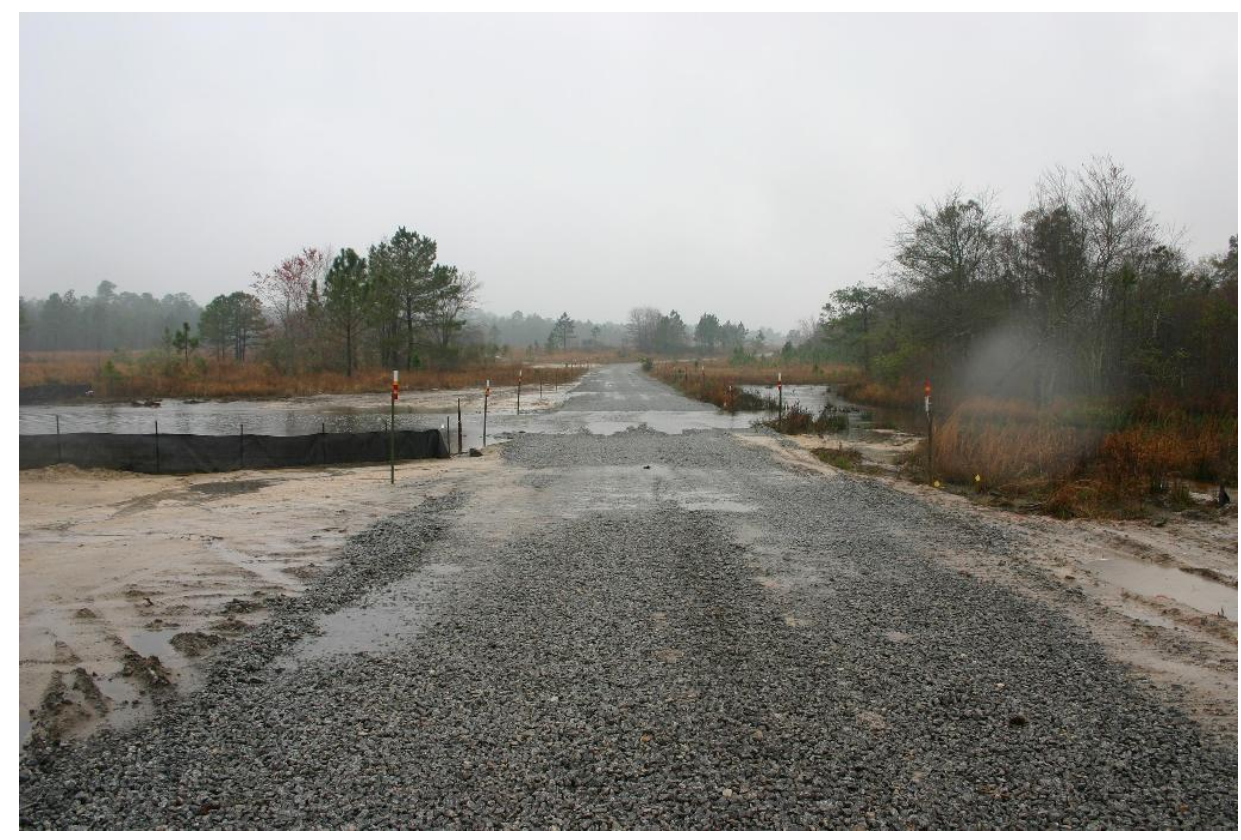

Fort Stewart Low Water Crossing

As a contrast, Fort Knox has LWCs that cross fast moving streams on a range and in training areas. These LWCs are concrete structures with culverts for the water to flow through at normal flow heights with anticipated flooding over the road surface at peak flow levels. This style of LWC provides for safe crossing during low water and markers are in place for vehicle safety when water is above the surface of the crossing.

The crossing in the photo shows a LWC built with one side on a granite bank. The other side is primarily loose soil. Large rock (riprap) is placed on the bank to minimize erosion and sedimentation runoff. When construction is complete the bare areas on the far side will be reseeded. 


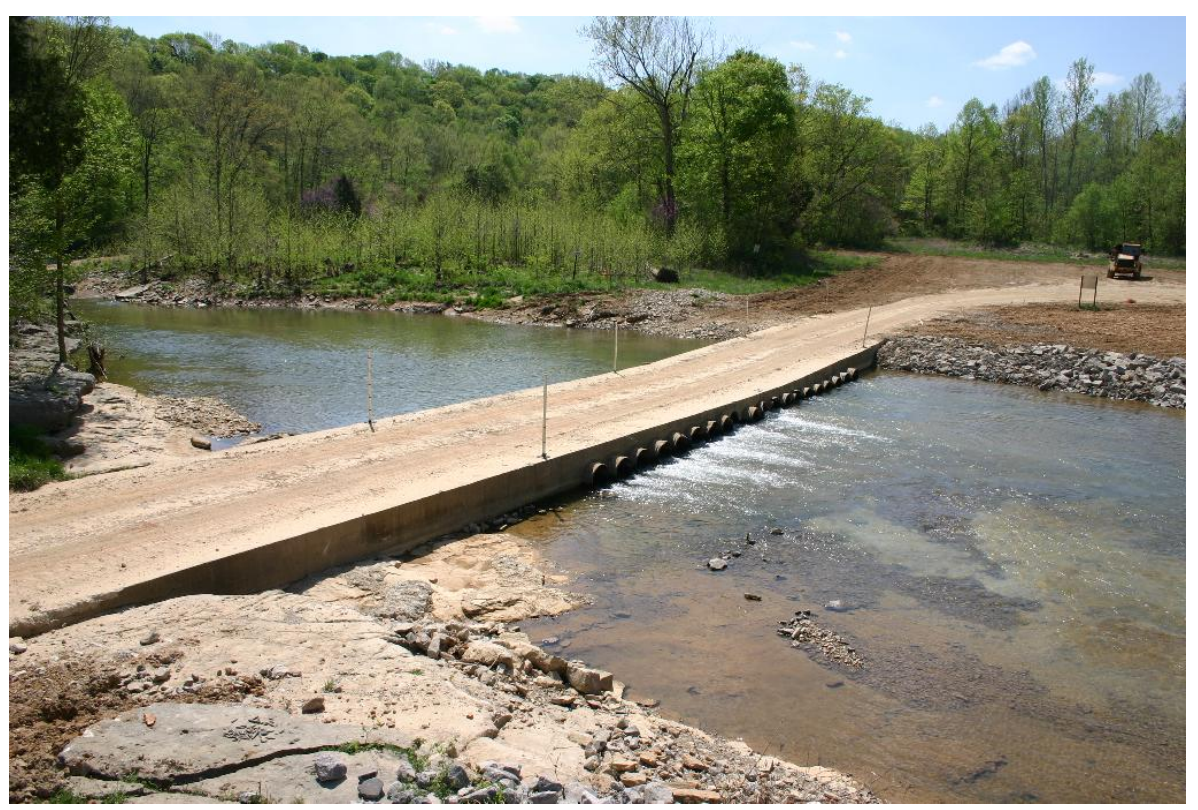

Fort Knox Low Water Crossing

As a third example, Fort Carson is located in a semi-arid climate. The area's average rainfall is approximately 16 inches a year. Most of the year the streambeds are dry; however after the snow melts on the mountains west of the fort or after a rainfall, the streambeds will rapidly fill with water. Several tank trails cross the streambeds, and the high water flows or flash floods can wash out the crossing. This style of LWC is a concrete slab with Shotcrete covered riprap on either side of the slab. 


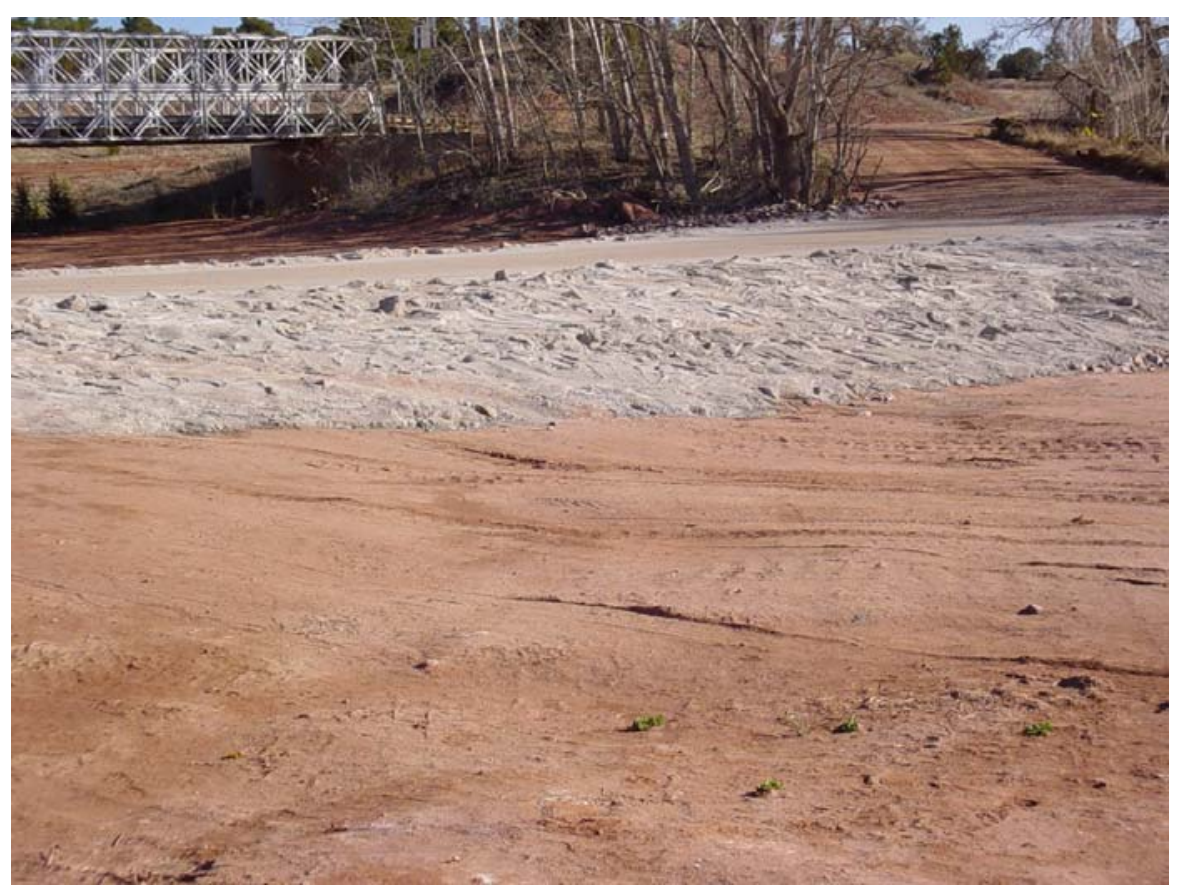

Fort Carson Low Water Crossing

Fort Hunter Liggett has 4 concrete LWCs that cross intermittent streams. These LWCs act almost like dams on the streams they cross. These LWCs do not have embedded culverts to allow fish to swim upstream past the LWC during periods of normal water levels. A characteristic of Fort Hunter Liggett that differs from Ft Knox or Ft Stewart is that during the summer dry season, the 2 primary rivers on the installation go below ground. This causes fish to be caught in pools until the rivers return to the surface. 


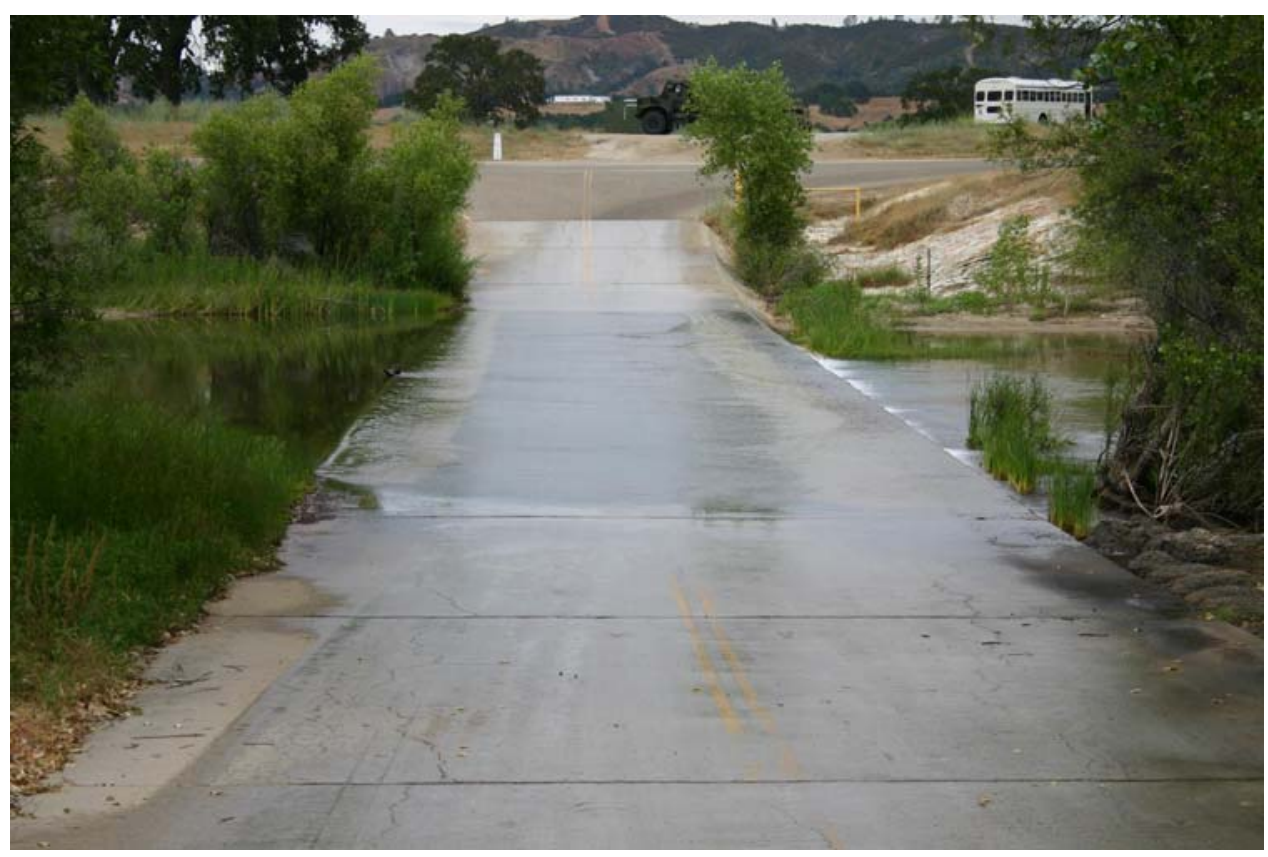

Fort Hunter Liggett Low Water Crossing

As an example of operational issues that can arise from a design that doesn't consider all environmental aspects, the LWC on the Fort Hunter Liggett Multi-Purpose Range Complex that provides access to the back side of the range has caused significant environmental problems for fish and aquatic species. This LWC also alters the high water/ flood dynamics for this area.

This LWC was built in the late 1990s due to the collapse of the previous LWC during the 1997/98 rainy season. This LWC is 125' of reinforced concrete. There is riprap on the upstream side and a grouted concrete apron on the downstream side. Grouting was injected through the deck to fill the undermined cavity.

These measures have provided temporary protection, but continued erosion/scour is evident. Additionally, the river channel has been focused on the central portion of the ford, causing significant undercutting both upstream and downstream for several hundred meters.

Fort Hunter Liggett ITAM has contracted both a geomorphologic assessment of the San Antonio River near the failed ford site and engineering design alternatives for repair and/or reconstruction of the existing ford, based on the geomorphologic assessment findings. It is estimated that the cost to construct a new LWC will approach \$1M. 


\subsubsection{Recommendations}

Standard designs for LWCs may be impractical as each LWC is unique to its specific site location and the stream characteristics. There are, however, categories of LWCs that can be described (i.e. stream bed submerged crossing, base flow control with culverts with high flow submerged crossing, total flow control with culverts, bridges) and presenting a typical pictorial of each type along with some guidance on costs of LWCs may be sufficient. This guidance would illustrate to the designer that the objective can be met with a variety of designs that are dependent on local and State environmental requirements, site hydrology, stream bed and flow characteristics, and available funds.

The following items are provided as a checklist of issues that should be addressed by the designer and planning team early in the range design process.

- Installations should conduct an assessment of the LWCs based on environmental issues, including aquatic life impacts, sedimentation, long-term erosion of embankments, water quality impacts, as well as other local issues that may arise.

- Identify areas where the construction of LWCs minimizes environmental impact without degrading current training capabilities and adjust the range layout to best fit these crossing areas.

- $\quad$ Obtain consensus of the type of crossing preferred by key personnel. Incorporate into the final decision the environmental impacts, the preferred crossing type, and the associated costs.

- $\quad$ The LWC design should include an analysis of vehicle type, level of activity, potential for drop-off from edge of crossing, and other user oriented data to determine the thickness of crossing materials and width of the crossing. Accessibility for long-term maintenance of the crossing as well as the upstream and downstream impacted areas should also be incorporated into the design.

- Develop a central LWC database that is accessible to all installation ITAM offices. The database will maintain all the information that pertains to each LWC. 
- In the event of an existing LWC failure, minimize the repair to the LWC to what is absolutely necessary. Use this opportunity to construct a modern LWC that supports all considerations.

- $\quad$ For LWCs that are periodically dry beds or are constructed when flow is diverted, and for stream banks that are subject to scouring during heavy rains, consider the possibility of applying soil amendments that improve water resistance and erosion control and decrease maintenance costs and down time for repair.

- $\quad$ Ensure Best Management Practices are used in the design and construction of LWCs. State level Department of Transportation criteria, local forestry services, and other government organizations can provide excellent local guidance to the designer. The following websites provide an example of guidance on BMP information available:

\section{http://www.epa.gov/watertrain/forestry/subd5.htm}

http://www.iowadnr.com/forestry/bmp12.html

http://parks.state.co.us/cnap/Wetlands_BMP/BMPindex.htm

http://www.pfmt.org/BMPs/bmps_stream.htm

\subsection{Battle Positions}

\subsubsection{Current Design Principals}

Battle positions for armor vehicles, or defilade positions, are generally designed for hulldown and turret-down positions. Battle positions generally have berms at the front and sides of the firing point. A battle position's height is determined by 3 factors:

- The line of sight (LOS) analysis from the battle position to the target berms that can be engaged from that battle position

- Installation directives

- $\quad$ Costs

The LOS analysis is conducted from 72-inches above grade at the firing point in the battle position. This height is the center of the muzzle for the M1A1/A2 tank. The target point is 
measured approximately 14" above the top of the target berm. This ensures that the target will be hit. If the LOS is good, then the analyst moves to the next shot. If the LOS is bad, then the designer has to adjust the height of the battle position, target berm, or any interfering object.

On some ranges, the first battle positions are 3 tier positions, meaning a vehicle has hide, turret down, and hull down positions. Subsequent battle positions are either turret/hull down or just hull down positions. The decision for each battle position is typically based on LOS, training objectives, and cost. The size of the 2 and 3 tier positions may interfere with the LOS for downrange targets. Also the cost of a single tier battle position is far less expensive than a 2 or 3 tier battle position.

A battle position may have either one entry/exit road or separate entry/exit roads as illustrated in the following two standard design examples.

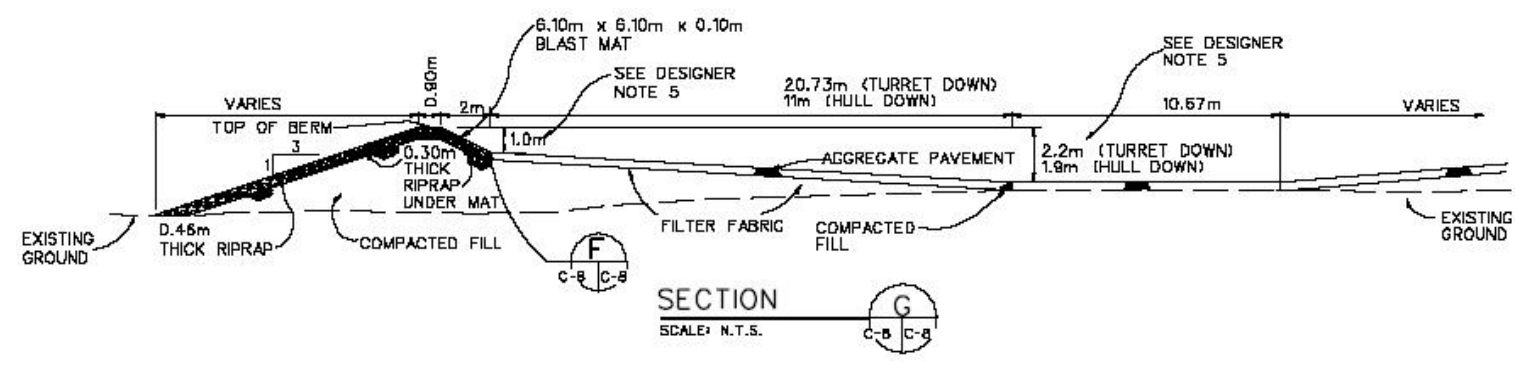

Profile of Battle Position with Single Entry/Exit

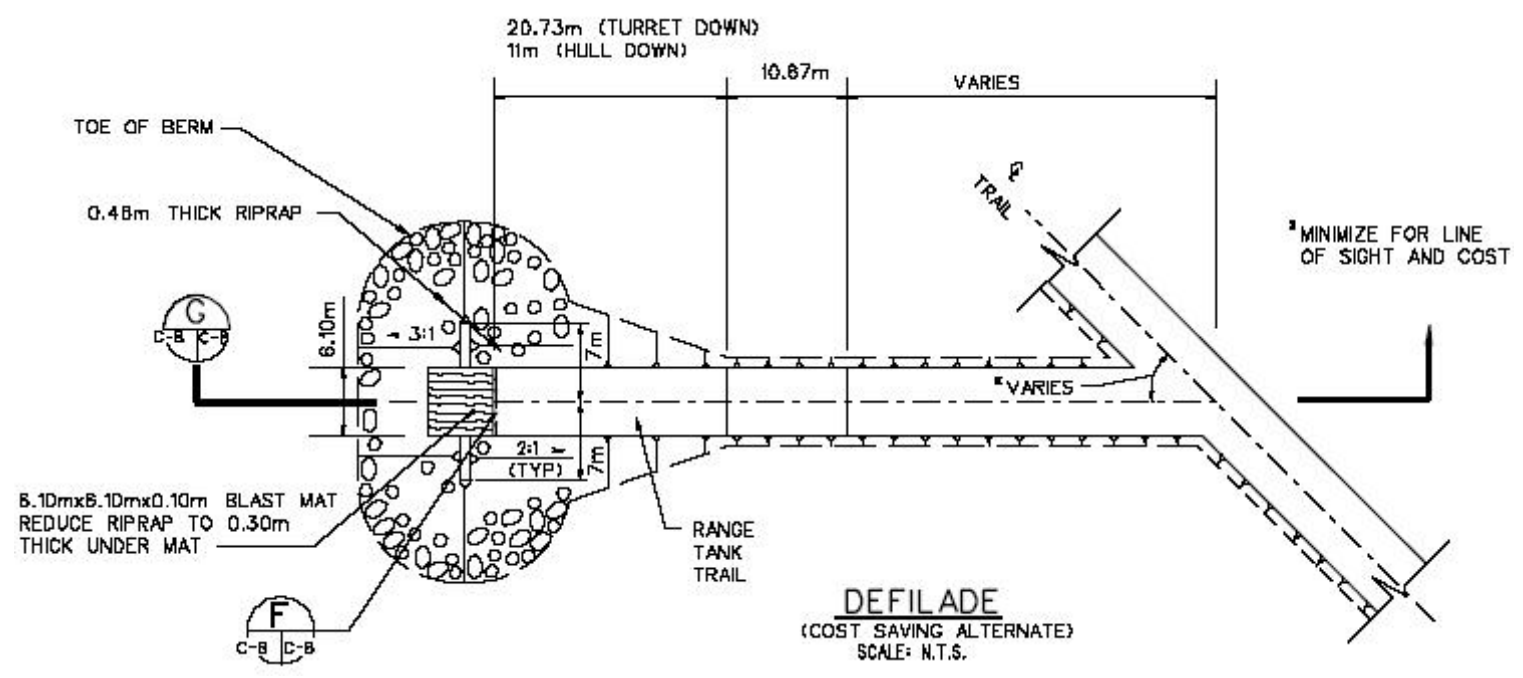

Plan View of Battle Position with Single Entry/Exit 


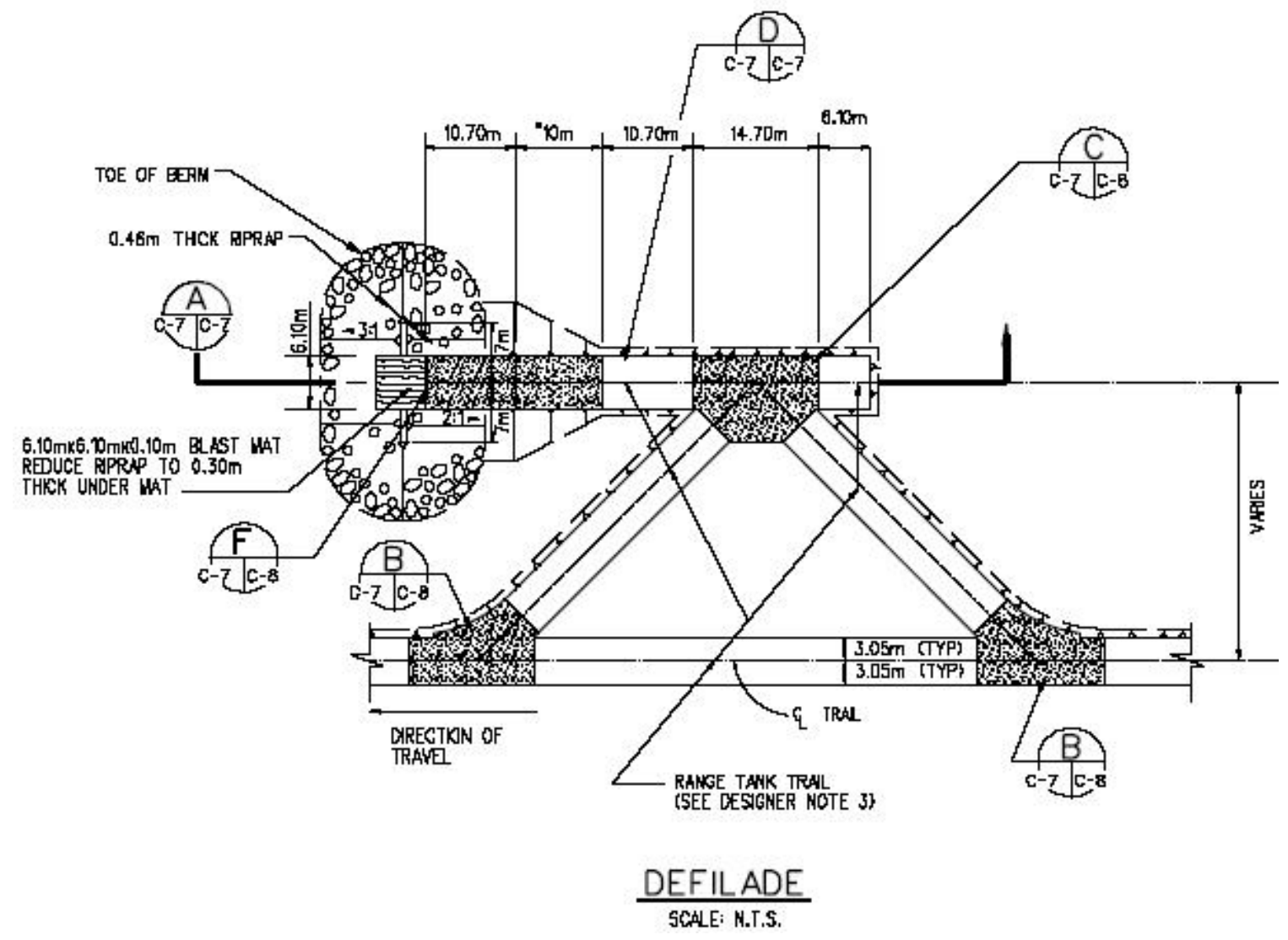

Profile of Battle Position with Separate Entry and Exit Trail

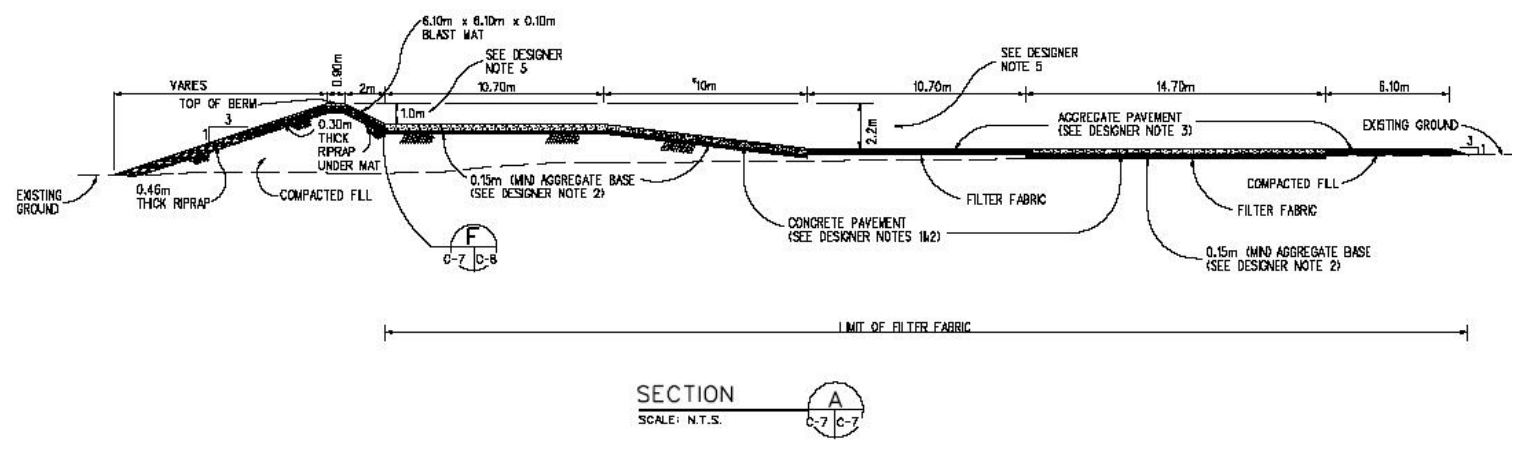

Plan View of Battle Position with Separate Entry and Exit Trail 
The battle position and defilade designs have evolved over the past few years and significant improvements have been made. The next section includes a discussion of the most recent designs.

\subsubsection{Design Alternatives}

The key features of the battle position which create the most significant maintenance issues and environmental impacts include the following:

- $\quad$ Areas where vehicles are required to turn

- $\quad$ The front berm which absorbs the maximum blast force

- $\quad$ Dust created by both the vehicle movement and the blast force

\subsubsection{Concrete Turning Pads}

Concrete vehicle turn pads are recognized as a critical component for turning of both tracked and tired vehicles. These concrete pads have demonstrated long-term life expectancy even under heavy use conditions. When older ranges used dirt or gravel in these areas, the level of dust would increase significantly, the gravel replacement costs would be high, and the edges of the turn would develop ruts and gravel piles (see photo below). The current concrete turn pad design eliminates these issues and provides a level turning area. The current width of 6.1 meters (approximately 20 feet) appears adequate. Regarding maintenance, it is suggested that the pads be routinely brushed to remove gravel, stones, and other debris that will crush and add to an airborne dust issue.

The extreme example of using concrete is the battle positions at Redcloud Alpha MPTR at Fort Stewart. These battle positions have concrete pads the length of the battle position. 


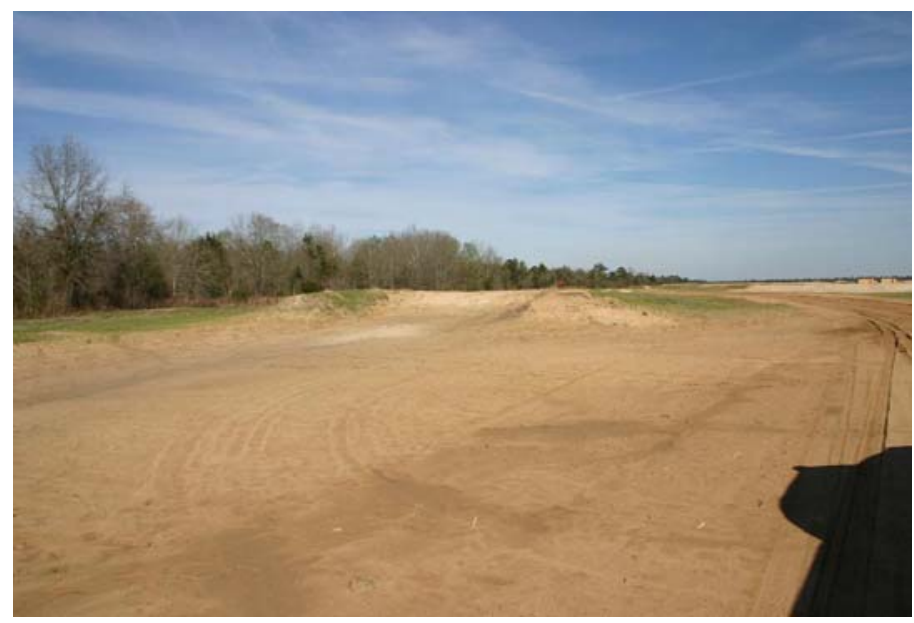

Single Tier Dirt Battle Position Redcloud MPRC at Fort Stewart

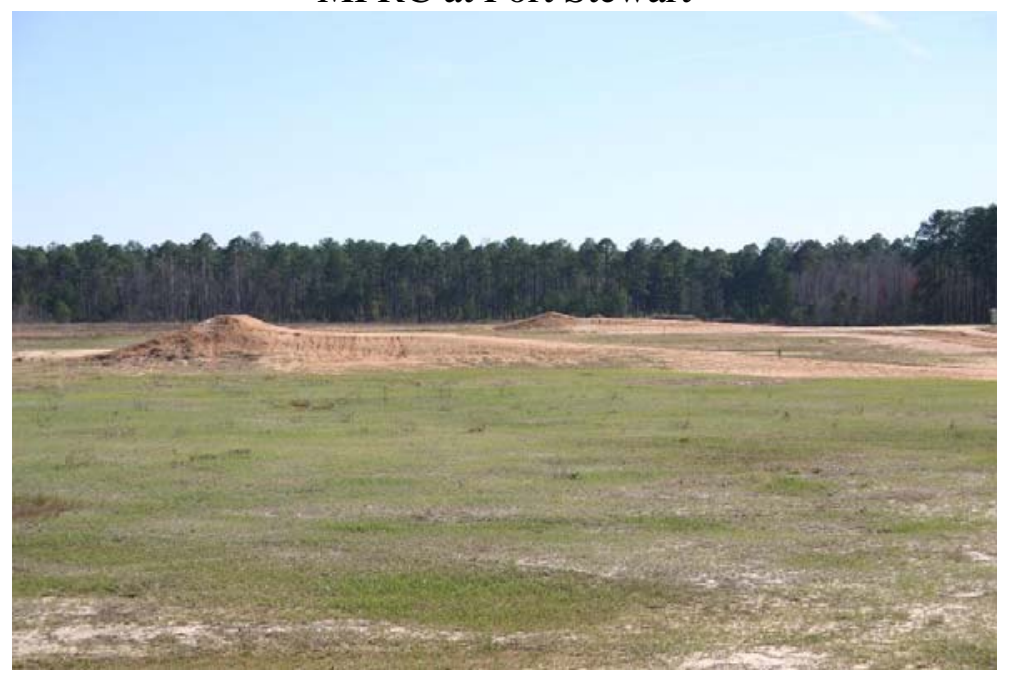

Double Tier Battle Position Redcloud MPRC at Fort Stewart

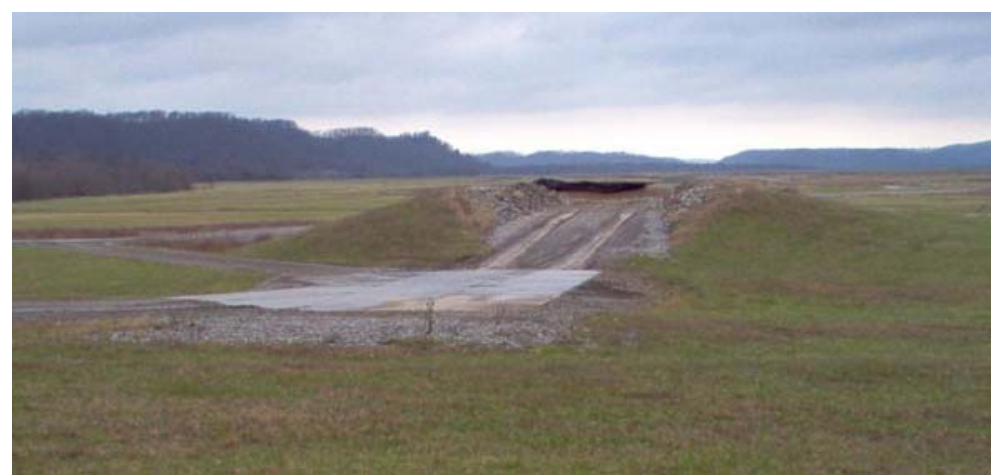

3-Tier Battle Position with concrete turning pad Yano MPRC at Fort Knox 
An alternative design that might be applicable for specific range conditions and training objectives is a drive through battle position. This design would simply include a 1 meter dip in the trail for a length of about 12 meters to "blind" the driver. Since this would be a drive-through battle position, the concrete turning pads and front berms would not be required. While this design would not be appropriate at every location, it may be adequate at select locations to reduce overall range costs.

\subsubsection{Battle Position Front Wall and Berm}

The front wall of the battle position serves to mark the point for the vehicle to stop as it pulls into the firing position. These walls historically have been made of concrete panels or timber crossties. Downrange from these walls has been a soil berm to support the wall and to absorb the blast. Based on observations of many battle positions, it is evident that the muzzle blast can seriously damage the front wall as well as pulverize the berm materials which results in dust clouds with every shot.

The evolution of these battle positions has occurred over the past three to five years. Blast mats made of steel cabled re-cycled tire walls have been used to reduce the dust and deflect the muzzle blast. While this change helped, it still did not protect the front wall as seen in the following pictures.

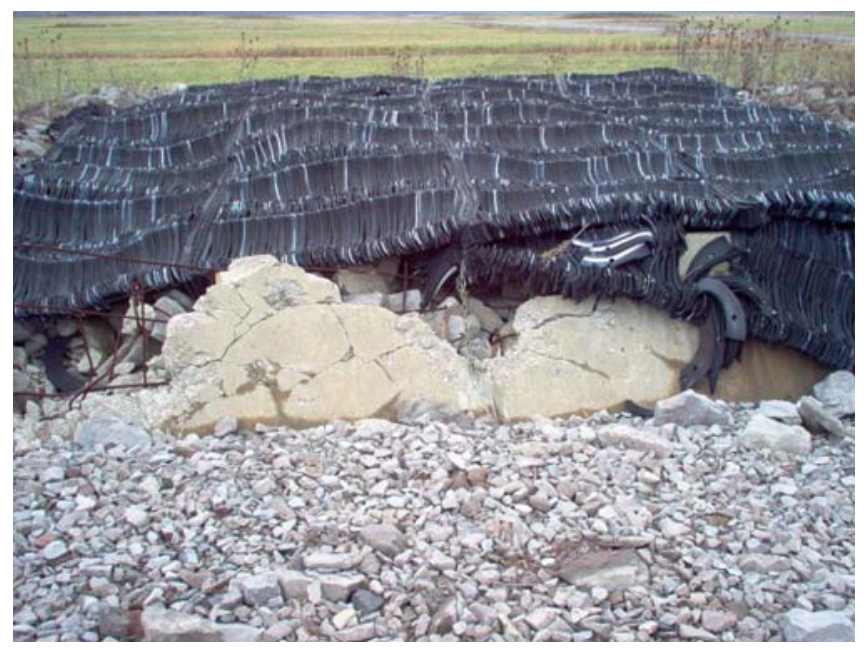

Concrete damage on battle position

Yano MPRC at Fort Knox 


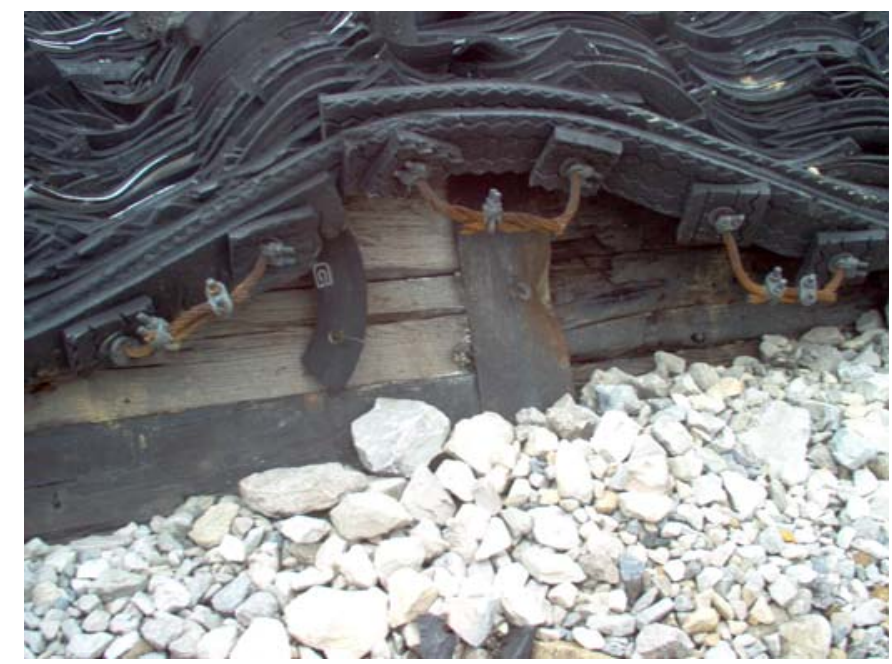

Wood and mount damage on battle position

Cedar Creek MPTR at Fort Knox

The current and most successful design for battle positions and defilades can be seen at Fort Stewart. The battle positions on Redcloud Alpha were constructed without a front wall and side walls. A dirt berm is overlaid by a layer of large stone and then a blast mat is draped over the entire berm, from the battle position ground surface to the downrange side of the stone. This design has now been adopted by Huntsville (see Section 3.5.1). This design minimizes the impacts of the muzzle blast and allows a vehicle, if the driver fails to stop the vehicle, to roll up and over the front of the battle position.
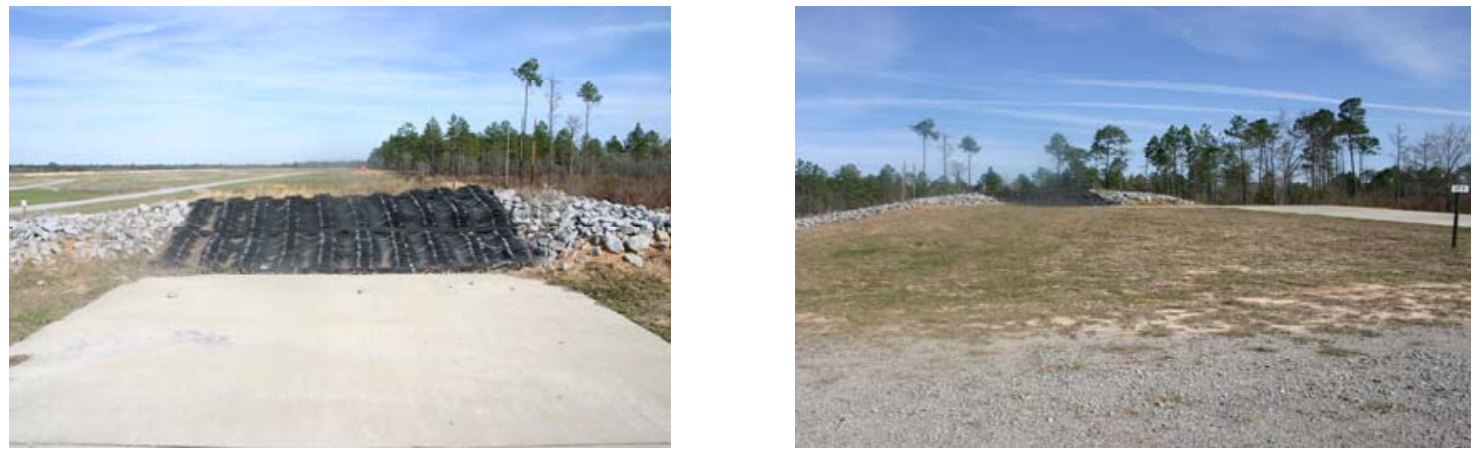

No front wall on battle position on Redcloud Alpha MPTR at Fort Stewart 


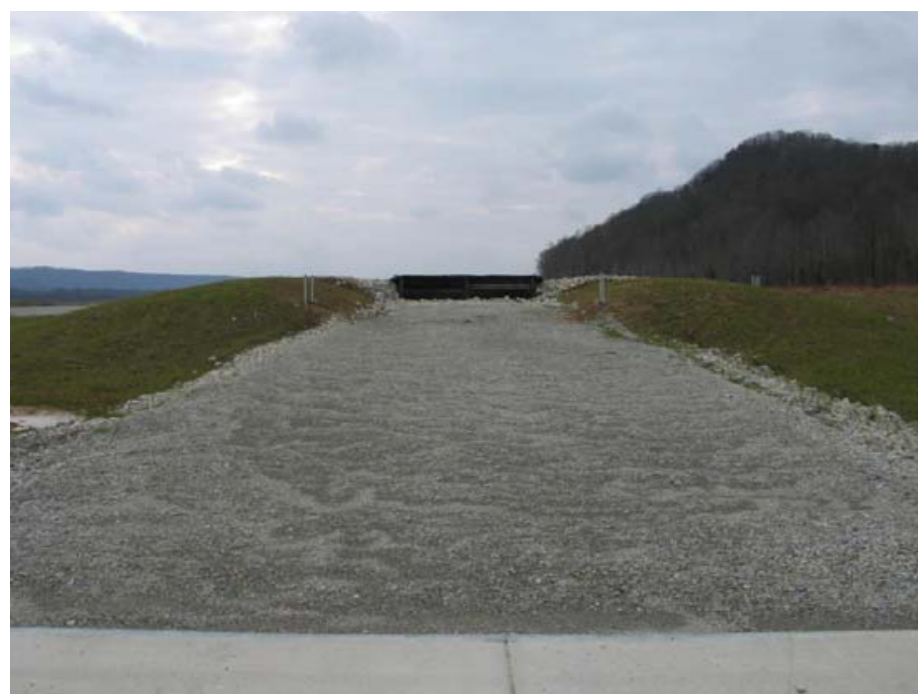

Battle Position on Wilcox D-MPTR Fort Knox

\subsubsection{Recommendations}

The battle position and defilades design has evolved over the past few years, with dramatic improvements already being applied during new range construction. The following summary recommends the most appropriate design criteria.

- The preferred design includes a concrete turning pad for entry/ exit. While this has higher capital costs, it will have a much longer life-expectancy, is more protective of environmental issues (i.e. erosion and dust control), and have much smaller maintenance costs. The packed dirt access trails are the least desirable due to erosion and dust control.

- $\quad$ The front wall of the battle position must be able to absorb the impact of current training ammunitions and made of an easily repairable/replaceable material. The current design which eliminates the front wall and uses the blast mats as a protective barrier appears to be the concrete walls which are not easily repairable.

- $\quad$ Berms around the sides of the battle positions should be an installation requested addition rather than part of the standard design. The savings in time and money over the number of battle positions on a range may be significant.

- $\quad$ Berm stability may be enhanced by applying soil amendments as discussed in 
previous sections for tank trails and targetry berms. The application during design should be further considered. 


\subsection{QUALITY CONTROL/QUALITY ASSURANCE GUIDANCE DURING DESIGN AND CONSTRUCTION}

As is stated in Chapter 7 of HQUSACE/OCE ARMY TECHNICAL MANUALS, TM5818-4: "In contrast to the contractor's quality control, the Government is responsible for quality assurance, which includes: the checks, inspections, and tests of the products that comprise the construction; the processes used in the work; and the finished work for the purpose of determining whether the contractor's quality control is effective and he is meeting the requirements of the contract. These activities are to assure that defective work or materials are not incorporated in the construction.” The same thing can be said of the application of quality assurance techniques in the design process, which is of equal importance. The following sections address Quality Assurance/Quality Control guidance beginning with the 15\% design phase and going through construction with recommendations of how to improve the process and improve environmental sustainability as it applies to Range design in general and roads, berms, defilades, and low-water crossings in particular.

\subsection{5\% Design/3086}

The $15 \%$ design effort is normally developed approximately $1 \frac{1}{2} 2$ years prior to a range project construction year. In the past, this effort went to $35 \%$ design to ensure that Congress approved a viable well-defined project and associated reasonable cost estimate. In an effort to save design dollars on projects which may not make it through the final stages of Congressional approval, this level of effort was dropped from 35\% to 15\%. This resulted in a comprehensive review of the DD 1391 documentation with very limited engineering review of available survey, geotechnical and utility documentation. Following the 15\% design, the 3086 form is developed which is why this stage is referred to as the $15 \%$ design or 3086 process interchangeably. This is the last stage of design with the option to change the Programmed Amount of a project.

The consequences of this change has been the Programmed Amount for a given range project can be significantly different (higher or lower) from the eventual project cost estimates once more detailed design effort is conducted. However, because the Programmed Amount is set, many times the range elements are reduced or eliminated to meet the Programmed Amount. Some recommended actions to address this issue include the following. 
1. Due to the large impact that site conditions have on range layout and costs, funding for the topographic survey at this stage of design would increase the validity of large range projects greatly. As an alternative, range projects would benefit greatly if the 35\% design phase is included for large range projects, with the Programmed Amount not being locked until this step is completed. The topography and range layout greatly define the costs associated with each project and could be refined to a much higher level by the $35 \%$ design .

2. SRP Support Agencies must be involved in the $15 \%$ design kick off meetings and submission meetings; these agencies see numerous ranges each year and this knowledge lends itself to identifying errors or omissions early in the process. If the SRP Support Agencies are only involved at the 15\% design review meeting, it is too late in the process to make corrections.

3. A trainer knowledgeable of the SRP process, standard range composition and Army training requirements needs to be involved throughout the process to aid the Installation in meeting its training goals and ensuring that the Installation understands the SRP process and players, educate the Architect-Engineering (AE) Firm on the critical components of the range and protect the interest of the Major Command (MACOM) and DA by notifying each of the components of the design which go beyond the intent of the standard range.

4. The use of multiple year-multiple contractor $\mathrm{AE}$ contracting vehicles should be continued to provide knowledgeable $\mathrm{AE}$ support to Installations and to train $\mathrm{AE}$ firms by allowing them to work on a greater number of range projects than is available on general solicitation contracts. The use \& education of dependable $\mathrm{AE}$ contractors bring quality and consistently to the range design process.

5. SRP Support Agencies must be resourced to provide consistent knowledgeable support to the Installations on all range projects. In this era of diminishing 
Government resources, SRP Support Agencies should develop processes where resources between agencies may be cross-utilized to ensure continuity, knowledgeable and seamless support to the Installations. If inter-agency resource leveling is not adequate to ensure support; a series of select knowledgeable contractors should be utilized across agency boundaries to ensure continuity.

\subsection{Final Design}

Costs increases during design are common due to unexpected site conditions, owner and range management desires, lack of early topographic survey and UXO data, and limited or no geotechnical data. Cost increases which surface at design review meetings derail the design review process with the more urgent cost reduction exercise. Some issues have been identified which are beyond the scope of this effort, but that should be further reviewed include the following.

1. The designing of range options to address funding concerns late in the design process can contribute to design errors and omissions. A system to provide funding flexibility as far into the design process as possible would be of benefit. Additionally, obtaining field data as early in the design process as possible will allow better initial cost estimates to be developed.

2. The notification of SRP Support Agencies is haphazard with very little response time and no centralized system to broadcast upcoming events to other SRP Support Agencies. The SRP Support Agencies need to develop a scheduling process which gives each range project a window of time for its submittals and meetings which would level the review and travel schedules of the SRP Support Agencies. This effort would require a constant effort upfront to maintain schedules and to consistently address changes and oncoming projects; in a labor strapped Government workforce it is hard to realize benefits of long term project management during daily firestorms. The optimum condition for a schedule of this sort to work would be for coordination at DA level to begin the process with 
planned project kick offs, which come to the design agency with a draft schedule, flexible enough for the design agency to operate but not unrestrained as the current process is. The use of centralized contracts held by the SRP Support Agencies can also greatly facilitate schedule management. A better notification system and/or greater use of teleconferencing may improve the cost-effective interaction of key personnel.

3. Due to the high deployment rate and the quickly changing standard range inventory, Installations commonly receive range projects which they do not fully understand the training intent of. Through the use of contract training specialists and the increased involvement of the Army Executive Support Agent (ATSC), this gap has been reduced; but a systematic approach to educating the Installations on their range projects could greatly improve communication. Installations should be advised by training specialists prior to each phase in a range project's development, if an Installation is constantly appraised of its range's function and training goals - less confusion and more support would be forthcoming from the Installation. This effort could be as little as an extra day in front of each range development meeting for a training specialist to have face-to-face time with the Installation's training personnel to go through training issues. This would also facilitate the range development meeting to flow smoother and faster, since training issues would be consolidated prior to the start of each meeting instead of as the meeting went along.

4. Design agencies and their $\mathrm{AE}$ contractors understanding of each range's training objectives is limited and their understanding of the SRP process is likewise limited. The more an AE firm understands about the function of a range and the SRP process, the more likely it will be that the Government will receive a quality product. Strides have been made over the last few years, with the addition of contract training specialists on some of the SRP Support Agency's contracts. This start should be expanded to include all range designs (Army, Reserve \& NG) through contract forces and Government forces. The time invested with the $\mathrm{AE}$ 
firms pay dividends on each design and over time develops more capable AE firms familiar with range unique requirements.

5. SRP Support Agencies should encourage local Corps of Engineer Districts and State agencies in charge of range design projects, to require AEs to submit cost data prior to design review meeting attendance. Cost data provided at a design review meeting gives the Government no time to digest the information, determine validity of line item costs or areas of concern. If cost issues supersede a design review meeting, the SRP Support Agencies should require either additional days or another meeting to review the quality of design documents. Several projects in the past have had cost issues at every design stage and never had the quality of the design reviews due to the constant cost issues which must be addressed; this causes construction errors and cost increases.

6. Options should be laid out by the 35\% design phase in order that they can be reviewed as the design progresses. Options which are added at or after the $95 \%$ design review meeting are often incomplete or do not consider their impact if any or part of the Options are awarded or not awarded. Each Option should be reviewed as a stand-alone item \& whether its tie-in points to the basis design and other Options have been completed.

\subsection{Communications Between Agencies on Meeting Action Items}

As problems or potential problems occur in the design/development of ranges at the various stages, the SRP Support Agencies develop “Action Item” lists during the Design Review meetings. Depending on the severity of the problem and its impact across multiple agencies, unresolved Actions can cause frustration and resentment between the SRP Support Agencies, the Installation and other agencies. Some recommended actions to address this issue include the following. 
1. In addition to the Dr Checks procedures, a line of communications needs to be set-up between the Project Manager and the representatives of the support agencies. The PM should send a weekly or bi-weekly email to each SRP Support Agency representative asking for a "Status Report" on their outstanding Action Items. The PM should then compile all replies and forward it to all SRP Support Agency representatives and reassign Action Items which must be completed.

2. Prior to the conclusion of any Design Review meeting, each agency should sketch out its plan for resolution of its Action Items and each Action must have a completion date. Many of the SRP Support Agency's personnel are traveling 2-3 weeks every month, which may contribute to poor communication and the oversight of Action Items without a set deadline for completion.

\subsection{Environmental Considerations during Range Design}

The Installation Environmental Office will have GIS overlay data available in its ITAM office that pertains to all areas of environmental concern. Designers, engineers, and trainers work with the Installation to use this information to design a range layout that meets the trainers needs and the requirements of environmental regulations.

\section{Threatened and Endangered (TES)}

The Installation Environmental Office identifies TES in the proposed construction site. The Environmental Office determines whether or not TES can be relocated or if construction/ training can coexist with the TES. If the TES cannot coexist with construction/training, then the designers will resite, or adjust the project as necessary.

\section{Wetlands}

The Installation Environmental Office may identify wetlands in a proposed range site within their ITAM overlay or the designers will have to conduct a wetland delineation early in the 
design process. The designers and trainers with the wetland delineation input will develop a design that will minimize the impact to wetlands. The Environmental Office will determine whether there is a sufficient "bank" of wetlands that will mitigate the wetlands used in the construction process. Again, avoidance of wetland areas is the most preferable alternative.

\section{Low Water Crossings (LWC)}

The design topographic survey, stormwater runoff analysis and the Environmental Office identify areas where LWCs may be needed during the design of the project. The Environmental Office and design engineers will develop a LWC plan that meets the needs of the trainer and the environment. On a range, the LWC may be integral to an access road, course road or it may be on a target maintenance trail. The LWC must be designed to allow vehicles to safely cross while the crossing is under water. There must be a reference marker or sign at the LWC that marks the water height so vehicle drivers will not enter the LWC if unsafe conditions exist. LWC should be minimized on a site due to cost and environmental impacts; design of new LWCs should include all lessons learned from the Installation on their past LWC projects.

\subsection{Pre-Construction Meeting Attendance}

Each range project prior to construction start has a pre-design meeting with the Construction oversight agency to emphasize specific construction issues with that Installation. Due to manpower constraints, SRP Support Agencies have attended very few of these meetings in the last few years, leading to a void in the construction contractor's understanding of the critical construction elements for each range project. Additionally, the design engineer is also typically not contracted to attend this meeting.

It is imperative that the design oversight \& target installation SRP Support Agencies attend each Pre-Construction Meeting for each of their range projects. The design oversight agency needs to explain the critical elements of their design to the Construction Contractor and allow the Construction Contractor to associate a face with the design agent for the purpose of communication during construction. The target installation agency needs to explain the critical 
elements of their target interface to the Construction Contractor and allow the Construction Contractor to associate a face with the target installation agent for the purpose of communication during construction. Understanding that neither of these agencies may dictate new scope to the Construction Contractor, both can answer clarification questions that arise at the meeting or during construction. This function should be completed by contract personnel if Government personnel are not available; it is imperative that a knowledgeable SRP representative is at each of these meetings.

As further support during the construction activities, the design engineer should also attend the Pre-Construction Meeting so that he can answer any technical design questions and to help clarify the overall design intent.

\subsection{Typical Construction Packages}

During the RETS target era, construction inspection personnel had templates to lend to the construction contractors and for their own use to ensure that the electrical components of the design were correct. The use of standard design templates allows the Design/Construction Team to foresee and resolve issues that may impact environmental range elements. Understanding that NGATS, is still currently under development and changing, consideration should be given to demonstrating a typical box and wire type to each construction contractor optimally at the preconstruction meeting.

A cut-sheet handout package could be used for vendors that the Government has previously researched and meet the standard design requirements or actual hardware typical of the standard design could be provided. As NGATS moves closer to true off-the-shelf, this would greatly reduce the changes for incorrect hardware being purchased and installed prior to the CCI or Tl I inspections.

\subsection{Standard Inspections}

Construction Compliance Inspections (CCI) and Target Interface Inspections (TII) were clearly defined and aggressively executed during the RETS targetry era; since RETS completion in 1996 till the present. However, interface standards have been in flux anticipating NGATS 
fielding. This has lead to confusion within and without the SRP Support Agencies on the requirements of CCI \& TII and their execution.

Interface inspection checklists must be completed for CCI \& TII even while NGATS criteria is still evolving. These checklists establish the basis for design elements inspection and the follow-on targetry installation. In addition, CCI \& TII must again be established as a mandatory element during construction. No matter what the size of a range or who the owner is (Army, Reserve or NG), all targetry should be received from the same source which require that interface be uniform.

\subsection{Construction Oversight}

At optimum levels, ranges under construction are visited three (3) times during their construction (pre-construction meeting, CCI \& TII). On large dollar critical ranges which normally require $1 \frac{1 / 2}{2}$ years -2 years to construct, this leaves large amounts of time for problems to surface which could be quickly resolved if a knowledgeable person had only been on site.

A small team approach should be incorporated into the SRP process. This small team should be no larger than 2 -3 people who are familiar with all aspects of range standards (civil,

electrical, training). They should visit each large/complex/emerging range often during the early layout/earthwork portion and again during the early power and data implementation portion of construction. This team would ensure the project is progressing correctly; catch problems before they are completely installed and provide the construction contractor with familiar faces to address issues that arise. The team should be consistently staffed to ensure project specific knowledge.

\subsection{Improve Environmental Sustainability}

The standard designs drawings from the Range \& Training Land Program's Mandatory Center of Expertise (RTLP-MCX) reflect a 3:1 slope for berm construction, but it also refers to the site specific geotechnical report. The 3:1 slope was determined to be the best slope to allow for safe mowing \& maintenance, stable slope for most every soil condition, and acceptable amount of fill material needed to construct (i.e. cost). Typically, AE designers do not deviate 
from the 3:1 because it is a "Standard" and trainers have little input into the berm slope since it does not directly affect training.

A berm slope of 4:1 or 5:1 will result in a berm with a more "gentle" slope which will lessen water runoff and soil erosion, more readily blend into existing landscape and increase ease of mowing \& maintenance. However, berms with these slopes will have a bigger footprint and will, therefore, cost more to construct and maintain than a berm of 3:1 slope.

The slope of a berm is based on several factors:

1. Material
a. Type (clay, sand, rock)
b. Compaction value
c. Soil In-Place Density

2. Cost
a. Is material on-site or off-site?
b. Hauling distance?
c. Will soil amendments be required?
d. Berm cost factors originally input into DD 1391

The material used in construction of a berm will be a factor in the determination of the slope of the berm. Sandy soil will require a shallower slope than a clay based soil unless an amendment is added to the soil.

The compaction value and the density of the available soil will determine what weight the soil is capable of bearing and if it is capable of meeting projectile impact requirements. This will determine whether or not an amendment must be added to the soil to help it bear the weight of construction vehicles, projectile impacts, and to retain the designed slope of the berm.

Costs will be lower if the material is available on the construction site, and amendments do not have to be added.

Prior to designing the berms, designers should consult the site's geotechnical report. This report will tell the designers what slopes will be acceptable for the berms. Once the target layout is completed, the designers should develop a MicroStation /AutoCAD drawing for each different 
berm slope. This will determine the amount of soil required for the berm and in doing so, the cost of the berm.

An item that goes hand in hand with the layout is the terrain the berm will be placed on. If the berm is in a low spot and must be built up to provide for Line of Site (LOS) then the cost of the berm will increase. Each berm should be blended into the existing landscape as smoothly as possible with the least amount of fill to enhance training realism and maintain costs.

Each target berm may have to be evaluated to determine the berms slope rather than constructing all to one standard slope (i.e. berms on ridgelines or hillsides may have to have steeper slopes so that the berm will toe-out at a reasonable distance).

Since target locations on newly designed ranges are laid out to achieve maximum efficiency, no target should be used to a greater extent than any other. Initial design target placement should ensure that multiple targets meet each required training engagement. This will spread the projectile impacts to multiple target emplacement berms, rather than to a select few berms.

After construction and during repair from training damage, soil used must meet the original compaction value. This will be facilitated if the Range and Facility Managers are provided excerpts from the construction documents that identify the compaction values and are instructed how to determine if the repair work was completed to the design specs. The Facility Engineers Office must ensure the organization doing the repair work understands the requirement to repair to the design standards and are held accountable to repair to the standard. This means using the proper soil, and equipment. Using a bulldozer to compact the replacement soil does not accomplish compaction in the same manner as a soil compactor. Once the repairs are completed the repair must be tested to determine is it meets the design specs compaction value. A method to test the compaction must be developed that is "quick and easy", that doesn't require a laboratory to perform.

\subsection{Recommendations for Improving QA and Adherence to Specifications in Construction}

Quality assurance includes the checks, inspections, and tests of the products that comprise the construction; the processes used in the work; and the finished work for the purpose 
of determining whether the contractor's quality control is effective and he is meeting the requirements of the contract. These activities are to assure that defective work or materials are not incorporated in the construction and that the finished product, be it a road, berm, defilade, or low-water crossing, will fulfill its mission. Incorporated into the construction documents should be the requirement for adherence to established protocols and reference documents and should include the following:

- $\quad$ HQUSACE/OCE ARMY TECHNICAL MANUALS TM5-818-4 Backfill for subsurface structures, Chapter 7 Construction Control

- $\quad$ ENGINEER MANUALS EM 110-2-1911 Chap 5 and Appendix B and C

- WBDG: Unified Facilities Guide Specifications (UFGS) see UF-02300, UF02315N, UF-02330

- Earth Manual, U.S. Department Of The Interior, Bureau Of Reclamation, "Control of Earth Construction"

Prior to construction, the contractor must submit his plan for controlling construction quality. The plan must contain all of the elements outlined in the special provisions and demonstrate a capability for controlling all of the construction operations specified in the technical provisions. The plan must include the personnel (whether contractor's personnel or outside private firm) and procedures the contractor intends to use for controlling quality, instructions and authority he is giving his personnel, and the report form he will use. The plan should be coordinated with his project construction schedule.

During construction, the contractor is responsible for exercising day by day construction quality control in consonance with his accepted control plan. He must maintain current records of his quality control operations. Reports of his operations must be submitted at specified intervals and be in sufficient detail to identify each specific test.

Difficulties in construction of a compacted backfill can be attributed at least in part to inexperience of the control personnel in this phase of construction work or lack of emphasis as to the importance of proper procedure and control. Control is achieved by a review of construction plans and specifications, visual inspection of construction operations and procedures, and physical testing. The necessary authority to assure that compacted backfill is in compliance with 
the specifications is given in the specifications. The control consists of inspecting and testing materials to be used, checking the amount and uniformity of soil water content, maintaining the proper thickness of the lifts being placed, and determining the dry unit weight being obtained by the compaction process. Many factors influence the frequency and location of quality acceptance density tests. They should be more frequent at the start of backfill placement. After compaction effort requirements have been firmly established and inspection personnel have become familiar with materials behavior and acceptable compaction procedures, the amount of testing can be reduced. The frequency will be dependent on the type of material, adequacy of the compaction procedures, and how critical the backfill being compacted is in relation to the performance of the structure. Guidance for frequency of testing can be found in UF-02315N Excavation and Fill, approved for use by USACE / NAVFAC / AFCESA.

In addition to routine acceptance control tests, tests should be made in the following areas: where the inspector has reason to doubt the adequacy of the compaction; where the contractor is concentrating fill operations over relatively small areas; where small compaction equipment is being used such as in confined areas; and where field instrumentation is installed, mainly around riser pipes. When test results indicate (as determined by the Contracting Officer) that compaction is not as specified, the material should be removed, replaced, and recompacted to meet specification requirements.

The following steps should be enforced during the construction process requiring earth moving, fill, shaping, and compacting:

- $\quad$ Enforce specification requirements for preparation of the area for backfill.

- $\quad$ Be cognizant of detailed site adapted plans for stockpiling and placing backfill at specific locations.

- $\quad$ Process backfill material and adjust water content on the fill prior to placement.

- $\quad$ Ensure lift thickness that is consistent with equipment capabilities and allowed by specifications.

- $\quad$ Ensure that slopes meet specifications and are not too steep to obtain the full effect of compaction equipment. (See Section 3.2.2.3 for a discussion of berm slopes.).

- $\quad$ Verify that the fill is built up uniformly in a well-defined pattern. 
- Employ proper hauling, dumping, and spreading techniques to prevent segregation of coarse-grained, non-cohesive materials.

- $\quad$ Utilize compaction equipment suited to material being compacted.

- $\quad$ Perform sufficient field density testing in critical areas during construction on a schedule consistent with governing specifications.

- $\quad$ Do not allow material that is too wet or too dry to be compacted.

- $\quad$ To improve environmental effects of the operation, require surfaces be shaped to drain during backfilling at other locations.

To maintain adequate control of compaction operations, there should be at least one inspector at the fill when backfill is being placed whose sole duty should be inspection of earthwork.

Details of requirements to be included in the specifications for processing of backfill materials are contained in HQUSACE/OCE ARMY TECHNICAL MANUALS, TM5-818-4 Backfill for Subsurface Structures. Some rules of thumb for making the inspection process successful in obtaining a well-constructed road, berm, defilade, or low-water crossing are contained in that document and include:

- $\quad$ The thickness of loose lifts can be checked easily by probing with a calibrated rod just prior to compaction. It is a requisite that lift thickness be controlled on a loose-thickness basis prior to compaction.

- $\quad$ Checks for proper bond between layers can be made by digging through a lift after compaction and using a shovel to check this bond.

- $\quad$ Critical areas are the confined spaces around and adjacent to structures that are not accessible to the rolling and spreading equipment.

For field moisture-density control, a key element in effective earth compaction, the following guidelines should be used as an adjunct to laboratory testing: 
- To judge if the water content of a fine grained, plastic material is near the optimum water content, roll the material between the hands until it forms a thread approximately one inch in diameter. If the material at this stage tends to crack or crumble, it is in the proper water content range for compaction.

- $\quad$ Observe the compacting equipment. At optimum water content it may be expected that a few clods will be picked up by the roller but a general sticking will not occur. Other, more detailed, indications are included in the above referenced document.

- Insist that the inspector spend some time in the field laboratory, performing several compaction tests on each type of backfill material to become familiar with the differences in looks, feel, and behavior and learning to recognize when they are too dry or too wet, as well as when they are at optimum water content.

Indirect methods of determining the density and water content involve measurement of the characteristic of the material that has been previously correlated to the maximum density and optimum water content. These methods include:

- $\quad$ The nuclear moisture-density method conducted in accordance with ASTM D 2922 (for density determination) and ASTM D 3017 (for water content determination).

- $\quad$ Penetrometers, such as the Proctor and hand cone penetrometers, are useful under certain conditions for approximating density.

- $\quad$ Observing the resistance of the compacted soil to penetration by a spade.

Direct methods - - The three methods used for the USACE quality acceptance density determination are:

- $\quad$ The sand-cone method according toMIL-STD-621 (Method 106) and ASTM D 1556;

- $\quad$ The rubber-balloon method according to ASTM D 2167; and

- $\quad$ For soft, fine-grained cohesive soils, the drive-cylinder method according to MILSTD-621 (Method 102) and ASTM D 2937. 


\section{Low Water Crossing Considerations}

As discussed in Section 3.4 of this report, an important consideration is the reduction of sedimentation during construction and associated scouring either during construction or afterward as a result of faulty construction techniques or design flaws that don't take all factors into consideration. There is so much diversity in each site location - - climate, usage, environmental concerns - - that one answer will not fill all applications, Quality Assurance considerations for this activity must start with the design aspect and consideration given to the best configuration in a given instance that will minimize the potential for sedimentation, scouring action, and environmental sustainability. These include:

- Where possible, use stream diversion during construction and then constructing the LWC in the dry stream bed to minimize sedimentation at the LWC. Utilize soil amendments on stream banks to help minimize scouring after completion of the LWC.

- $\quad$ Dredging while the stream is still flowing requires control of flow downstream.

o Placing a rock dam or other temporary control structure in the stream bed across the width of the stream downstream from the construction site will slow the water flow and allow silt and sedimentation to drop out of the water column. Utilize 100-year flood stream flows to design a structure that will not cause the stream to leave its banks during construction or afterward if it is left in place to provide long-term protection downstream of the LWC.

o Control of debris downstream - Debris brought downstream, either from the construction activity or effects of weather post-construction may collect and block the flow of water through the crossing. Water can then backup and eventually flow around the crossing, causing unwanted scouring and erosion of the side embankments. Included in the inspection criteria should be a requirement that the Environmental and Range Control offices must jointly ensure that the flow of water is not impeded through 
regular inspections, especially after heavy or prolonged rains, to ensure that the training area is not compromised by high water in the LWC caused by debris downstream. Designs of LWCs should have a QA requirement that ensures consideration be made in the selection of a design that will limit or minimize debris accumulation downstream.

- $\quad$ For arid areas that are subject to occasional wet periods, utilize soil amendments as part of the construction to increase resistance to erosion and scouring. Periodic re-applications should be used during dry periods based on regular inspections to determine amount of deterioration in the LWC.

- $\quad$ For areas involving wetlands, employ longer, packed rock approach and exit roads. During construction, erect silt fences to reduce the amount of sediment entering the stream. After construction, the installations must maintain the fences to prevent siltation and scouring. Ground areas damaged by the construction vehicles are to be seeded and natural vegetation allowed to start reclaiming this ground.

- $\quad$ For LWCs that cross fast moving streams utilize concrete structures with culverts for the water to flow through at normal flow heights with anticipated flooding over the road surface at peak flow levels.

- $\quad$ To prevent damaging effects of LWCs to fish and wildlife, avoid designs that can act as dams to restrict flow and prevent migration through the LWC during normal periods of stream flow.

\subsection{Post-Construction of Ranges}

Once the range construction is completed, targetry installed and the range is operational, there is no method to capture "What went right/wrong with the design, construction and target installation process?”

During all Design Meetings, minutes of the meetings are captured for inclusion in the Design Analysis. Once the Design Meetings are concluded and construction starts on the range, the formal note taking stops. The construction supervisor and the on-site COE representative should develop notes that capture pertinent information during the construction process. This is 
another function that a small construction oversight team could facilitate during their visits to the range during construction. This documentation should continue through the following targetry installation process.

Within 12 months of the range's opening, a meeting should be held at the range with all SRP Support Agencies represented. The 12 month period will allow training to be conducted on the range and will identify any shortcomings or deficiencies with the design, construction and targetry. At the conclusion of the meeting, a "Lessons Learned" should be developed and passed back to the Lessons Learned database and improvements be reworked into the range standard design guides. 
APPENDIX A

KICK OFF AND QUARTERLY MEETING NOTES 


\title{
Development of Environmentally Stable Range Design Elements and Quality Control Guidance to Reduce Maintenance Requirements on Training Ranges
}

Date of Meeting: November 09, 2004

Place of Meeting: CERL at Champaign, IL

\author{
Participants: \\ Dan Plugge - USAESCH \\ Vernon Petty - RWA \\ Jared Lock - MHG \\ Richard Smith - HSW \\ William Stephenson - USAESCH \\ Jorge Hernandez - HSW \\ Sheron Belcher - USAESCH \\ Dick Gebhart - ERDC-CERL \\ Mike Denight - ERDC-CERL \\ M. Sharif - ERDC-CERL \\ Heidi Howard - ERDC-CERL \\ Ryan Busby - ERDC-CERL
}

\section{Meeting Began Tuesday at 0900 hours}

The meeting started with participants introducing themselves and their organization. Bill Stephenson and Dick Gebhart provided an overview of the Scope of Work and a description of goals to accomplish and the improvements desired by the Huntsville District and CERL.

The overall project objective is to review current designs and standards for specific range elements; develop innovative new designs that reduce environmental constraints and maintenance costs and increase the life expectancy of the elements; and examine construction policies and practices that will improve the range elements long-term viability.

The meeting discussions focused on three areas: (1) general project items; (2) issues specific to the development of innovative range design elements; and (3) Quality Control/Quality Assurance Issues. 


\section{General Discussion Items:}

Quarterly In Progress Review (IPR) Meetings were scheduled. This kick-off meeting will be followed by three additional meetings:

- A 1-day meeting at HSW offices in Tampa in late February;

- A third meeting is anticipated to be a 2-day meeting in the Louisville/Fort Knox area and will include a one day range visit (anticipated to be at Fort Knox); and

- A fourth and final meeting will be held in Huntsville.

It is understood that this project will evolve as it moves forward, with each IPR providing more information and better definition of the final study elements.

The requirement for a Project Safety Plan was briefly discussed. It was noted that this is needed for range site visits. It is anticipated that a prior to the IPR at Fort Knox or any other range location, the Safety Plan will be prepared.

The focus of the design improvements and range sustainability should be kept in alignment with the final training objectives of the element and their usage criteria. Communication between the designer, the user and the maintenance personnel should operate with more fluidity to get better design results and reduce cost.

Erosion control and storm water controls were noted as key areas to be evaluated. In order to improve the elements further vegetative controls would be preferred for both environmental and training realism issues.

Maintenance practices will be investigated to determine how favorable they are to the range elements being reviewed. Issues such as how often are ranges mowed, and how often and what type of dust control measures are being used will be evaluated.

CERL has Exit Criteria for this R\&D effort. Some of these were discussed, including: 1) improve berm maintenance cycles to $20-32$ months; and 2) determine the impact and relevance of regional soil composition to the areas of study. Project tasks and deliverables will have the following format: Problem-Suggestions-Solutions.

Other issues of concern were noise in the urban type ranges as the Battle Area Course, BAC. Noise issues are planned to be investigated in the near future. Noise is a recurring problem very difficult to resolve and any input in this issue is welcome.

\section{Innovative Range Design Elements}

Bill Stephenson presented design and specification documents for a number of ranges from different locations. After some discussion, the following ranges were agreed to be the initial basis for evaluating current range designs. 


\begin{tabular}{|l|l|l|}
\hline Range Location & Type & Date \\
\hline Camp Atterbury & Multipurpose Training Range & September, 1997 \\
\hline Fort Knox, Kentucky & MPDTR, Wilcox Tank Range & May, 1999 \\
\hline Fort Stewart, Georgia & Red Cloud Alpha Range & January, 2000 \\
\hline Fort Shelby, Mississippi & Multipurpose Range Complex - Heavy & March, 2000 \\
\hline Fort Hood, Texas & Digital Multipurpose Range Complex & August, 2001 \\
\hline Fort Wainwright, Alaska & IPBC/DMPTR at Yukon Training Area & July, 2003 \\
\hline Fort Polk, Louisiana & Digital Multipurpose Battle Area Course & August, 2003 \\
\hline Fort Pickett, Virginia & Multipurpose Range Complex - Heavy & October, 2003 \\
\hline Fort Benning, Georgia & Digital Multipurpose Range Complex & April, 2004 \\
\hline Fort Shafter, Hawaii & $\begin{array}{l}\text { Combined Arms Training Facility at } \\
\text { KTA }\end{array}$ & September, 2004 \\
\hline
\end{tabular}

A table will be created for the ranges being reviewed. The elements will be inventoried for specific design characteristics (i.e. berm thickness, slopes, soil type, compaction requirements, variation for geographic areas, etc.), as well as reviewed for positive and negative (or non-stated) design components.

Specific elements to be reviewed include the following.

Protective Berms for Targetry: One of the main goals HNC wishes to accomplish is the extension of the life for berms designed to protect target mechanisms. The maintenance schedule for berms is not accurately known at this time; however the desired major maintenance cycle for berms is 20 to 36 months.

Berms present maintenance and repair problems. Erosion after the berms are hit is a significant issue which causes a decrease in strength and durability. Spot maintenance and repairs are not always adequate and in some cases may produce more harm over the life of the berms.

It was noted that the design of the berms should be changed for individual ranges. Available soil materials vary from location to location and it is not typically taken into consideration while designing berms. Different compaction requirements may need to be specified for different types of soils and locations. Stronger specifications, and QA/QC controls and construction controls are needed.

Other ideas such as sacrificial walls, or pop-up (toaster) targets were also suggested. The berm width may also be re-evaluated; with the front berm needing more width than the side berms which are not impacted as often.

It was also noted that range operations preferred sheet flow instead of point discharge for the storm water management.

Firing Trenches: Options for storm water management and proper drainage to be evaluated since storm water can damage the walls and structural stability of the trench. Additionally, the fire hazard associated with timber walls will be reviewed. The use of 
SACON walls at Fort McCoy was given as an example of fire resistant and bullet absorbing material that may be used in the design of this range element.

Creek Crossings: Culverts are a problem when they are used in flooding conditions as in the desert. The annual monsoon washes culverts away or fills them with sand. This is an example where the standard design may not be appropriate at every location.

Additionally, Tanks and high-profile fighting vehicles have difficulty maneuvering over narrow bridges and trails during training due to visibility constraints. Many times constructed creek crossings are avoided and the users drive through the creeks where they have more control, but pose a variety of environmental issues. A better low-water crossing design will be evaluated which will be more user friendly.

Roads \& Trails: Dust and erosion are major problems. The dust control practices and erosion control measures by geographic region will be reviewed and compared to the design specifications.

The current standard design does not take into account local conditions or for the usage rate of the trails. For example, on a 4,000 meter armor trail the first 1,500 meters may be used in every training session, but the last 1,000 meters of the trail may only be used every fifth training session. If this is found to be true, the design and maintenance procedures may be different for different portions of the trail. Consequently, a tabulation of the usage rate of armor trails in the form of high, medium, and low usage will be developed and designs evaluated to address these variable usage rates. For example, additives for heavily used trails may be appropriate.

In addition, as described above for the creek crossings, poor visibility on narrow trails may result in tanks leaving the road which may have adverse site environmental impacts during training. Design considerations along roadway edges, such as dips, humps, and stair-steps that provide the driver an indication that he is at the edge of the road will be evaluated.

Firing Positions/Defilades: Base line firing positions are generally open. However, typically defilades have a significant amount of concrete which block the view of driver/gunner. Tanks may crush the rock beneath them which can cause dust to be a major problem. Inefficient anchors for side walls also fail regularly and are in need of improvement. In addition, firing positions may not be properly coordinated for height. Blast mats can also create maintenance issues. In addition, the concrete walls reflect the sun light towards the tank guide. Alternative design for blast mats and defilades will be reviewed to make these elements more efficient with less maintenance.

\section{Quality Control/Quality Assurance Elements}

The QA/QC portion of the project will focus on the planning stage. The goal is to improve the Planning-Design-Construction-Use/Maintenance process. 
$\mathrm{HNC}$ is tasked to provide standard design details to facilitate the efficient range design effort, but would like to emphasize that the standard details from the design manual are a tool that may not fit every location. A better means of emphasizing the standards need to be adjusted for the specific range location and use, and not just copied into projects was discussed.

The design manual is probably the best resource for designers, but the current design manual only describes design details by type of range and not by location; this could be improved. Additionally, getting the design information out to the user was discussed.

The concept of selective disturbance was discussed and should be emphasized during the construction phase; to minimize unnecessary site impacts.

The idea of providing an Operations \& Maintenance Manual to the user along with the design was mentioned as a possible solution. The installation would get a final product utilization guide which would define the types of weapons and munitions the range was designed for, training tables, possible a line-of-sight table for each shot, and maintenance steps. It was suggested this information could be delivered to the user in much the same format as the Operations and Maintenance Manuals that the Navy/Marine Corps prefer.

Range location and layout is a critical first step in minimizing changes throughout the design and construction phases. To develop a more accurately 1391 cost estimate, the AEC designer has been involved in some projects at the planning stage of the project. This has resulted in the reduction of delays due to unforeseen problems during the design phase and also reducing cost by finding better solutions for the range designs. One project where this could have been beneficial is the BAX at PTA, Hawaii. During the Range $15 \%$ Design it was determined that shifting the range location could have been more efficient and economical, but EA/EIS data was not available to confirm the move.

\section{Deliverables For Second Meeting}

- Range Element Characteristics Matrix: A table will be created for the ranges being reviewed. The elements will be inventoried for specific design characteristics (i.e. berm thickness, slopes, soil type, compaction requirements, variation for geographic areas, etc.), as well as reviewed for positive and negative (or non-stated) design components. The matrix will also incorporate RWA analysis of trail usage rates of armor ranges.

- RWA will demonstrate the design manual web tool at the next meeting for a better understanding of how the manual is to be used.

- RWA will provide photos of defilades and berms; focused on the evolution of design at Fort Knox from Yano to Cedar Creek to Buam-St Vith and finally Wilcox DMPTR. 


\section{STATEMENT OF WORK}

for

\section{DEVELOPMENT OF INNOVATIVE RANGE DESIGN}

KICK-OFF MEETING SIGN IN SHEET

NOVEMBER 9, 2004

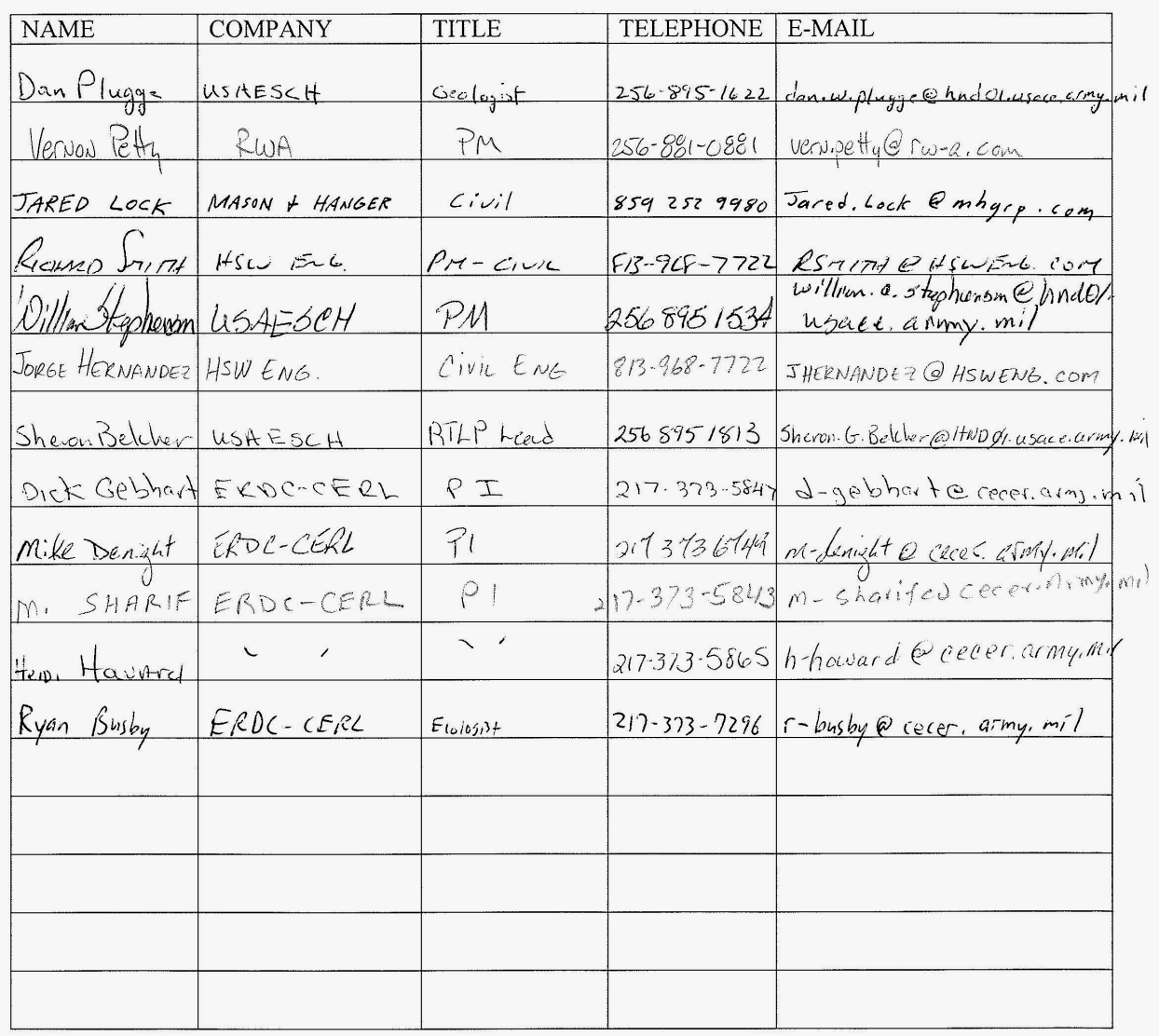




\title{
Development of Environmentally Stable Range Design Elements and Quality Control Guidance to Reduce Maintenance Requirements on Training Ranges
}

\author{
Date of Meeting: 23 February 2005 \\ Place of Meeting: Tampa, Florida \\ Attachments: Agenda and Presentations
}

\author{
Participants: \\ Dick Gebhart - ERDC-CERL \\ Mike Denight - ERDC-CERL \\ William Stephenson - USAESCH \\ Sheron Belcher - USAESCH \\ Richard Smith - HSW \\ Dennis Peek - HSW \\ Jason Christopherson - HSW \\ Jared Lock - MHG \\ Vernon Petty - RWA \\ Mike Curtis - RWA \\ Lee Sulzberger - RWA
}

\section{Meeting Began Wednesday at 0815}

The meeting started with participants introducing themselves and their affiliation. Richard Smith began by presenting the meeting agenda and schedule (see attached agenda). The overall project objective is to review current designs and standards for specific civil engineering range elements; develop innovative new designs that reduce environmental constraints and maintenance costs and increase the life expectancy of the elements; and examine construction policies and practices that will improve the range elements long-term.

At the Project Kickoff Meeting in November 2004, 10 range designs were selected as examples of existing range design practices. The design team reviewed specific elements for each of these ranges: soil classification, target berms, tank trails and service roads, defilades and firing positions, fighting trenches, and low-water crossings.

This quarterly meeting objective was to focus on the results of the design review and identify design and operational issues that should be further studied, and what specific action items should be taken to continue research efforts. The project status and results to 
date were presented by Richard Smith (see attached power point presentation) which detailed the various design elements specific to each range.

The 10 ranges reviewed included:

\begin{tabular}{|l|l|}
\hline Camp Atterbury, Indiana & Multipurpose Training Range \\
\hline Ft Knox, Kentucky & MPDTR, Wilcox Tank Range \\
\hline Fort Stewart, Georgia & Red Cloud Alpha Range - Multi-purpose \\
\hline Fort Shelby, Mississippi & Multipurpose Range Complex - Heavy \\
\hline Fort Hood, Texas & Digital Multipurpose Range Complex \\
\hline Fort Wainwright, Alaska & IPBC / DMPTR at Yukon Training Area \\
\hline Fort Polk, Louisiana & Digital Multipurpose Battle Area Complex \\
\hline Fort Pickett, Virginia & Multipurpose Range Complex - Heavy \\
\hline Fort Benning, Georgia & Digital Multipurpose Range Complex \\
\hline Fort Shafter, Hawaii & Combined Arms Training Facility at KTA \\
\hline
\end{tabular}

The following discussion summarizes the important elements of the presentation and discussion that occurred during the meeting.

\section{Soil Classification and Berms}

In general, geotechnical investigations and soil classification are being completed during the design process. However, it appears this data is more focused on structural integrity for buildings and not necessarily performed for berm construction. The discussion brought out the need to emphasize that geotechnical work is needed to classify borrow soil that will be used in either first-time berm construction or berm repair.

Targetry protection is best accomplished by placing below-grade emplacements and eliminating the berm. Although this option can create some emplacement drainage issues and is subject to collection of silt and debris, it is still preferred if the range layout and target locations can accommodate this design. The design manual should expand the emphasis on this issue.

Berms designs that were reviewed followed closely the Huntsville Range Design Manual (CEHNC 1110-1-23); Chapter 6. This design addresses force/dissipation of impacts, but does not address surface impacts and erosion. Consequently, some over design appears to be common practice in berm design and construction. It was stated that the design figures in Chapter 6 for determining berm crest width have a factor of safety embedded into the compaction curves. However, the designers are generally adding additional berm width either as a safety factor or to aid in the berm maintenance based upon the local range manager's experience. The following bullets describe discussion items of interest.

- Fort Wilcox retaining walls for Stationary Infantry Targets (SIT's) and Stationary 
Armor Targets (SAT's) were designed using pre-fabricated concrete and railroad ties on the upper 1.5 feet. The typical design would have only one timber beam across the concrete face for protection. During training the upper portion of the retaining wall receives most of the damage. The railroad ties can be easily replaced and are inexpensive. Timber is used extensively in designs to protect concrete structures and as retaining walls in the designs.

- At Ft Knox, an arrow SIT target design, with a protector lip located over the target mechanism was tried. This configuration was found to make maintenance and wiring of the target more complicated because the target is less accessible. Snakes and other animals also use the enclosure to nest in the target cavity. In addition, field experience shows that it provides little additional protection.

- A combination berm design worth further review is at Fort Benning. A sacrificial concrete wall was designed and built within the berm. In this case, the width of the berm could be reduced because of the combination berm. It was stated that the combination berm (Figure 6-16 in the standards manual) is not intended to replace berm width with the retaining wall thickness, but rather as a secondary sacrificial wall located within the berm.

- An item for further review is berm design using plastics. In particular, the availability and performance of different plastics, including recycled plastics, as a berm additive or sacrificial wall may provide better berm sustainability.

- A design that is known to perform well is the below grade SIT. RWA has experience with below grade SIT's and the range manager at Fort Knox stressed that it worked well, which coincides with the standards manual. But a common problem with this design is drainage; the drains tend to clog easily. In addition, some ranges are using covers to minimize storm water issues, but the covers have a host of other problems (longevity, manually opening each one, weight, etc.).

- It was mentioned that the standard design manual should include a maintenance section to address recurring problems with berms. An example give by RWA was a SAT target that was positioned in front of another target in such a way that a direct hit of the target resulted in the projectile landing in a down range berm, eventually causing a recurring large hole in the down range berm. The design manual should identify maintenance options to correct recurring maintenance issues. Another example was given for Fort Knox on a training range that saw very heavy use (hundreds of rounds in just 2 weeks time) of 3 or 4 particular targets because they were qualified shots for beginning tank gunneries. In this case, the range manager began to address the issue by adding as much as 20 feet of berm with loose and steeply (2:1) graded soil as a sacrificial berm. The maintenance section should suggest whom to consult on particular range issues that are out of the ordinary usage types for targets.

- It was suggested that the standard design is a good starting point for targets, but after 
a few maintenance cycles recurring issues may show up. At that time, it may be necessary to implement innovative technologies into the berm design, such as soil amendments, composite berm construction, or other techniques.

- Another suggestion for the standard range manual is to specify the method to be used in the soil cut and fill balance. Designer's soil cut and fill balance might be including berms as a fill area instead of just using only roads in the cut and fill balance. This practice could be leading to over construction of berms.

CERL expressed an interest in the continued efforts related to berm design including enhancement by soil amendments, combination material berms, and retro fit packages for maintenance of problem areas at current ranges. In addition, environmental sustainability measures should be considered, such as soil washout and runoff drainage. The design team will focus on these areas during the next quarter.

\section{Tank and Service Trails}

As with the berms, the reviewed designs appeared to follow the Huntsville Range Design Manual, Chapter 7. In addition, there were several references to applicable state DOT standards for aggregate materials which is a reasonable approach to the trail designs. To everyone's knowledge, no road material amendments have been used as part of the design mix at any range facility to extend the life-expectancy of the trails or for dust control. Dust control was agreed to be the most significant issue. The following bullets describe discussion items of interest.

- RWA informed the group that the most common practice (implemented at Fort Knox and other ranges) is to follow tanks down the range with water trucks, keeping the roads moist during training operations.

- CERL suggested inquiring into the Camp Ripley, Minnesota approach of dust control. The Camp applies a liquid mix to tank roads on an approximately 6 month basis to minimize dust. Usage rates, material, and the success of this approach should be investigated.

- CERL has study results showing significant dust control obtained by addition of amendments during the construction phase, incorporating the additive throughout the top layer of road material. CERL suggests visiting their website. There is a section within their website that has dust control suggestions for gravel roads. The website is located at: http://aec.army.mil/usaec/technology/rangexxi04.html.

- Addition of a dust control section into the design manual may spur incorporation of dust control measures into road design by the range designers.

- There was common agreement that there was no real runoff erosion problem. But, site layout needs to also consider the 100-year flood plain. RWA pointed out that Fort Knox has previously experienced flood waters that prevented the use of the 
entire range and required extra range maintenance.

\section{Tank Trail Usage Rates}

At the project kickoff meeting, RWA suggested tank trail designs might be focused on the usage rates of trail segments over the entire range. Mike Curtis evaluated several ranges at Ft. Knox to determine if this was a viable concept and presented his findings on tank trail usage rates (presentation attached).

The basic idea is that even though the whole range can be used by tanks, common practice suggests that only a percentage of the available roads are used heavily (say greater than $75 \%$ of the time); other portions of the trail may be used at a moderate rate (25\% - 75\% of the time); and some the remaining portions may be used at a light rate (less than $25 \%$ of the time).

Mike's conclusion was that the usage rate is very dependent upon the type of training occurring at a facility, and can change over time as the training needs of the facility change. Mike also indicated that tank gunnery training tables might be changing in the near future to mimic urban combat scenarios; which could also impact trail usage rates.

It was agreed that the concept of variable usage rates was worth additional study. Additionally, the designers would initiate a new design approach for both a heavy and low use trail; with special consideration given to amendments for dust control.

\section{Defilades}

Defilades and battle position design follow the Huntsville standard design. The main mechanism destroying the defilades is the concussion caused by muzzle blast. The muzzle blasts crack concrete and rip rap used to support the berm eventually creating a significant dust issue. Structurally the berm materials (rip rap and timber) may also be blown forward if not adequately anchored. Mike Curtis presented a variety of photos of defilades at Ft Knox, which illustrated the changes that have occurred based on experience over the years. The following bullets describe discussion items of interest.

- Concrete retaining walls at the face of the defilade are being replaced with timber because muzzle blast concussion quickly cracks and destroys the concrete wall. Repair and replacement of timber is much easier and quicker than concrete.

- Blast mats made of recycled rubber tires are typically installed over a rip rap berm and anchored to contain the rock and minimize dust potential. New technology from the mining industry may be available and will be researched as alternative methods for containment.

- Alternatives to blast mats are cabled concrete, mostly because of the expense of alternatives. It was believed that the current rubber blast mats costs around $\$ 15,000$, but they work very well. Muzzle blasts seem to worsen cracks in concrete, and then 
cause the concrete to break apart sooner than expected.

- Soil amendments and recycled plastics were also suggested as possible options for the retaining wall and will be further researched. These materials must be viable through many weather conditions and freeze-thaw cycles. Materials for the defilade berms and wall materials with a lower heat signature would be advantageous since the walls tend to have a similar heat signature as range targets.

- The purpose of the defilade front wall was questioned; Mike Curtis with RWA responded that they are mainly used as a signal by the driver to stop. Although current standard designs do not specify a wall, the trend is to include a timber wall in the design.

It was agreed to look closer at other range's defilade designs and alternative designs. The design team will also check with the mining community to see what the latest technology for blast mats are or if other options are being used. RWA will check current defilade designs and HSW will check commercial design aspects. An aspect to keep in mind for replacement materials is how easily they can be replaced.

\section{Fighting Trench}

Four of the ranges reviewed had fighting trenches that were designed based on the Huntsville standards. The major issue is with the retaining wall construction. The first issue identified was simply improper design or construction, with drainage being a significant issue. A second issue is related to the timber retaining wall catching fire from tracer rounds and brush fires.

Suggestions for wall materials were plastic inserts, that won't burn, or intermittent SACON walls similar to the design used by the design team at Ft. McCoy. Since gunfire within the trenches is expected, materials that will not create ricochet issues are needed. Materials also need to withstand freeze and thaw conditions. Alternative materials will be further studied in the next quarter.

\section{Low Water Crossings}

Three of the ranges reviewed had low water crossings. These crossings are typically concrete pads installed on the creek bottom to allow tank crossing or slightly elevated concrete crossings with culverts. It was established that low water crossings do not create any significant training issues. The issue related to low water crossings is environmental; protection of the creek/stream bed. The concrete over time can be undercut by stream flow, and culverts can be damaged by tanks running off the crossing. It was suggested that local DOT regulations/guidance may be a viable source of information for acceptable designs of these crossings.

\section{CERL QA/QC Study presented by RWA (Vernon Petty)}


Vernon Petty presented a summary of the status and direction he envisioned for the QA/QC review of construction policies and practices. His presentation (included as an attachment) covers the entire planning through design process. It was agreed that the approach presented was consistent with the scope of work and was acceptable for focusing the efforts.

\section{Project Schedule}

HSW will send meeting minutes for review next week (2/28/05-3/4/05).

Alternative dates for the next quarterly meeting were selected as follows: April $25^{\text {th }}$, May $16^{\text {th }}$, and May $23^{\text {rd }}$.

The meeting adjourned about 1700 . 


\section{Development of Environmentally Stable Range Design Elements and Quality Control Guidance to Reduce Maintenance Requirements on Training Ranges}

Date of Meeting: 26 and 27 April 2005

Place of Meeting: Ft Knox, Kentucky

Attachments: Presentations

Participants:

\begin{tabular}{|l|l|l|l|}
\hline \multicolumn{1}{|c|}{ Attendee } & \multicolumn{1}{c|}{ Organization } & \multicolumn{1}{c|}{ Phone } & \multicolumn{1}{c|}{ E-Mail } \\
\hline Andy Andrews & $\begin{array}{l}\text { Ft. Knox Range } \\
\text { Manager }\end{array}$ & $502-624-1447$ & Andy.andrews@us.army.mil \\
\hline Russ Boyd & COE-PM-A & $502-315-6887$ & Russ.e.boyd@ 1r102.usace.army.mil \\
\hline Gail Pollock & EMD-DBOS & $502-624-3629$ & Linda.pollock@knox.army.mil \\
\hline Mike Denight & CERL-Champaign & $217-373-6749$ & $\underline{\text { m-denight@ ceces.army.mil }}$ \\
\hline Richard Smith & HSW & $813-968-7722$ & rsmith@ @ hsweng.com \\
\hline Denis Peek & HSW & $813-968-7722$ & cdpeek@ hsweng.com \\
\hline Al Luttrell & HSW & $615-591-3394$ & alluttrell@ @omcast.net \\
\hline Jared Lock & MHG & $859-252-4980$ & Jared.lock@ mhgrp.com \\
\hline Sheron Belcher & RTLPCX, & $256-895-1813$ & Sheron.g.belcher@hnd01.usace.army.mil \\
\hline Ronnie Ward & RWA & $417-485-6401$ & Ronnie.ward@ @rw-a.com \\
\hline Vernon Petty & RWA & $256-881-0881$ & Vern.petty@ rw-a.com \\
\hline Mike Curtis & RWA & $256-509-1827$ & Mike.curtis@ rw-a.com \\
\hline
\end{tabular}

The overall project objective is to review current designs and standards for specific civil engineering range elements; develop innovative new designs that reduce environmental constraints and maintenance costs and increase the life expectancy of the elements; and examine construction policies and practices that will improve the range elements longterm. 
The primary purpose of this meeting at Ft. Knox was to obtain a first-hand understanding of the range issues from Mr. Andrew Andrews, the Ft. Knox Range Manager. The agenda was as follows.

\section{Monday 25 Apr 05:}

Travel Day

\section{Tuesday 26 Apr 05:}

AM:

Introductions and In-Brief Topics of discussion:

Mr Andrews' presentation

- Range construction methods

- Range maintenance

- Defilades

- Target Berms

- Dust Control

- Low water crossings

PM:

Status on execution/investigation

Format of final report

Determine last IPR date

\section{Wednesday 27 Apr 05:}

Range Tour: Probably Yano, Cedar Creek, Wilcox

Wrap up meeting, AAR, Outbrief after range tour

\section{Meeting Began Tuesday at 0900}

The meeting started with participants introducing themselves and their affiliation. Mike Curtis introduced Mr. Andy Andrews, Ft. Knox Range Manager.

Mr. Andrews gave a briefing on range construction from the point of view of the installation. He was accompanied by Ms. Gail Pollock from Fort Knox Environmental and Mr. Russ Boyd from the Corps of Engineers Louisville District at Fort Knox.

The briefing was developed to cover the items pertaining to the CERL study and how they relate to the Fort Knox range complex. Mr. Andrews discussed the development of tank ranges to include defilade positions and target berms starting from Yano MPRC-H to Wilcox DMPTR, dust control, and low water crossings. Key points in this discussion were the need to keep the Environmental office and the COE involved in the range development process right from the beginning. 
His presentation is attached for reference. Mr Andrews also provided a handout of design elements for several Ft. Knox ranges. A summary of highlights from this presentation include:

- Critical to incorporate "Maintenance in Design" concept

- Safety, Environment, and Training - Work together to design best training facility possible.

- Berms at Ft. Knox have typically three month maintenance cycle; performed as the range is available (between training exercises)

- Combined training needs to be considered; airborne helicopter training as part of combined training

- Large ranges encroach flood plains - water always wins - design for it

- Target berms

- 1 round hitting berm can penetrate $2-4$ feet; skips can create a trench in top of berm

- Always bring in new dirt from borrow area to fill holes; scooping dirt in front of berms to fill holes creates mud pools which are bigger problems

- Source of borrow material - distance can be an issue

- Berm thickness (crest) starts at about 50 feet; when it gets to less than 20 feet they shut down the berm/target for maintenance.

- High use berms/targets can lose $10-15 \mathrm{ft}$ of berm per month; requires major maintenance every three months

- Battle Positions

○ Overpressure from barrel can be devastating (can cause injuries to the rear, fatalities to the front). Can collapse buildings in urban environments.

- Blast Mats - best result at battle positions

- 5 ton mats made of recycled rubber tires and steel cable

- place large rock underneath mat

o has BPs that are up to 10 years old

○ .50 cal tracers can ignite blast mats

- Blast overpressure destroys grass makes reestablishment futile

○ Flame ball from tube does not usually ignite blast mats

- Tanks turns

○ high-pressure concrete turn pads; make them wide-enough to reduce potential for tanks to run off edge

- If concrete pads are too small, concrete edges break up

- Brush off concrete and it will last

$\circ$ Gravel turns will get scooped out at edge of track and generate dust clouds

- Dust Management -

○ No real answer yet; universal problem

- Stryker's have significantly different impact on course road then tanks and can create more damage; wheel load is more concentrated than track vehicles

- Contemporary Operation Environment (COE) - new mode of training resulting in changing design needs 
- Recycling Actions

- Allows shell salvage program during range down-time.

- Low-water crossings

- Tanks can float off trail if too deep and the stream is running

- Maintenance issue; Ft. Knox has crossings with several 24" culverts in parallel; debris gets caught and sedimentation issues are created

- Beavers have created problems on their ranges as their dams cause flooding

- Ft. Knox features

$\circ$ Lightning is a major problem on base. They have lightening monitors and storm watch; targetry and soldiers are susceptible to hits;

- arrow head targets to protect mechanism from above

- Grass mowing a continuous problem; need to keep LOS to targets; any down-time is used to jump on mowers mow grass by all-available personnel

○ Front and side skirts of tanks can be damaged by large rocks. Placing rocks along road keeps tanks on roads.

- Watch for drop-offs on road sides - they can lead to rollovers

- Simply shutting down a range and restarting it can cost $\$ 9,000$ in electronics parts damaged on startup

- Asphalt is too soft when warm and too brittle when cold (cracks)

- Concrete structures downrange have a good thermal signature and may be mistakenly shot

Closing discussion included interest in having CERL on-line session with range managers at next range conference to create a "think-tank" discussion of issues, lessons learned, and generate new ideas for regional/national consideration.

\section{PM Session}

Mike Curtis (RWA) gave a presentation of findings from trips to Ft Stewart and Ft Knox. Topics included defilades and low-water crossings. Mike's presentation is attached. Key elements include:

- Defilades - Mike presented a slide show of the defilade positions on Redcloud Alpha and Redcloud MPRC at Fort Stewart.

○ Iraqi experience will impact the future development of the defilades; may use more natural obstructions rather than designed defilades.

$\circ$ Drive-thru defilades being tried - low spot (2 - $4 \mathrm{ft}$ drop) in road for hull/turret down positions

○ Two-tiered positions at BP-1 still valuable, but downrange defilades can be modified

- Low-Water Crossings - Mike presented slides of the development of Low Water Crossings at Fort Knox and Fort Stewart.

- Drainage fabric and rock crossing; muck out first

$\circ$ Visual color coded stakes to help see trail 
o Multiple culverts with low concrete crossing; high water can still flow over top of trail; need wide enough to keep tanks on concrete

Vernon Petty (RWA) presented the Sustainable Range Program (SRP) Quality Assurance Study draft. The draft report was distributed to participants for review.

Richard Smith (HSW) presented a summary of dust control measures. The focus of the discussion was on a dust control product used in Afghanistan called "Envirotac II (aka Rhino Snot) from a company named Environmental Products and Applications, Inc. Further discussion with this manufacturer is planned.

Jared Lock (MHG) discussed the construction of course road construction using the light, moderate, and heavy models. His conclusion after factoring the construction techniques was that construction of the course road for various usage rates was dependent primarily on the soil characteristics of the specific range, not the usage rate of the trails. The usage rate only would save approximately an inch of road thickness.

At the conclusion of the meeting, Mr. Denight (CERL) stated that our direction was continuing in the right direction. He also stated that he would brief Dick Gebhart about all items presented in this meeting.

\section{Wednesday Range Visits}

Mr. Andrews conducted the site visit to three ranges at Ft. Knox; Yano, Cedar Creek, and Wilcox. The visit was valuable in observing design variations that have occurred during the progression of range development at Ft. Knox. Defilades, stationary and moving target emplacements, low-water crossings, bridges, and course and service roads were viewed.

\section{Project Schedule}

HSW will send meeting minutes for review.

The design team will develop a Report Outline for distribution.

Scheduled draft report submittal for end of July. Final review meeting at CERL in mid-August

Final corrected report by end of August 
APPENDIX B

APPLICATION RATES AND COST OF SOIL AMENDMENTS 


\section{APPLICATION RATES AND COST OF SOIL AMENDEMENTS}

Envirotac II and Soil Sement are products that have been used by the military for dust suppression and may be applicable for both range course roads as well as increased berm stability.

The manufacture's provided the following information regarding application rates and costs. Effective application rates are determined by several factors including soil type, type of traffic, climate, and operational and maintenance restrictions (active warfare, training requirements, etc.). These conditions determine if a longer lasting treatment involving mixing with the soil and greater compaction is employed or if more frequent, topical applications are more appropriate and cost-effective. Rates also vary with the product used. Discussed below are data on the two representative products discussed above.

\section{Envirotac II}

Application rates vary by the areas existing compaction. If the area to be treated is a road and is already compact, it should first be saturated with water. This keeps the dust particles down. Then one gallon of Envirotac II mixed with three parts water is applied for every 50 square feet. This can be applied out of a water truck, making sure to put the water in first, then the Envirotac II. When finished, spray a load of just water to clean and rinse the tank and nozzles.

If the area is not compacted, it should be sprayed with one gallon of Envirotac II mixed with six parts water to saturate the soils. The soil should then be ripped with any piece of equipment that has teeth on it, such as loaders that have buckets with teeth on the buckets. Rip the soil to a depth of about three inches with these teeth, spray the ripped area at a rate of one gallon of Envirotac II mixed with three parts water, then blade and compact with a roller. Spray the compacted area with one gallon of Envirotac II mixed with three parts of water. These three applications work out to about one gallon of Envirotac II per every 30 square feet.

The manufacturer suggests this application should give about 12 months of wear for the area before needing to spray a maintenance coat. Maintenance is at a rate of one gallon of Envirotac II mixed with five parts water per every 100 square feet. After two maintenance coats 
(24 months) the road is said to be brick-like in consistency and can be maintained less frequently (about every two years).

The manufacturer suggests application rates for berms consist of 250 gallons of Envirotac II mixed with six parts water per acre (43,560 sq. ft.), or one gallon of Envirotac II mixed with six parts water per every $175 \mathrm{sq}$. ft. Battle fire positions require one gallon of Envirotac II mixed with five parts water per every 100 square feet.

The cost per gallon is based on quantity but generally goes for $\$ 2.75$ to $\$ 3.25$ a gallon.

\section{Soil Sement}

Soil Sement is an acrylic co-polymer that is applied by mixing with water and spraying on the surface in concentrations dependent upon traffic usage and the other variables mentioned above. Its manufacturer uses two methods of application with a determination made based on cost, time constraints, and accessibility. In one, the product is applied and blended with the soil in accordance with Good Construction Practices (GCP) standards and compacted to ensure longer lasting usage. The other is a topical type of application using a lower concentration rate to the surface and re-applying more frequently, perhaps once or twice per year depending on local conditions. For example, in the more sandy soil at Ft. Irwin, California, the topical application can be applied once a year, while the clayey soil at Ft. Benning, Georgia, might require 2-3 applications.

The application rate for initial use is about one gallon per $50 \mathrm{sq}$. $\mathrm{ft}$. with half that amount required for maintenance. Rates higher than that can be difficult to be absorbed, but sandy soils can accommodate rates as high as one gallon per $20 \mathrm{sq}$. ft. if so desired. The cost of the product under GSA pricing is currently $\$ 4.01 /$ gallon but can vary with increased volume. This price represents a significant increase over what it was a year ago, reflecting the increase in raw material (petroleum) prices. 


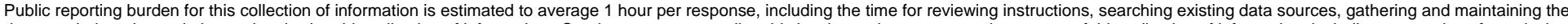

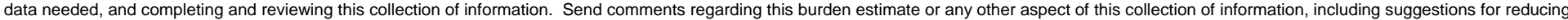

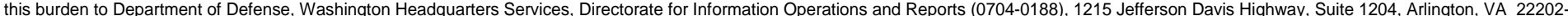

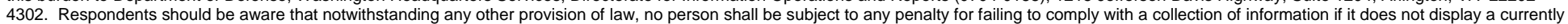
valid OMB control number. PLEASE DO NOT RETURN YOUR FORM TO THE ABOVE ADDRESS.

\section{REPORT DATE (DD-MM-YYYY) 11-2006}

4. TITLE AND SUBTITLE

Development of Range Design Elements and

Quality Control/Quality Assurance Guidance to Reduce Maintenance Requirements on Training Ranges

6. AUTHOR(S)

J. Hernandez, R. Smith, V. Petty, and J. Lock
3. DATES COVERED (From - To)

5a. CONTRACT NUMBER

5b. GRANT NUMBER

5c. PROGRAM ELEMENT NUMBER

5d. PROJECT NUMBER

5e. TASK NUMBER

5f. WORK UNIT NUMBER

8. PERFORMING ORGANIZATION REPORT NUMBER

ERDC/CERL CR-06-3

\section{PERFORMING ORG}

HSW Engineering, Inc.

3820 Northdale Blvd., Suite 210B

Tampa, FL 33624
The Mason \& Hangar Group

300 W. Vine St., Suite 1300

Lexington, KY 40507

and

R. Ward \& Associates, Inc.

1812 N. 22nd St.

Ozark, MO 65721

\section{SPONSORING I MONITORING AGENCY NAME(S) AND} ADDRESS(ES)

U.S. Army Engineer Research and Development Center (ERDC)

Construction Engineering Research Laboratory (CERL)

PO Box 9005

Champaign, IL 61826-9005

U.S. Army Engineering

and Support Center

P.O. Box 1600

Huntsville, AL 35807-4301
10. SPONSOR/MONITOR'S ACRONYM(S)

11. SPONSOR/MONITOR'S REPORT NUMBER(S)

\section{DISTRIBUTION I AVAILABILITY STATEMENT}

Approved for public release; distribution is unlimited.

\section{SUPPLEMENTARY NOTES}

Copies are available from the National Technical Information Service, 5285 Port Royal Road, Springfield, VA 22161.

\section{ABSTRACT}

This report includes an evaluation and assessment of range designs and Quality Assurance and Quality Control (QA/QC) guidelines for Army training ranges. This project represents the initial efforts to review the current status of specific range design elements and construction QA/QC issues related to selected civil engineering range elements. The research team reviewed the specific engineering elements of each design, including stationary and mover berms, roads and trails, low-water crossings, and battle positions (defilades, firing points, and other offensive and defensive positions). The research team also reviewed current range designs and received input from range managers to focus on environmental compliance and reduced maintenance cost attributes. Recommendations for further evaluation and field studies are included.

\section{SUBJECT TERMS}

range design

design-construction

16. SECURITY CLASSIFICATION OF:

\begin{tabular}{|l|l|l|}
\hline $\begin{array}{c}\text { a. REPORT } \\
\text { Unclassified }\end{array}$ & $\begin{array}{c}\text { b. ABSTRACT } \\
\text { Unclassified }\end{array}$ & $\begin{array}{c}\text { c. THIS PAGE } \\
\text { Unclassified }\end{array}$ \\
\hline
\end{tabular}

range management

quality assurance

NSN 7540-01-280-5500 training lands

dust

\begin{tabular}{|c|c|c|}
\hline $\begin{array}{c}\text { 17. LIMITATION } \\
\text { OF ABSTRACT }\end{array}$ & $\begin{array}{c}\text { 18. NUMBER } \\
\text { OF PAGES }\end{array}$ & 19 \\
\cline { 3 - 3 } SAR & 105 & \\
\end{tabular}

19a. NAME OF RESPONSIBLE PERSON Dick Gebhart

19b. TELEPHONE NUMBER (include area code) (217) 352-6511, ext 5847

Standard Form 298 (Rev. 8-98)

Prescribed by ANSI Std. 239.18 